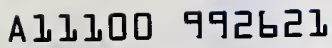

NAT'L INST OF STANDARDS \& TECH R.I.C.

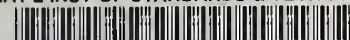

A11100992621

Peavy, Bradley A/Dynamic thermal pertorm 435 .U58 V45;1973 C.1 NBS-PUB-C 1973

r UDLIUR:

BUILDING SCIENCE SERIES 45

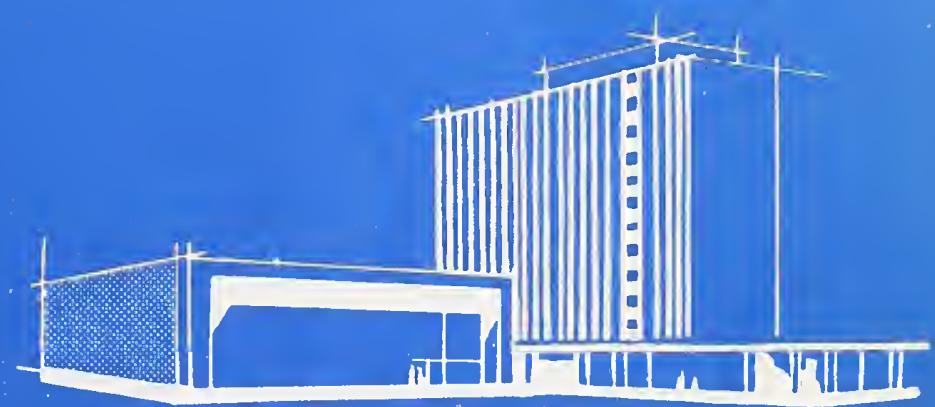

TA

435

.458

no. 45

1973

c.2

U.S.

Dynamic Thermal Performance

OF

COMMERCE

National

Bureau

of

Standards

\author{
of an Experimental
}

Masonry Building 


\section{The Building Science Series}

The Building Science Series disseminates technical information developed at the National Bureau of Standards on building materials, components, systems, and whole structures. The Series presents research results, Lest methods, and performance criteria related to the structural and environmental functions and the durability and safety characteristics of building elements and systems.

These publications, similar in style and content to the NBS Building Materials and Structures Reports (1938-59), are directed toward the manufacturing, design, construction, and research segments of the building industry, standards organizations, and officials responsible for building codes.

The material for this Series originates principally in the Center for Building Technology of the NBS Institute forApplied Technology. The publications are divided into three general groups: Building Systems and Processes; Health, Safety and Comfort; and Structures and Materials. Listed below are other publications in the category of -

\section{Health, Safety and Comfort}

- Doors and Barriers to Fire and Smoke (C13.29/2:3) 35 cents

- Field Burnout Tests of Apartment Dwelling Units (C13.29/2:10) 25 cents

- Fire Resistance of Steel Deck Floor Assemblies (C13.29/2:11) 25 cents

- Performance of Square-Edged Orifices and Orifice-Target Combinations as Air Mixers (C13.29/2:12) 15 cents

- Algorithms for Psychrometric Calculations (Skeleton Tables for the Thermodynamic Properties of Moist Air) (C13.29/2:21) 55 cents

- Investigation of Performance Characteristics for Sanitary Plumbing Fixtures (C13.29/2:22) 70 cents

- Radiation Error in Air Ducts under Nonisothermal Conditions Using Thermocouples, Thermistors and a Resistance Thermometer (C13.29/2:26) 25 cents

- Performance of Louvered Devices as Air Mixers (C13.29/2:27) 30 cents

- Performance of a Single-Stack DWV System Utilizing Low-Angle Stack-Branch Confluence and Bottom-Shunt Venting (C13.29/2:41) 35 cents

Send orders (use Superintendent of Documents Catalog Nos.) with remittance to: Superintendent of Documents, U.S. Government Printing Office, W ashington, D.C. 20402. Remittance from foreign countries should include an additional one-fourth of the purchase price for postage.

[See mailing list announcement on last page] 


\section{Dynamic Thermal Performance of an Experimental Masonry Building}

Bulaig Science Series

Bradley A. Peavy, Frank J. Powell, and Douglas M. Burch

Building Environment Division Center for Building 1 echnology Institute for Applied Technology

National Bureau of Standards

Washington, D.C. 20234
National Buroan of :-anereds

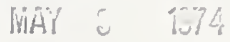

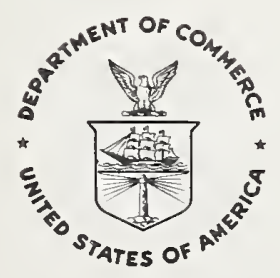

U.S. DEPARTMENT OF COMMERCE, Frederick B. Dent, Secretary NATIONAL BUREAU OF STANDARDS, Richard W. Roberts, Director 
Library of Congress Catalog Card Number: 72-600347

National Bureau of Standards Building Science Series 45

Nat. Bur. Stand. (U.S.), Bldg. Sci. Ser. 45, 103 pages (July 1973)

CODEN: BSSNBV

For sale by the Superintendent of Documents, U.S. Government Printing Office, Washington, D.C. 20402 (Order by SD Catalog No. C13.29/2:45). Price: $\$ 1.25$.

Stock Number 0303-01119 
1. Introduction

2. Prediction and evaluation analyses

3. Description of building

4. Instrumentation and transducers

5. Experimental procedure

5.1. Floating tests

5.2. Thermostated tests

6. Results and discussion

6.1. Floating tests

6.2. Thermostated tests

6.3. Heating load predictions

7. Conclusions

Appendix A. Air infiltration measurements on the NBS experimental building

Appendix B. Noise transmission measurements of the NBS experimental building _-__-__- 29

Appendix C. Computer programs (NBSLD) to obtain heating and cooling loads and to estimate

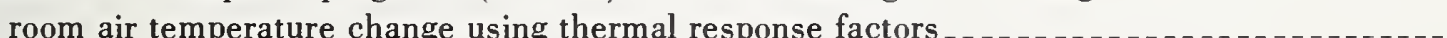

Appendix D. Computer program used in evaluation for the experimental building _._._._._. 71

Appendix E. Input and output for the response factor program 



\title{
Dynamic Thermal Performance of an Experimental Masonry Building
}

\author{
B. A. Peavy, F. J. Powell, and D. M. Burch
}

\begin{abstract}
Measurements of the dynamic heat transfer in an experimental masonry building were made in a large environmental chamber to explore the validity of a computer program developed at NBS, labeled NBSLD, for computing heating and cooling loads, and indoor air temperatures. This study was jointly supported by the National Bureau of Standards and the Department of Housing and Urban Development, and is a part of a broader research program being supported by both agencies to improve performance test procedures and criteria for housing.

The experimental structure was a one-room house $20 \mathrm{ft}$ long, $20 \mathrm{ft}$ wide, and $10 \mathrm{ft}$ high with walls of solid concrete blocks and a flat roof made of reinforced precast concrete slabs. During the tests changes were made in fenestration, the amount and location of insulation, and the indoor mass; and the building was exposed to a diurnal temperature cycle.

It was found that the combination of mass in the masonry walls and roof, and insulation placed on the outside of the masonry was very effective in reducing and controlling the variation of indoor air temperature. The NBSLD computer program realistically predicted the heat storage effects and maximum heating loads during these tests. For five heating tests, the greatest difference between computed maximum heating load and measured values was 8 percent and the average difference was 4.3 percent. It was shown that steady-state methods of heating load calculation could result in oversizing heating equipment by 30 percent or more for this particular building and imposed exterior conditions if the lowest outdoor temperature was selected as the design temperature.
\end{abstract}

Key words: Building heat transfer; computer programs; dynamic thermal performance; heat flow analysis; heating and cooling loads; temperature predictions; thermal analysis; thermal behavior; transient heat flows.

\section{Introduction}

To provide a functional and habitable indoor environment for a building requires careful considera. tion of the properties and performance of the materials that cover the building frame together with careful design, specification, and installation of its mechanical and electrical systems. The building materials and systems taken together are a major part of the cost of a new building and the fuel consumption also constitutes a substantial long-term expense in the operation of a building.

The indoor thermal environment of a building is influenced by the weather, by the thermal behavior of the walls, roof and floors, by heat-producing occupant-related activities, and especially by the mechanical and electrical systems that serve to make living spaces habitable.

This study explores the actual dynamic or timevariable flow of heat into and out of the fabric of a building and the resulting temperature patterns of the indoor air and the building itself. Present practice in calculating heat transfer and in selecting equipment sizes is based largely on steady-state assumptions and techniques. The actual performance is dynamic because of the changing patterns of weather and climate. Therefore, analysis and predictions of hourly, daily, and seasonal system performance should be based on dynamic considerations. The theory and basic mathematics for the dynamics of such a system were first explained by Fourier about 1820 , but the complexity of calculation and the time and expense involved have deterred architects and engineers from using such sophisticated procedures to design and evaluate buildings. Simplified steady-state approaches have been and are still used in combination with engineering judgment.

Design calculations for the heating and cooling loads for buildings have been performed by a mul. 
tiplicity of arithmetic and algebraic computations. It was not practical to make an extensive type of design analysis and the loads were generally determined by employing simple equations using selected fixed winter and summer design temperatures. Experience has shown that systems designed on this basis are sometimes oversized and may never operate at full load and optimum efficiency.

With the advent of high speed electronic digital computers with a large memory bank, it is now possible to make a comprehensive design analysis which includes the dynamic performance of buildings as af fected by diurnal and seasonal patterns of the weather and the time dependent interactions within the building itself. This approach allows an engineer to calculate rapidly and inexpensively: (a) energy requirements with consideration of operating costs, (b) heating and cooling load profiles for equipment design or selection and operation, (c) the information needed to evaluate rapidly a large number of options in the design process, (d) optimum energy utilization, and (e) the need for zoning in large buildings.

Computer programs usually contain approximations that require experimental verification before being adopted for wide-scale use. In addition, the performance data on building materials and elements, design weather data, and boundary conditions at surfaces need better definition to assure accuracy of predicted results.

It is the objective of this study to utilize a computer program suited to the variable temperature and heat flow regimes in most real situations and to compare results as predicted by this program with measurements made in the laboratory on full scale buildings that are subjected to changing simulated weather patterns. Further, it was hypothesized that building walls, roofs, and floors can be better designed to take advantage of thermal lags that occur due to the mass of the building and thereby allow a reduction of the installed capacity of mechanical equipment for heating and cooling while still maintaining performance satisfactory for human comfort and health. For example, it was hypothesized that if the masonry of a building is located on the indoor side of walls and roofs with thermal insulation on the outside, the stability of indoor temperature changes should be improved with less gross energy expended for maintaining a selected indoor temperature level. Also, locating masonry on the inside of the walls and an insultion with appropriate weather surface on the outside provides other poten- tial advantages such as: a reduction of cracking and spalling because the masonry remains unexposed to weather and at essentially a constant temperature and moisture content; the use of strong durable indoor surfaces should allow a reduction in the costs of maintenance and redecorating; and a greater resistance of the building to an interior fire or its rapid spread. When compared with the usual construction of walls with masonry outside and insulation inside, the proposed inverted system with insulation outside has elicited considerable interest.

A concerted effort towards the experimental verification of computer calculation methods and the technical merits of the inverted system was needed. At the National Bureau of Standards the initial experimental phases in this regard included laboratory testing in a high-bay environmental chamber em. ploying an experimental building where the time varying external environment could be controlled and reproduced, and where variations in important parameters could be studied.

This report presents a computer program for prediction of dynamic thermal and energy loads of buildings, the experimental results obtained from laboratory measurements made on an experimental building, and the comparison of experimental results with those calculated by the computer program. In conjunction with the experimental phases involving the dynamic thermal performance of a building, two other significant experiments were performed on the building. The first experiment was concerned with the air infiltration rate of the building. The method, procedure, and results are contained in appendix $\mathrm{A}$ of this report. The second experiment involved a series of noise transmission measurements made on the building. The method, procedure, and results are contained in appendix B of this report. Other observations included monitoring of the moisture content of the experimental building and the movement of the walls of the building under the influence of the changes in simulated outdoor air temperatures. The moisture content reached low equilibrium values early in the program and remained steady thereafter. Wall movement was little and about what would be expected using predictive engineering calculations. No surface or through-the-wall cracks in masonry were observed at any time in the program.

This work was cosponsored by the National Bureau of Standards and the Department of Housing and Urban Development. This report represents the initial stage of a research program. It is planned to 
perform further measurements on completely furnished full-scale houses that encompass a range of types of construction from lightweight (wood) to heavyweight (masonry). It is expected that results of those measurements will be published in future issues of the Building Science Series.

\section{Prediction and Evaluation Analyses}

In order to evaluate the dynamic, rather than steady-state thermal behavior and response of the fabric of a building as affected by diurnal and seasonal variations of weather and the time dependent interactions within the building, it was necessary to make a comprehensive mathematical analysis of the various heat transfer problems and translate the derived expressions into computer programs. It was found that the heat conduction portion of the overall problem could not be satisfied by purely rigorous mathematical solutions to the applicable partial differential equations because some of the boundary conditions at solid surfaces cannot be represented in a rigorous closed form in a reasonable manner. For these reasons, the Response Factor method was employed for those portions of the problem involving heat conduction. It allows a time variation of boundary conditions and can readily be related to modes of heat flow other than conduction, such as radiation and time varying changes in the nature of convection heat flow.

Basically, the Response Factor method predicts one-dimensional heat flow by utilizing the superposition principle in such a manner that the overall thermal response of a solid at a selected time is the sum of the responses caused by many individual temperatures or heat flux pulses during preceding time steps. Thereby, transient boundary conditions are simulated by a train of pulses. By summing up the fluxes or temperatures caused by each pulse, the total heat flux or temperature at a given time can be determined. The differential equations of heat conduction for multilayer systems of a building may be solved in this method by employing matrix equations of the Laplace transforms. The matrix algebra, superposition principle, and inversion of the Laplace transforms are shown and discussed by Kusuda ${ }^{1}$. Ex perience has shown that when this method is com-

\footnotetext{
1 Thermal Response Factors for Multi.layer Structures of Various Heat Conduction Systems, American Society of Heating, Refrigerating, and Air.Conditioning Engineers (ASHRAE) Transactions, 1969, pp. 246-271.
}

pared with a rigorous analytical solution under simplified conditions, the agreement is very good, except for the case where sudden changes or amplitude peaks of a weather cycle are encountered. This is probably due to the time steps employed and is not considered to be a serious drawback.

Appendix C contains the complete computer program, NBSLD, Computer Programs to Obtain Heating and Cooling Loads and to Estimate Room Air Temperature Change Using Thermal Response Factors. For the purpose of predicting performance in the experiment, certain subroutines of NBSLD were not needed. Appendix D is the computer program as adapted from NBSLD for use in this report for comparing predicted results with experimentally measured results. Appendix E gives a sample set of input and a printout of corresponding computer results as used with the program of appendix D.

For this thermal analysis, the following assumptions were made:

1. The conduction heat transfer through all the components of the experimental building was assumed to be one-dimensional.

2. All building materials were assumed to be homogeneous having constant physical and thermal properties over the operating temperature range of the tests.

3. For the tests considered in this report, the heattransfer coefficients at the inside and outside surfaces of the experimental building were assumed to be constant.

4. Heat and mass transfer of water in vapor or liquid form or the latent heats of condensation and evaporation were not considered in the analysis. For most tests, the dew point temperature of the outside air was maintained below that for any temperature occurring in daily cycle.

5. Infiltration of air from the outside to the inside and from the inside to the outside was considered to be a constant for a particular test. Two tests were performed for determining the air infiltration rates of the building, one with and the other without win. dows installed. The description and results for the air infiltration tests are in appendix A.

\section{Description of Building}

The building was constructed in a high-bay environmental laboratory of approximately 70,000 cubic feet in volume. A photograph of the experi- 


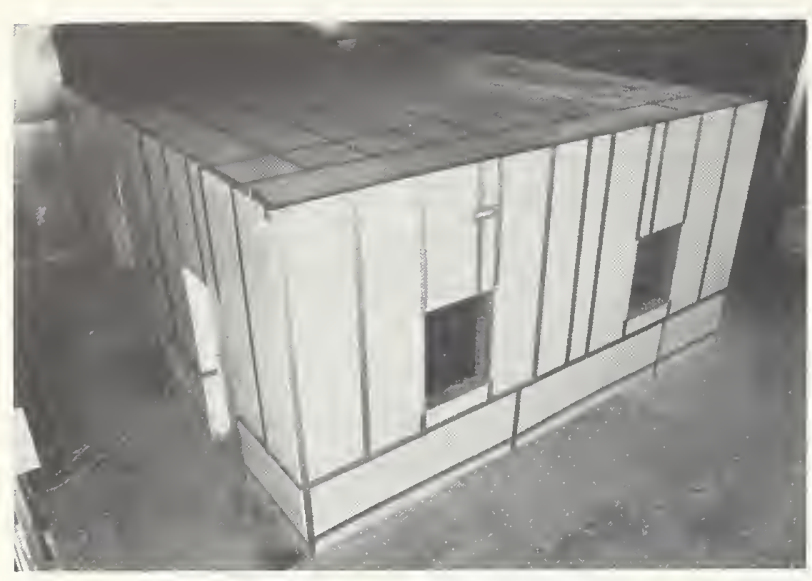

Figure 1. Experimental building in environmental chamber.

mental building located in the environmental chamber is shown in figure 1. In this laboratory, the temperature and relative humidity can be controlled over the ranges -50 to $150^{\circ} \mathrm{F}$ and 15 to 85 percent, respectively. Temperatures and relative humidities can be changed as a function of time using camoperated controllers. The floor of the laboratory is undisturbed earth suitable for placing building foundations.

The outside plan dimensions of the building were $20 \times 20 \mathrm{ft}$ with 10 -ft-high walls. The flat roof consisted of five 20 -ft-long by 4 -ft-wide and 4 -in-thick steel reinforced concrete roof slabs as shown in figure 2. The walls were made of nominal 8-in-high by 8-in-wide and 16-in-long solid cinder aggregate concrete blocks joined with fully bedded mortar joints. The blocks were of a nominal $100 \mathrm{lb} / \mathrm{ft}^{3}$ density. Eight concrete lintels were installed at appropriate locations; one above each of the seven windows that were 40 in high and 32 in wide and one

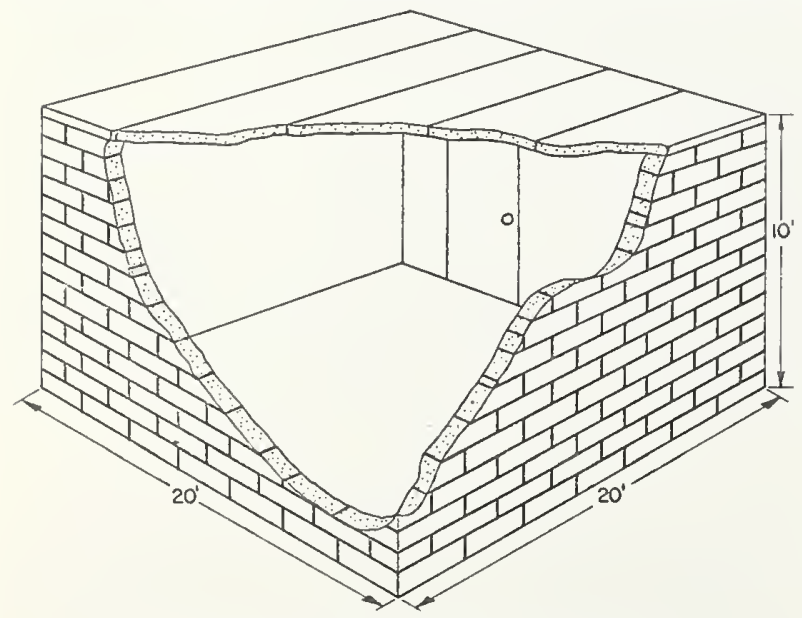

FIGURE 2. The basic experimental building.

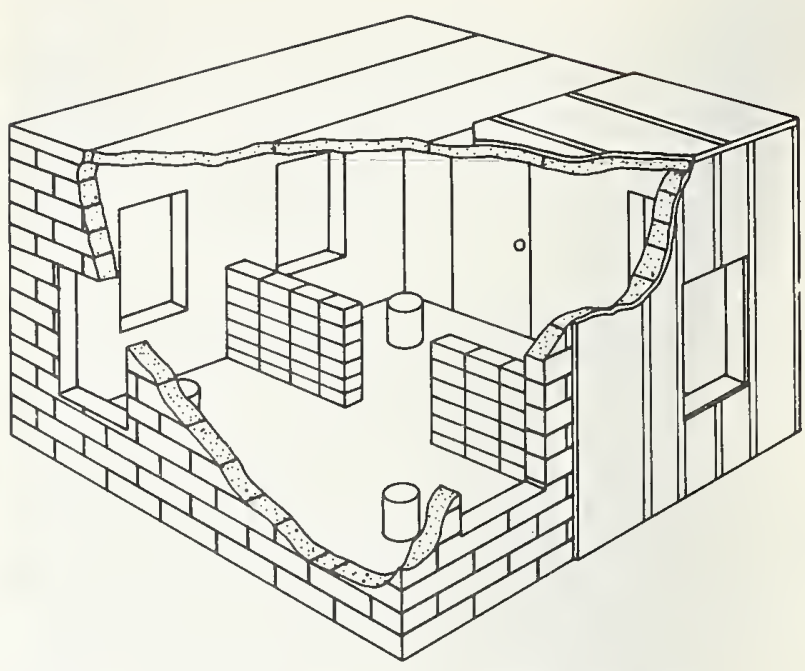

FIgURE 3. The experimental building showing windows, internal mass, heaters, and insulation on the outside of the building.

above the solid wood door measuring 79 in high $\times 32$ in wide $\times 2$ in thick. For the first two tests, there were no openings for windows and the spaces below these seven lintels were filled with blocks. The blocks were removed and the windows installed for the remaining tests. The exposed glass area was about 8 percent of the exposed wall area or about 18 percent of the floor area. Figure 3 shows the configuration.

A detailed illustration of the floor and the footing supporting the walls is given in figure 4 . Below the ground level, 4-in-thick polystyrene insulation was placed on the outside and a 1-in thickness on the inside of the concrete blocks to a depth of $16 \mathrm{in}$. Below the 16-in depth, a 1-in thickness was placed on the outside of the footing. The floor was made of 2 in of polystyrene insulation placed on the earth with a 2 in-thick concrete slab on top of the insulation. Considerable insulation was purposely placed below grade to reduce the known long-term influence of heat flow to the earth from the building and to minimize the time necessary for experimental test.

Cracks at the roof-wall interface and between the roof slabs were caulked with a polysulfide sealant. When the windows were installed, all cracks including those at the glass-wood frame interface were also caulked with the same sealant. Windows were as shown in figure 4.

Commercial expanded polystyrene board-type insulation 2 in thick, when used, was spot glued to either the inside or outside surfaces and all cracks were tape sealed. The identical insulation was used inside and outside. An internal mass consisting of 

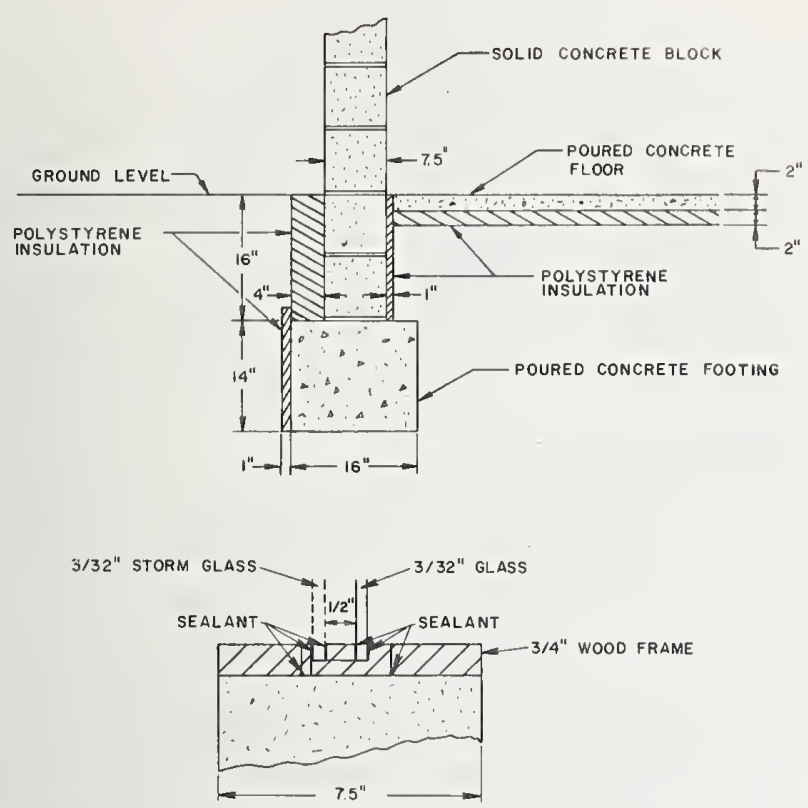

Figure 4. Floor, footing and window details.

2600 lbs of solid concrete blocks stacked on the floor, as shown in figure 3 , was used to simulate the heat capacity effect of interior partitions, furniture, etc.

\section{Instrumentation and Transducers}

Temperatures were measured using 24 gage copper-constantan thermocouples. The dots on figure 5 indicate thermocouple locations. The five vertical planes $A, B, C, D$, and $E$, as shown on the plan view of figure 6 , each contained the same thermocouple configuration given in figure 5 , except for the indoor air thermocouples which were located only in the vertical plane B. Four thermocouples were placed in the air $1 \mathrm{ft}$ from the outside surfaces. One of these was located at the center of the roof and the other three were located at the midheight of the three walls denoted by vertical planes $\mathrm{B}, \mathrm{D}$, and $\mathrm{E}$ of figure 6.

Six heat flow meters were placed on inside surfaces, five of them in vertical plane $B$ of figure 6 . One was placed at the center of the floor and a second meter was placed on the floor at a distance $2 \mathrm{ft}$ from the wall. Two meters were placed on the ceiling opposite those on the floor. The fifth meter was placed on the wall at midheight. The sixth meter was placed midheight on the wall of vertical plane $\mathrm{D}$. The heat flow meters were circular disks 2.0 in in diameter and 0.13 in thick, made of tan polyvinylchloride filler

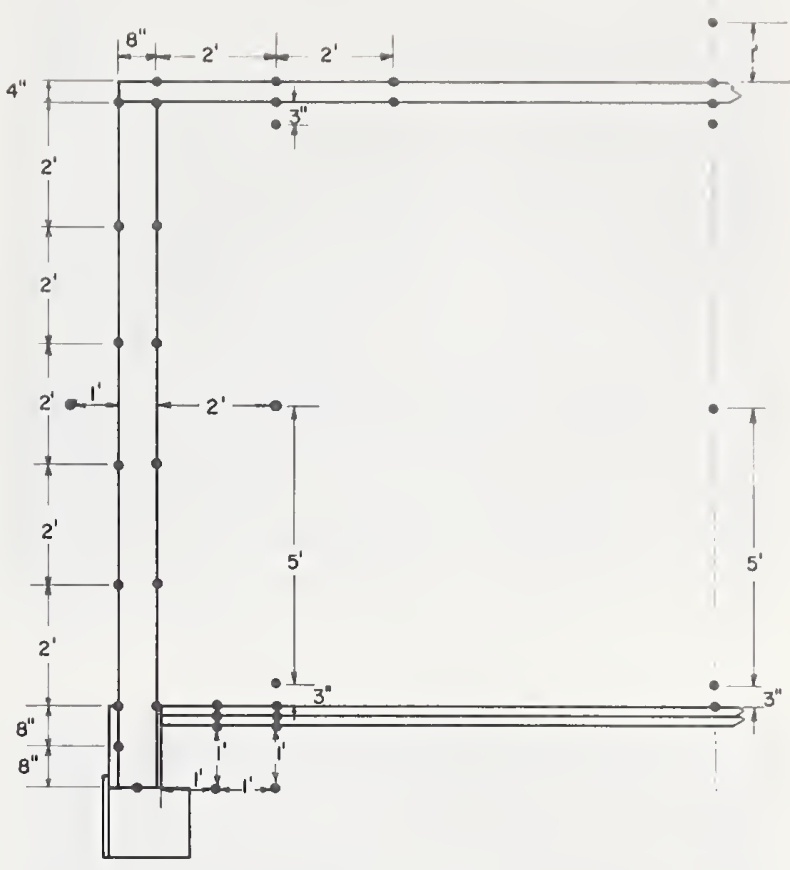

Figure 5. A vertical section through the experimental building showing thermocouple locations.

material, each having an embedded spiral of helically wound wire comprising a large number of thermojunctions in series (with internal resistance range of 135 to $170 \Omega$ ) distributed over a circular area $15 / 8$ in in diameter located centrally in the disk. Two wires attached in each meter acted as leads for the series thermopile of the meter. The meters were calibrated in an 8 in guarded hot plate apparatus

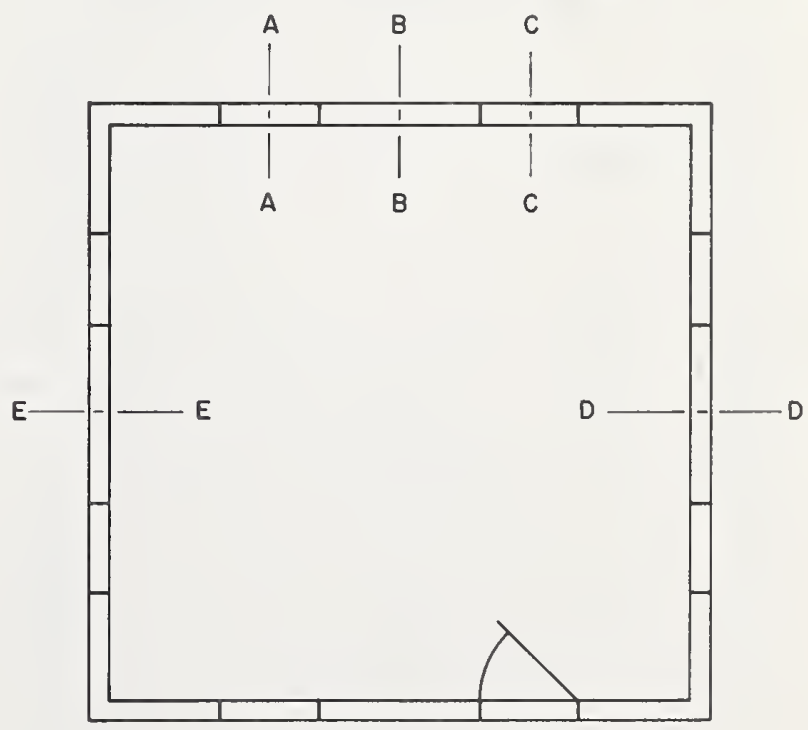

Figure 6. Plan view of thermocouple locations. 
conforming with the requirements of Standard Method of Test ASTM C177.

All thermocouple and heat flow meter leads were connected to thermally isolated terminal strips at the center of the room from which copper leads went to a data acquisition system. The terminal strips were mounted on a 1/4-in-thick aluminum plate which in turn was surrounded by 3 in of polyurethane insulation. All lead wires were surrounded by 3 in of the same insulation for a distance of $7 \mathrm{in}$. This assembly is termed a zone box. Four additional thermocouple leads were connected to the terminal strips at ends of the zone box and their junctions were placed in an ice point reference external to the building. The readings from these four thermocouples gave the temperature of the zone box as a reference temperature for the other thermocouple leads.

Copper leads from the zone box were connected to terminals of the data acquisition system which converted the analog signals to digital information which in turn was recorded on punched cards.

Electric energy supplied to the building was measured using a calibrated single-phase watthour meter equipped with an impulse generator. The impulse generator is a photoelectric device which counts the revolutions of the disk inside the watthour meter. A digital signal (number of revolutions of the disk) was fed into the data acquisition system which in turn recorded the digital signal on punched cards at selected time intervals.

\section{Experimental Procedure}

Figure 7 is a representative sample of the outside air temperature wave-form imposed on the experimental building for each 24 -h time period. For most of the tests, the limits 40 to $100^{\circ} \mathrm{F}$ were selected for experimental convenience and because their average would be approximately a normal room temperature. In test 10 , the limits were changed to the range 10 to $70^{\circ} \mathrm{F}$. The curve was used to control the average of the four individual temperatures indicated by thermocouples in the air $1 \mathrm{ft}$ from the exterior surface of the building. The maximum difference in temperature between any of these four locations was always less than $4^{\circ} \mathrm{F}$. The outside dew point temperature was maintained constant at approximately $5{ }^{\circ} \mathrm{F}$ below the lowest temperature of a cycle. The temperature cycle of figure 7 was derived as a simulated sol-air temperature pattern from the

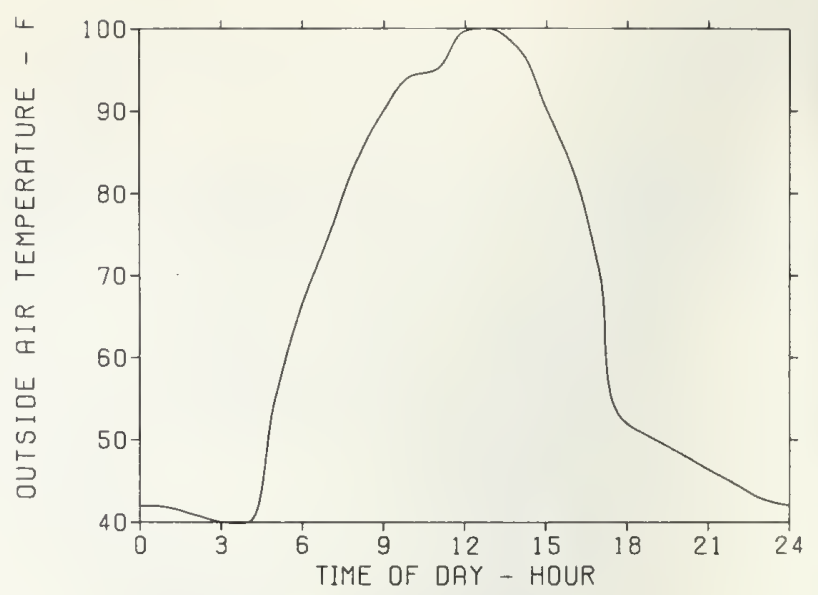

Figure 7. Outside sol-air temperature cycle.

data in table 25, page 490 of the "Handbook of Fundamentals," published by the American Society of Heating, Refrigerating, and Air-Conditioning Engineers, 1967. Sol-air temperatures were areaaveraged for orientations north, east, south, west, and horizontal. The temperature variation as indicated on figure 7 was maintained for a period of from 3 to 4 days before a final set of data was taken. This conditioning period was deemed to be necessary and sufficient to eliminate transient heat flows thereby giving only those heat flows that would recur in a periodic fashion.

A complete set of data for each test consisted of recording the digital output from analog signals of 171 sensing elements (thermocouples, etc.) every 30 min during a 24-h period. The raw data were converted by computer into temperatures, heat flows, etc. The converted data were then transferred to magnetic tape for use in analysis, and plotting as temperature and heat flow patterns.

The results from 10 tests given in this report are derived from the five floating tests and five thermostated tests summarized in tables 1 and 2 .

\subsection{Floating Tests}

Floating tests are defined as those tests where no heat energy was added to or taken away from the interior air of the experimental building by mechanical equipment. The temperature of the interior air was allowed to "float" or respond to changes in the outside air temperature. Five floating tests were con. ducted with variations in test conditions as shown in table 1 . 
TABLE 1. Floating tests

\begin{tabular}{c|l|l|l}
\hline Test No. & Insulation & Windows & Internal Mass \\
\hline 1 & None & None & None \\
2 & None & None & Mass* \\
3 & None & Single Pane & None \\
4 & Inside & Single Pane & Mass* \\
5 & Outside & Single Pane & Mass* \\
\hline
\end{tabular}

* 2600 lbs of concrete blocks.

\subsection{Thermostated Tests}

Thermostating tests are defined as those tests where heat energy was added to the interior air of the experimental building by four electric heaters under thermostatic control. The variations in test conditions are shown in table 2 along with the average inside air temperature maintained and its root mean square RMS deviation.

The sensing element for thermostating was a thermocouple placed in the middle of the room at midheight. It controlled the operation of four fan heaters placed as shown in figure 3 , in an on-off type of control with a differential of approximately $\pm 2{ }^{\circ} \mathrm{F}$. Each drum-type fan heater, as shown in figure 8 , consisted of a heating element and a blower which takes air from the floor level, passes it through the heater chamber and into the room through peripheral holes near the top of the drum. Each electric heating element was rated at $600 \mathrm{~W}$ for $110-\mathrm{V}$ input, and each blower delivered $100 \mathrm{~W}$. Heat was supplied by the elements, blowers, and the thermostat and voltage control equipment. For test 10 , the daily temperature cycle for the outside air ranged from 10 to $70^{\circ} \mathrm{F}$ as shown in figure 31 , but the cycle was similar in shape to that given in figure 7 .
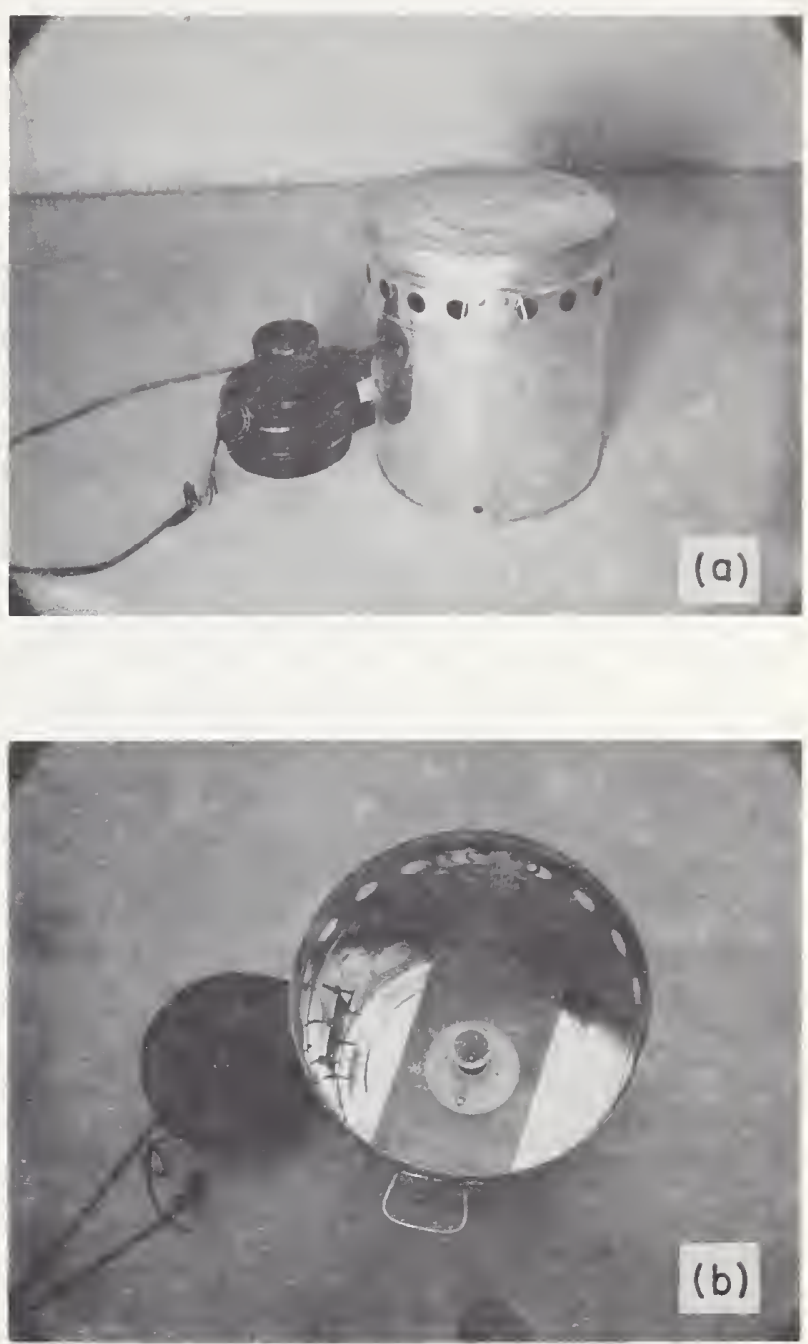

FIGURE 8. (a) Fan heater; (b) Fan heater with top cover removed.

TABLE 2. Thermostated tests

\begin{tabular}{c|c|l|l|c|c}
\hline \hline \multirow{2}{*}{ Test No. } & Insulation & Windows & $\begin{array}{l}\text { Internal } \\
\text { Mass }\end{array}$ & & \multicolumn{2}{|c}{ Inside Air Temp. } \\
\cline { 4 - 5 } & & & & Average & $\begin{array}{c}\text { RMS } \\
\text { deviation }\end{array}$ \\
\hline 6 & None & Single Pane & None & 78.9 & \pm 1.2 \\
7 & Inside & Single Pane & Mass* & 76.9 & \pm 0.8 \\
9 & Outside & Single Pane & Mass* & 77.6 & \pm 0.6 \\
10 & Outside & Double Pane & Mass* & 77.6 & \pm 0.6 \\
& Outside & Double Pane & Mass* & 74.2 & \pm 0.8 \\
\hline
\end{tabular}

*2600 lbs of concrete blocks. 


\section{Results and Discussion}

The thermal and physical properties of the materials comprising the building used in the computer program are given in table 3 .

TABLE 3, Thermal and physical properties

\begin{tabular}{|c|c|c|c|c|}
\hline & $\begin{array}{c}\text { Thick- } \\
\text { ness } \\
\text { in }\end{array}$ & $\begin{array}{l}\text { Thermal } \\
\text { Conduc- } \\
\text { tivity } \\
\text { Btu h }{ }^{-1} \\
\mathrm{ft}^{-1} \mathrm{~F}^{-1}\end{array}$ & $\begin{array}{l}\text { Density } \\
\mathrm{lb} \mathrm{ft}^{-3}\end{array}$ & $\begin{array}{c}\text { Specific } \\
\text { Heat } \\
\text { Btu lb-1 } \\
F^{-1}\end{array}$ \\
\hline 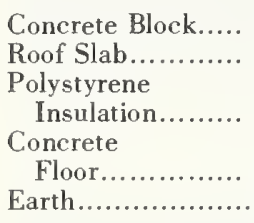 & $\begin{array}{l}7.5 \\
4 .\end{array}$ & $\begin{array}{r}0.29 \\
.80 \\
\\
.018 \\
.80 \\
.5\end{array}$ & $\begin{array}{c}100 \\
150 \\
\\
2.5 \\
\\
150 \\
120\end{array}$ & $\begin{array}{l}0.18 \\
.2 \\
.27 \\
.2 \\
.2\end{array}$ \\
\hline
\end{tabular}

Measurements of thermal conductivity, thickness, and density were made on oven-dried samples of the concrete block and polystyrene insulation in accordance with the hot plate method given in ASTM C177. All other properties were obtained from the applicable literature.

The areas used for computing heat flows through the roof, walls, and floor were the arithmetic average of the inside and outside areas for each of the components. The mean heat transfer areas of tests 1 through 10 are summarized in table 4 .

TABLE 4. Mean heat transfer areas, $f t^{2}$

\begin{tabular}{c|c|c|c|c}
\hline \hline Test No. & $\begin{array}{l}\text { Window } \\
\text { Area }\end{array}$ & Roof Area & Wall Area & Floor Area \\
\hline 1 & none & 375 & 814 & 375 \\
2 & none & 375 & 814 & 375 \\
3 & 58 & 375 & 750 & 375 \\
4 & 58 & 369 & 738 & 369 \\
5 & 58 & 381 & 763 & 381 \\
6 & 58 & 375 & 750 & 375 \\
7 & 58 & 369 & 738 & 369 \\
8 & 58 & 381 & 763 & 381 \\
9 & 58 & 381 & 763 & 381 \\
10 & 58 & 381 & 763 & 381 \\
\hline
\end{tabular}

Values for the coefficients of heat transfer at the various surfaces were selected and used in the computer program as constants for the time period of a test. The coefficients used for the inside surfaces at the ceiling, walls, and floor were $1.08,1.1$, and 1.08 Btu $\mathrm{h}^{-1} \mathrm{ft}^{-2}{ }^{\circ} \mathrm{F}^{-1}$, respectively. The heat transfer coefficient selected for the outside surfaces was 1.47
$\mathrm{Btu} \mathrm{h} \mathrm{h}^{-1} \mathrm{ft}^{-2}{ }^{\circ} \mathrm{F}^{-1}$. In general these values are based on a value of 0.9 for the radiation component of heat transfer and time-averaged temperature differences between surfaces and adjacent air of 1 and $14^{\circ} \mathrm{F}$ for the inside and the outside, respectively. For test 10 , where the outside temperature was considerably lower, the outside surface coefficient selected was 3.0 Btu/ $/ \mathrm{h}^{-1} \mathrm{ft}^{-2}{ }^{\circ} \mathrm{F}^{-1}$, owing to the larger temperature difference between the outside surface and the surrounding air. The surface film coefficient varies considerably with the direction of heat flow, air velocity, and the temperature difference from surface to air. Reasonable variations in these coefficients as high as 20 percent have shown a negligible effect on results from the computer program.

For the computer program, the heat capacity effects of the door and windows were assumed to be negligibly small and only the thermal resistance of these components was used. For the door and singleand double-pane windows, the overall coefficients of heat transfer were calculated to be $0.25,0.55$, and $0.41 \mathrm{Btu} / \mathrm{h}^{-1} \mathrm{ft}^{-2}{ }^{\circ} \mathrm{F}^{-1}$, respectively, for the conditions of tests 1 through 9 . For the double-pane windows of test 10 , the calculated coefficient was 0.47 . These overall heat transfer coefficients were calculated by the series resistance method. The film resistances at the inside and outside surfaces were taken to be the same as the corresponding wall values.

For heat flow to or from the floor, the underlying earth was considered to be a one-dimensional semiinfinite medium for the Response Factor program, and the average of temperatures measured at the 1 - $\mathrm{ft}$ depth in the earth was used as the earth temperature at a depth considerably removed from the floor. For the duration of the tests, this was deemed an adequate assumption because the root mean square deviation of the earth temperatures at the $1-\mathrm{ft}$ level was less than $0.2^{\circ} \mathrm{F}$ for all tests where the diurnal outside air temperature varied from 40 to $100^{\circ} \mathrm{F}$ and less than $0.3^{\circ} \mathrm{F}$ for the 10 to $70^{\circ} \mathrm{F}$ cycle. For the 40 to $100{ }^{\circ} \mathrm{F}$ tests, the average temperature at the top of the footing (fig. 5) was about $0.5^{\circ} \mathrm{F}$ lower than the earth temperature at the $1-\mathrm{ft}$ level, and for the 10 to $70{ }^{\circ} \mathrm{F}$ test was about $2{ }^{\circ} \mathrm{F}$ lower. This indicates that some of the heat is flowing from the earth underlying the floor toward the footing and was not accounted for in the one-dimensional heat transfer approach of the Response Factor program. The error due to this 
heat flow is believed to be very small in relation to other heat flows. A mathematical analysis was performed for the heat flow at the ground level in the wall section below ground level to the top of the foot . ing (fig. 4) using the temperature variations with time from thermostated test 6 . The computed heat flows showed that heat was flowing into and out of this section with time, but the magnitude of these heat flows was small in relation to other heat flows.

Air infiltration rates were determined by a tracer gas method using helium as the tracer gas (see appendix A). For the building without and with windows, measured values were 0.06 and 0.38 air changes per hour, respectively. The above values are considered maximum rates for air infiltration because the tests were performed when the thermal head (difference in temperature between the inside and outside) was the greatest. It would be expected that the air infiltration rate would be proportional to the thermal head. Based on the average indoor-outdoor temperature difference, average air infiltration rates were selected as being $2 \mathrm{cfm}$ for tests with no windows and $10 \mathrm{cfm}$ for test with windows. The tests of appendix A were performed on the building without thermal insulation. Placing insulation on either the inside or outside surfaces would increase the resistance to air infiltration. For this reason, a rate of $5 \mathrm{cfm}$ was used for tests with insulation.

Noise reduction measurements were made on the experimental building as given in appendix B. The results for conditions of no windows, single-pane windows only, single-pane windows with insulation inside, and single-pane windows with insulation outside are shown in figure 2 of appendix B. As indicated and expected, the noise reduction was greatest without windows and some improvement is shown when insulation was applied. Comparison of noise reduction measurements for the tests with insulation on the inside and on the outside indicate that insulation on the inside provided better characteristics because of the higher noise reduction values in the range from 500 to $2500 \mathrm{~Hz}$. This range is considered to contain the most objectionable portion of the audible frequency spectrum.

As mentioned in the introduction, an equilibrium moisture content of the block was rapidly achieved and the influence of moisture in these tests is considered to be negligible. The moisture content of the block was monitored by observing the changes of weight of two initially oven dried concrete blocks. One block was placed in the environmental chamber and the other in the test room throughout the tests. The equilibrium moisture content of the monitored blocks was 4 percent by weight. Similarly, vertical and horizontal thermal expansion of the concrete block wall was measured and attained an equilibrium range and was considered to be desirably low especially since no surface or through-the-wall cracks were visible.

\subsection{Floating Tests}

For the floating tests numbered 1 through 5 , table 1 , the measured and computer-calculated inside air temperatures are plotted in figures 9 through 13 , respectively, each with its measured outdoor air temperatures. The curve of measured indoor air temperature is the arithmetic average of the six indoor air thermocouples as shown in figure 5. The vertical distribution of temperature within the room will be treated later in this discussion. There was generally good agreement between the measured and predicted average inside air temperatures in all cases, although there is a trend for the predicted values to have slightly higher maximum values and lower minimum values during the 24 -h cycle. This indicates that the mass of the building dampens temperature changes more than is accounted for in the predictive computer program. This may result from the design of the theoretical model that was used in the computer program which neglects the additional thermal capacitance introduced at the corners of the building and the slight changes in material physical properties during exposure as compared with measured dry values.

Comparing the indoor air temperature curves of figures 9 through 13 , it can be seen that placing insulation on inside and outside building surfaces had a marked influence on the inside air temperature profiles. (Compare especially figs. 12 and 13 with fig. 11.) In order to examine differences, the observed temperature deviations from the daily average inside air temperature for the building with windows are plotted in figure 14 for the cases of no insulation, insulation on the inside building surface, and insulation on the outside building surface (corresponding to figs. 11, 12, and 13). Adding insulation on the in- 


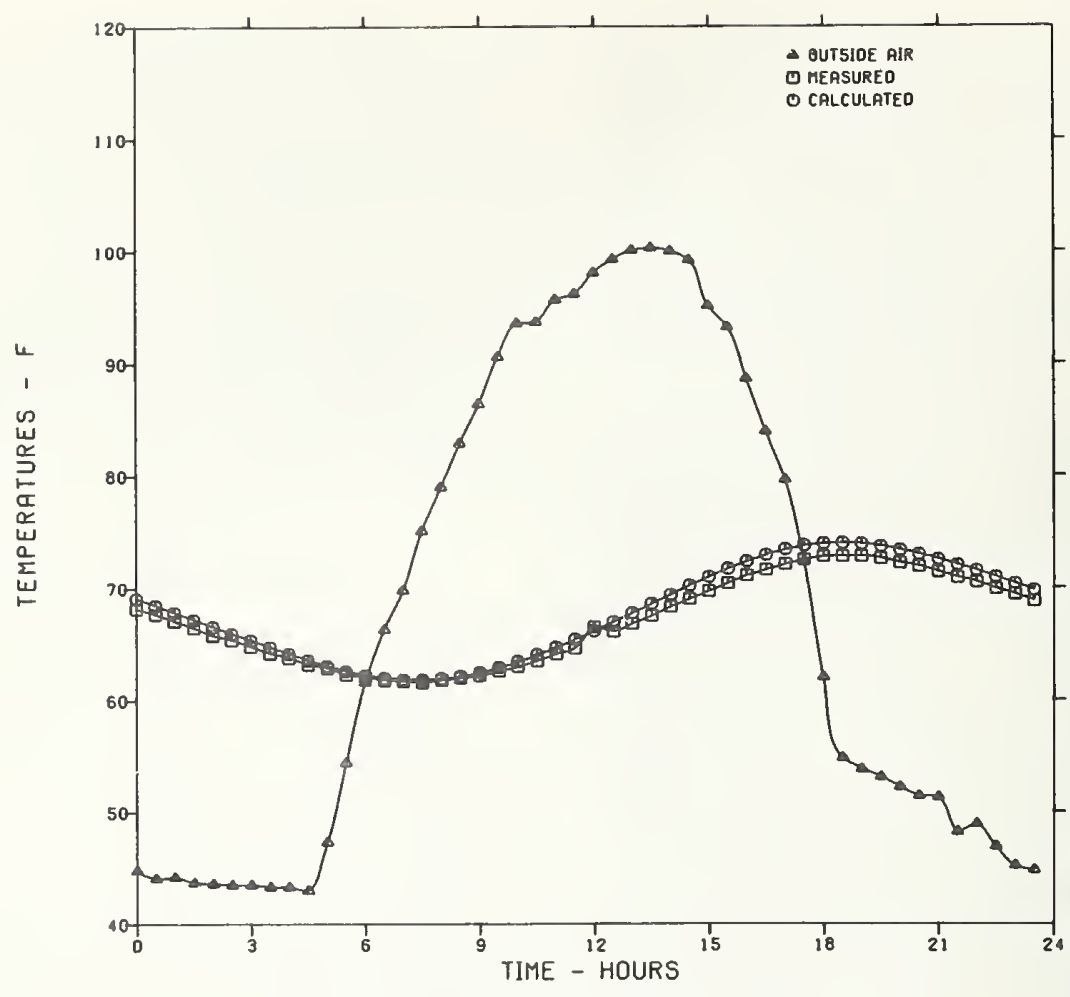

NO INSULATION, NO WINDOWS, NO INTERNAL MASS.

FIGURE 9. Comparison between measured and calculated inside air temperatures for floating test 1 .

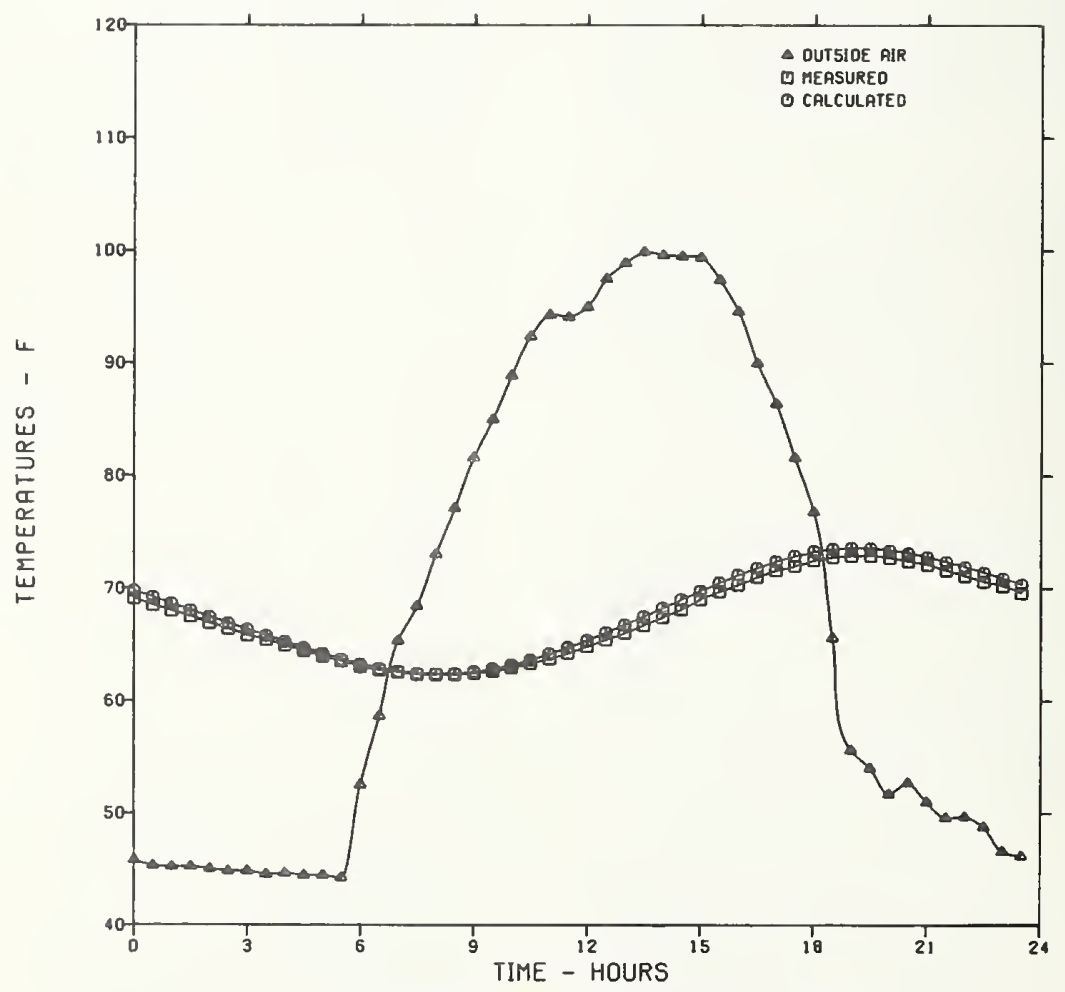

NO INSULATION, NO WINDOWS, INTERNAL MASS.

FIGURE 10. Comparison between measured and calculated inside air temperatures for floating test 2. 


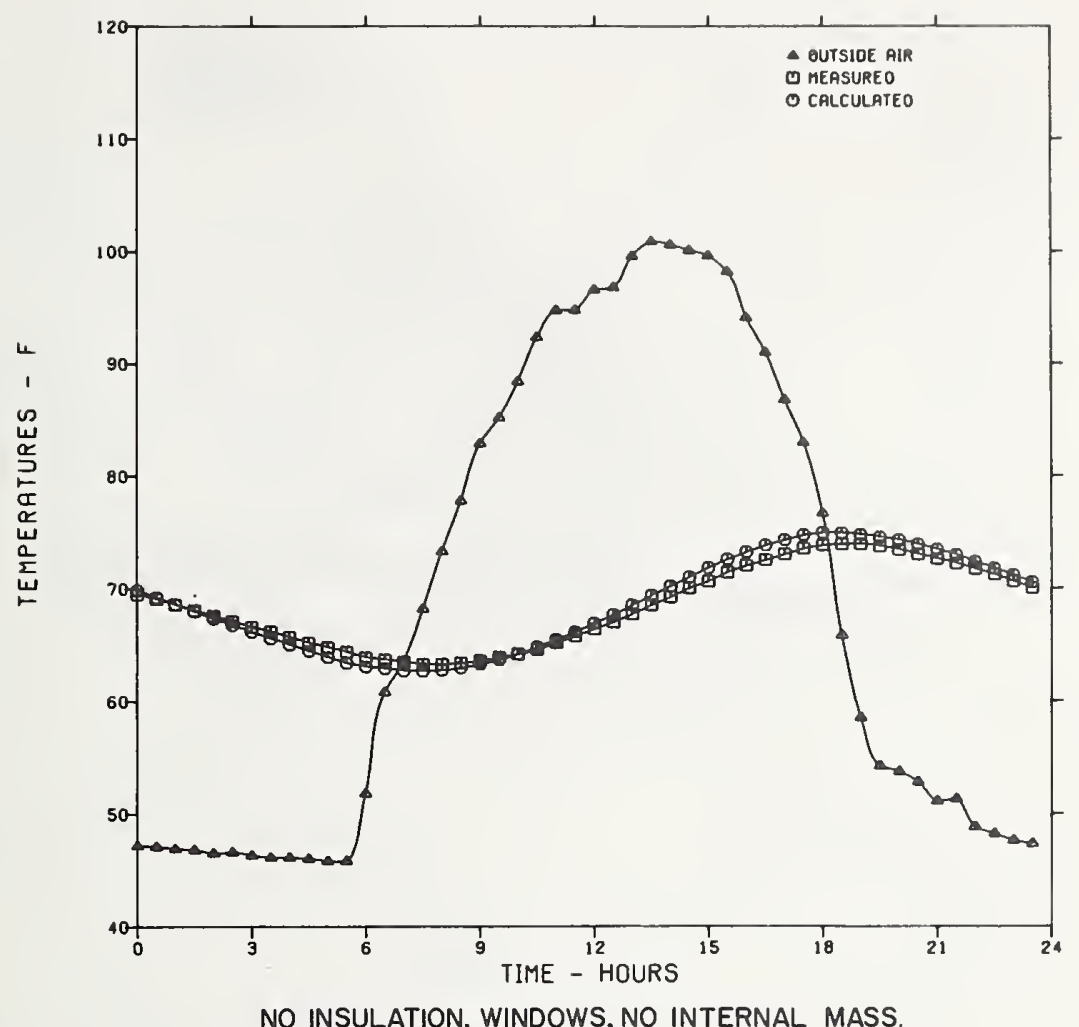

Figure 11. Comparison between measured and calculated inside air temperatures for floating test 3.

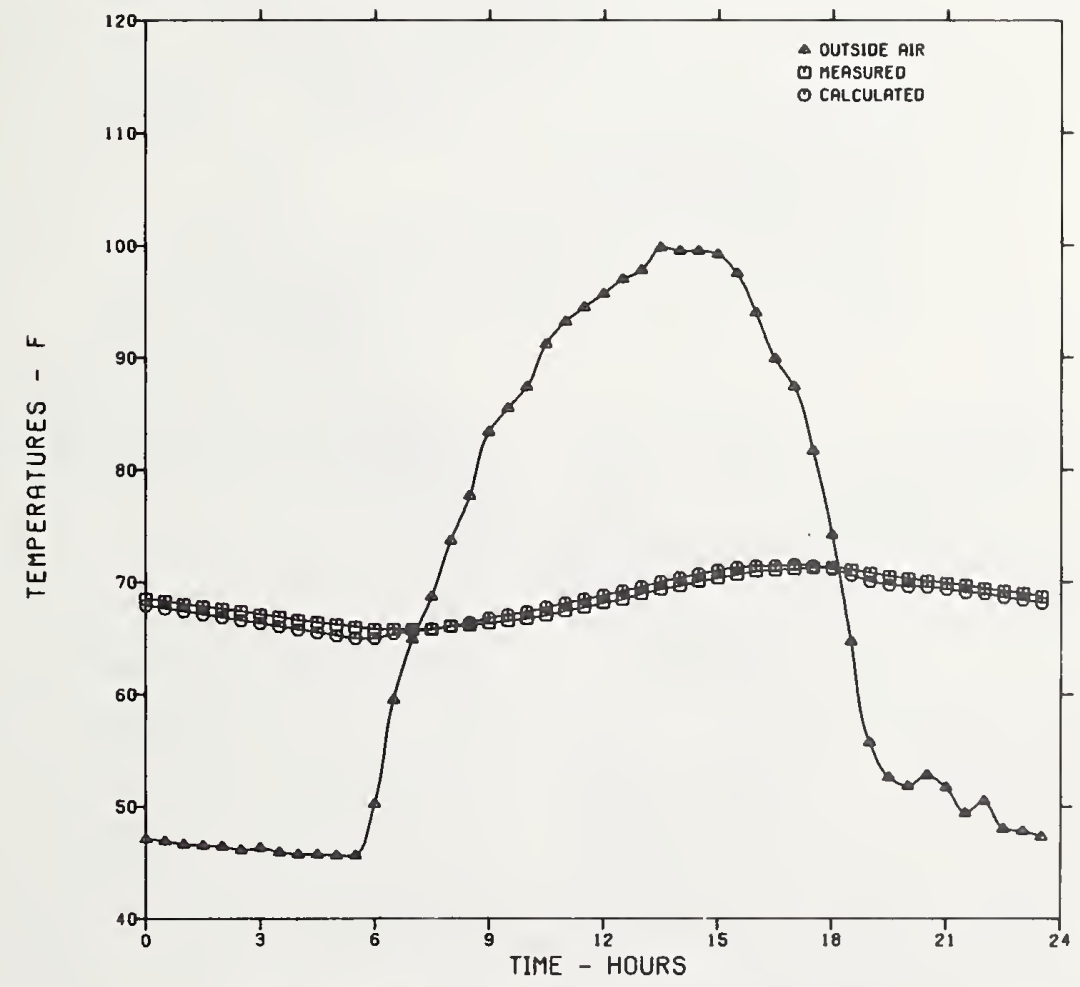

INSULATION INSIDE, WINDOWS, INTERNAL MASS.

FigURE 12. Comparison between measured and calculated inside air temperatures for floating test 4. 


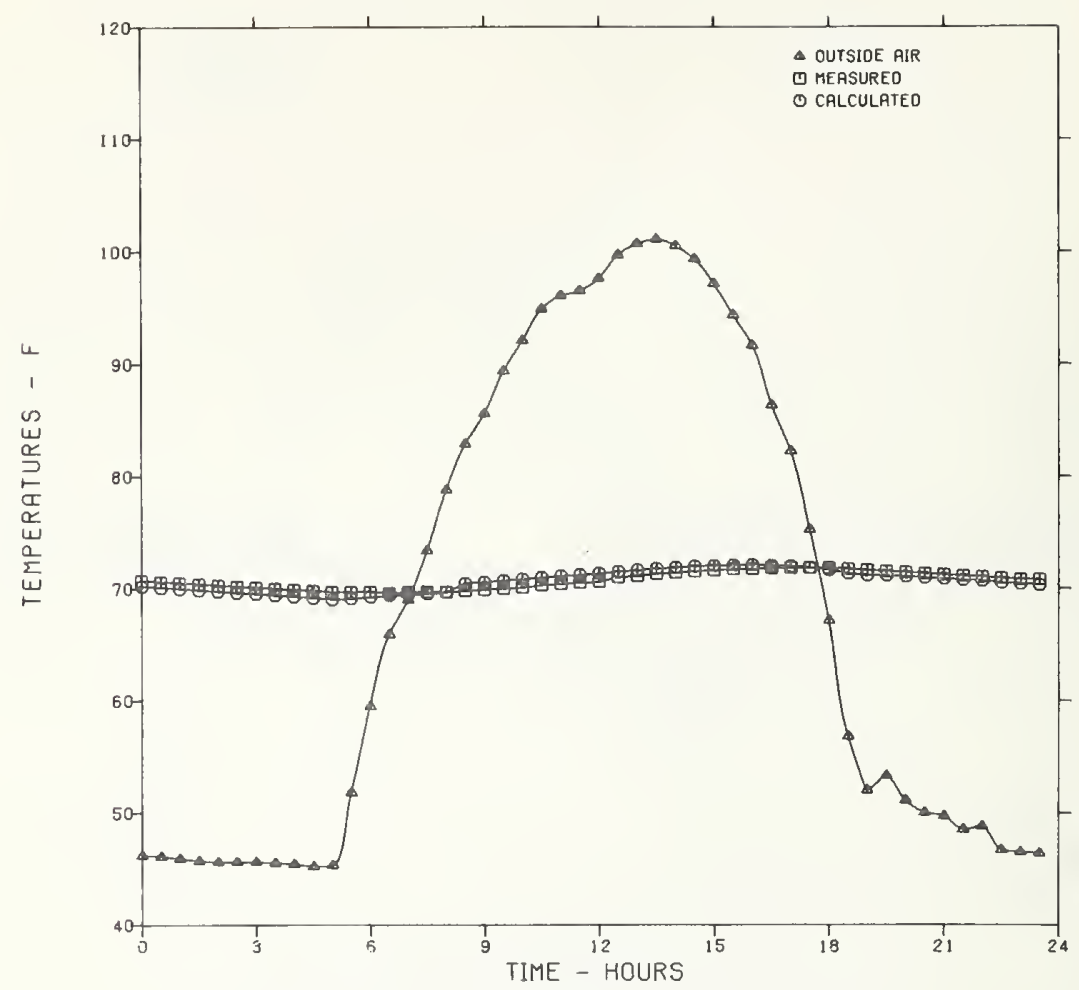

INSULATION OUTSIDE, WINDOWS, INTERNAL MASS

FIGURE 13. Comparison between measured and calculated inside air temperatures for floatıng test 5.

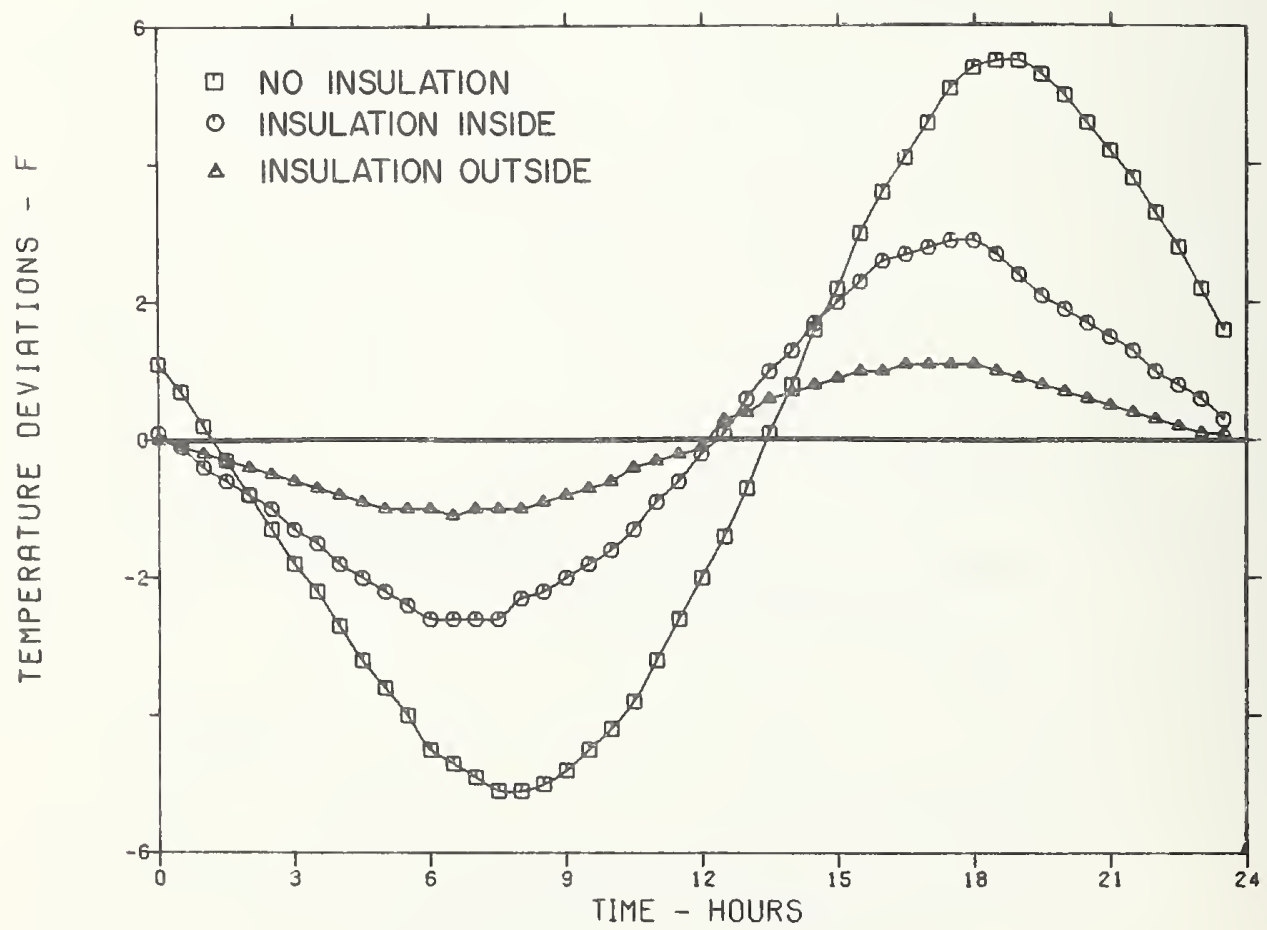

FIgURE 14. Comparison of inside air temperature deviations from daily average inside air temperature for identical buildings for cases of no insulation, insulation inside, and insulation outside. 


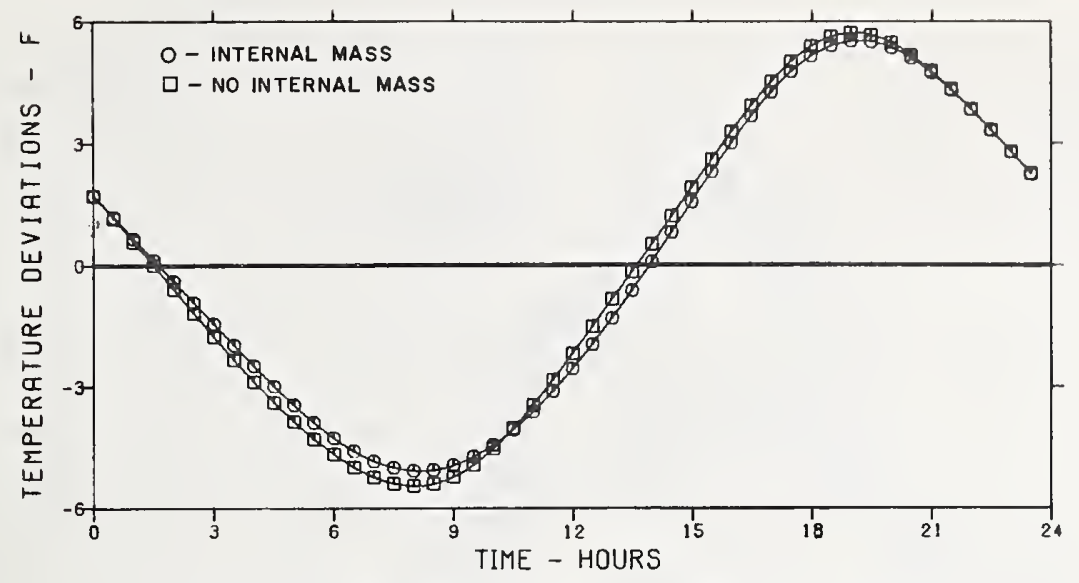

F1GURE 15. Comparison of the inside air temperature deviations from daily average for identical buildings with internal mass (test 2) and without internal mass (test 1).

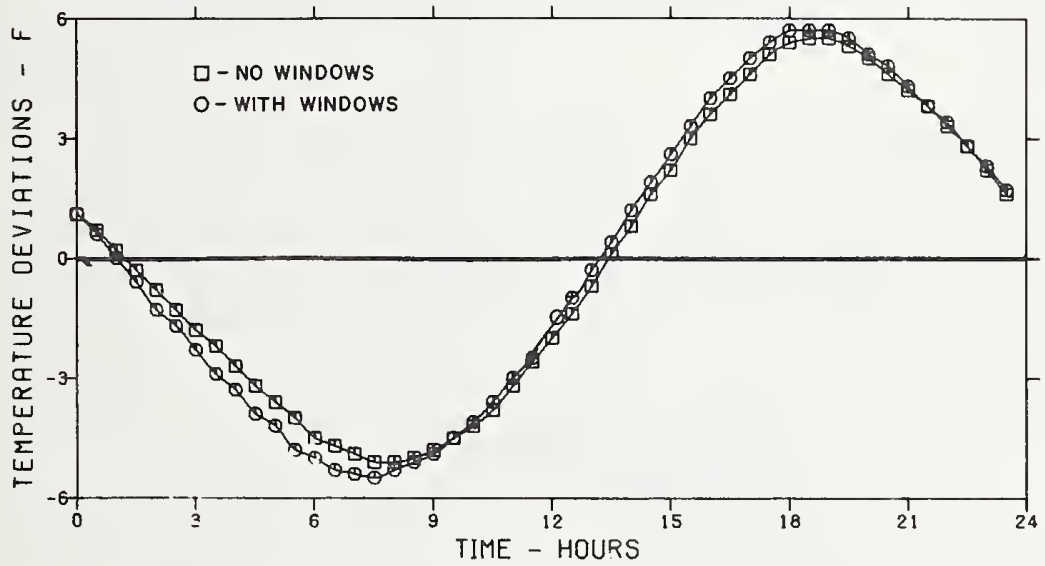

FIGURE 16. Comparison of the inside air temperature deviations from daily average inside air temperature for identical uninsulated buildings with windows (test 3) and without windows (test 1 ).

side surface of the building reduced the variations of the inside air temperature from about 10.5 to $5.5^{\circ} \mathrm{F}$. The effect of the insulation then was to damp out the cyclic fluctuations of inside air temperature. Furthermore, when insulation was placed on the outside surfaces instead of the inside, the variation was reduced to about $2{ }^{\circ} \mathrm{F}$. This experimental finding is considered to be significant because no heat energy was purposely added to or taken away from the indoor air during the tests, and the performance results illustrate that considerable reduction of the indoor air temperature variations can be obtained by simply placing the mass of the walls and roof inside with insulation outside.

To investigate the effect of an interior mass on the inside air temperature for a floating test, a com- parison was made between tests 1 and 2 (figs. 9 and 10). Temperature deviations from the measured mean inside air temperature for these two tests are plotted in figure 15. It can be seen that for these cases with no insulation, the presence of an internal mass slightly dampens the inside air temperature cy. cle. This effect was also predicted by the Response Factor program. For floating tests with insulation either on the inside or outside surfaces (figs. 10 and 11), the effect of an internal mass is reduced to negligible proportions. This is because the heat absorption and rejection by the internal mass is very small when the cyclic fluctuations of the inside air temperature are small.

To examine the effect of windows on the inside air temperature, a comparison was made between tests 
numbered 1 and 3 . The measured temperature deviations from the mean inside air temperature for these two tests are plotted in figure 16. From figure 16 , it may be seen that for the two cases without insulation the effect of adding windows had little effect on the cyclic fluctuations of the inside air temperature. The glass area was about 8.4 percent of the total wall area. For cases with insulation, one would expect the addition of windows would have a more pronounced effect on the cyclic fluctuations of the inside air temperature, since the heat flow through windows would be a larger percentage of the total heat flow. Direct experimental comparison is not possible because measurements were not made on the building with insulation either inside or outside without windows. For practical purposes, an improvement in the indoor temperature profile as shown in figure 16 by elimination of windows is considered to be negligible.

Figures 17 and 18 show the inside and outside wall surface temperature variations for test 1 ; no insulation, no windows, and no internal mass. Each curve represents the average temperature of five thermocouples located at the same height above the floor and at the wall positions as shown in figure 6 . From these graphs it can be seen that the wall surface temperatures for this floating test differ from each other within a $2{ }^{\circ} \mathrm{F}$ band except for the temperatures at the 0 - and 10 -ft levels. This suggests that the assumption of one-dimensional heat transfer is valid over a major area of the wall surface, multi-dimensional effects being confined in a region near the junctures of the floor to wall and the roof to wall. Figures 17 and 18 also show by comparison the effect of thermal resistance and mass of the building, i.e., at the $10-\mathrm{ft}$ level, the outside surface changed in temperature by about $30^{\circ} \mathrm{F}$ while the inside surface at the same level changed by about $16{ }^{\circ} \mathrm{F}$. Also, the highest and lowest temperatures on the outside surface occurred about 2 hours sooner than the inside surface. The use of thermal insulation resulted in a much more uniform inside wall temperature distribution. For instance, when insulation was placed on the outside surface of the building (floating test numbered 5), a maximum inside wall surface temperature fluctuation of $2.3^{\circ} \mathrm{F}$ occurred over the 24-h cycle at the juncture of the wall and the ceiling. In addition, at any instant the maximum floor to ceiling temperature difference along the inside wall surface was $1.8^{\circ} \mathrm{F}$.

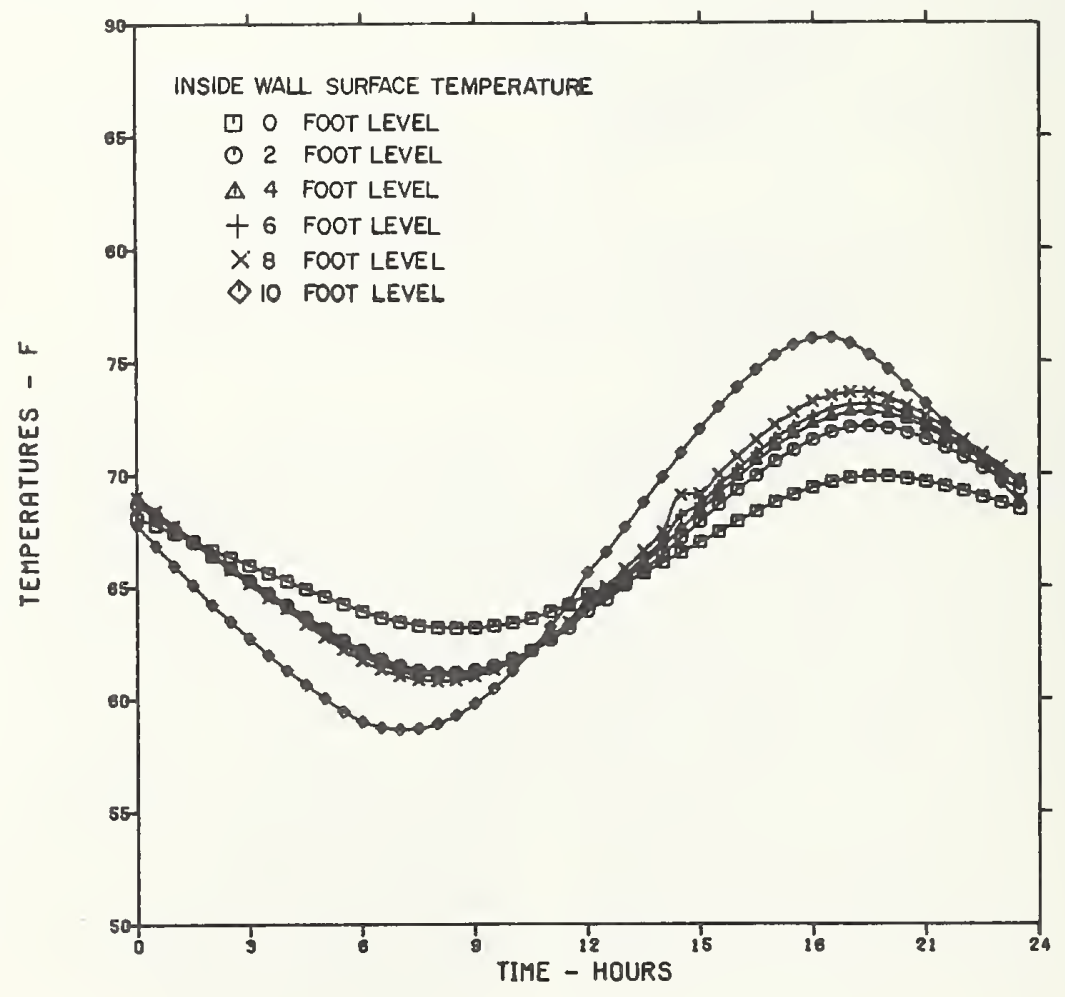

FIGURE 17. Variations of inside wall surface temperatures for test 1. 


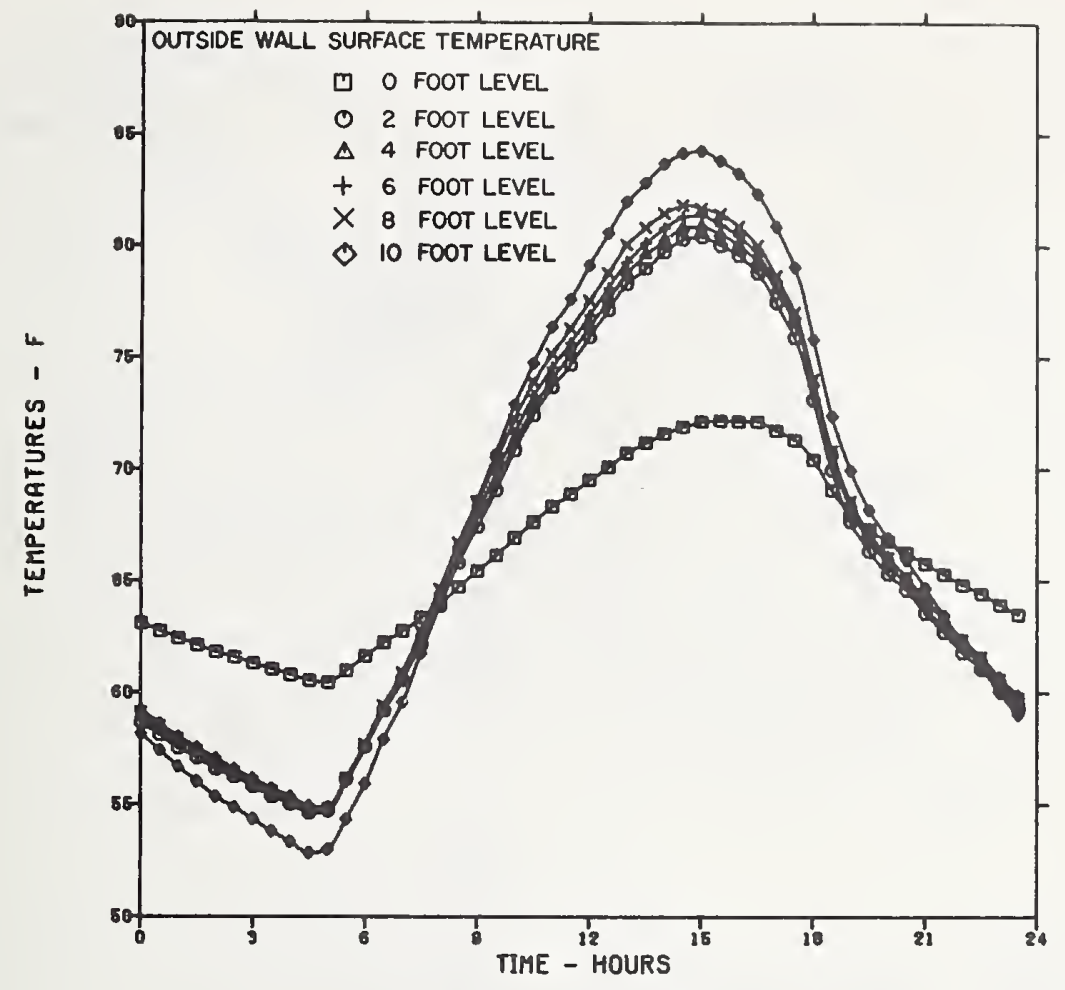

Figure 18. Variations of outside wall surface temperatures for test 1 .

Comparisons between the measured and calculated heat fluxes at the inside surfaces of major building components for floating test 1 are shown in figures 19 through 21 where negative values denote heat flow into the room. Measured heat fluxes shown for the floor, roof, and the wall were obtained using heat flow meters located at the center of the floor, the center of the roof, and at the midpoint of wall in plane B, respectively (see fig. 6). Since both the measured and calculated data contain many small fluctuations due to local variations of the inside air temperature, it was necessary to apply a harmonic analysis to each set of heat flux data, maintaining only the first eight terms to give the smoothed curves shown in the graphs. From figures 19 and 20 it can be seen that the agreement between the measured and calculated heat fluxes at the inside surface for floor and the roof was reasonably good.

Figure 21 shows fairly large deviations for the smoothed measured wall heat flux from the calculated values. The same type of behavior was obtained in other tests where the floor and ceiling also showed good agreement. The calculated heat flux values were computed assuming a constant film resistance for all heat flow conditions. Because of air motion the film resistance will not be a constant, but will be a function of the heat flow conditions that promote air flow adjacent to the surfaces. Figures 19-21 show that zero heat flux occurred at different times for the floor, roof, and walls, and, therefore, the time of reversal of direction of heat flow by convection was different for the different surfaces. Thus, there would be different degrees of reinforcement or interference to convection heat flow near the floor-wall and ceiling-wall junctions for an hour or so just before and just after the time of zero heat flux at the various surfaces. This may account for some of the disparity between calculated and measured heat flux for the walls shown in figure 21 .

To study the processes which combine together to produce the thermal performance of the air inside a building, the profiles of the heat flux at the separate inside surfaces during the outside air temperature cycle were plotted. Figure 22 shows the variations of the heat flux at the inside surfaces of the roof, walls, floor, and window for the case of no insulation (floating test 3 ). The heat flux profiles appearing in this graph were calculated by the Response Factor com. puter program. Positive values signify heat flow in a direction from the inside to the outside. The net heat 


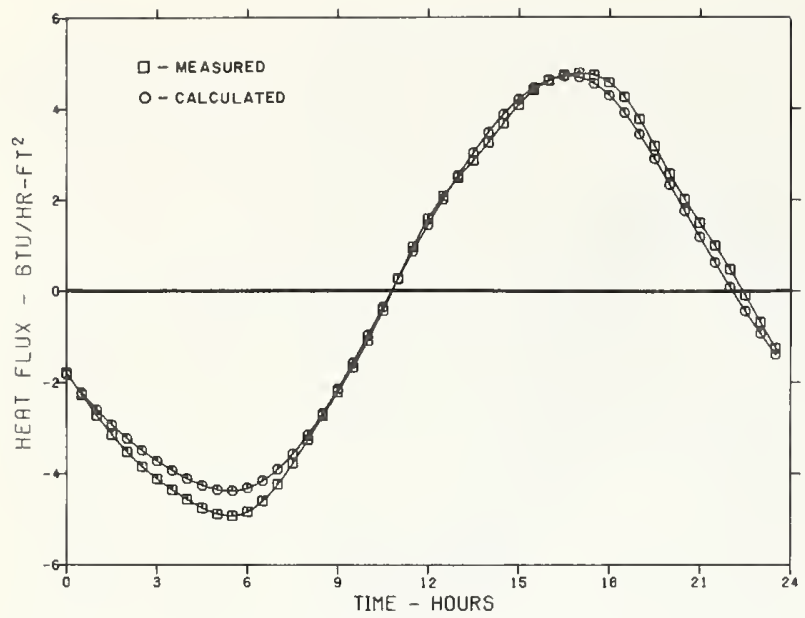

Figure 19. Comparison between the measured and calculated heat fluxes at the inside surface of the floor for test 1 .

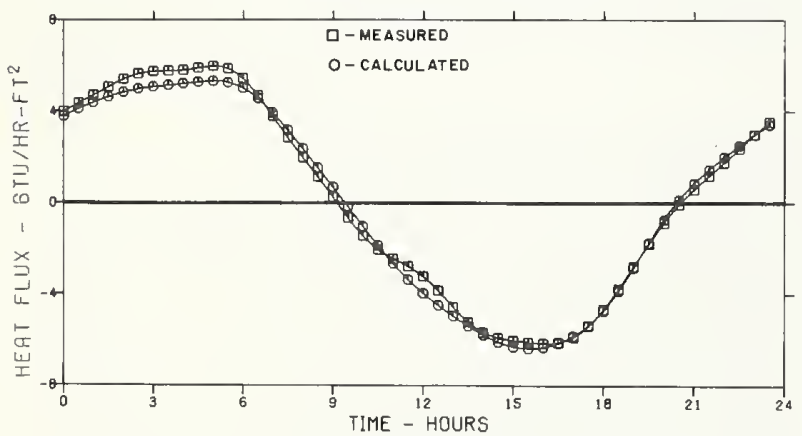

Figure 20. Comparison between the measured and calculated heat fluxes at the inside surface of the roof for test 1 .

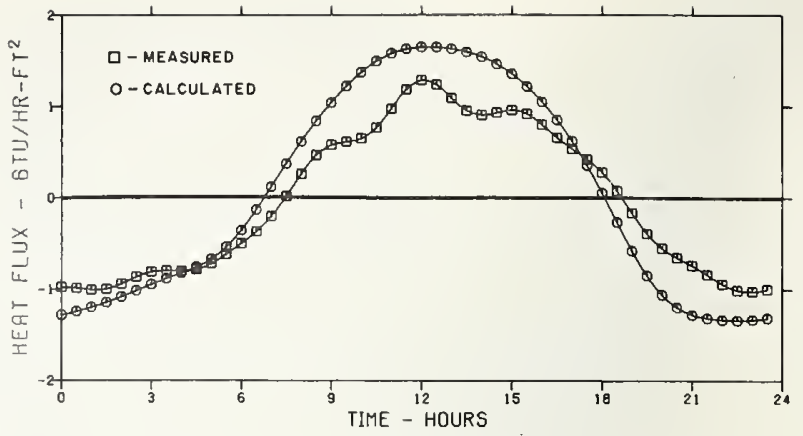

Figure 2l. Comparison between the measured and calculated heat fluxes at the inside surface of the wall for test 1 .

transfer to or from the indoor air at any instant of time is equal to the algebraic sum of the products of the heat fluxes at the surfaces and their respective areas plus the heat exchange resulting from air infiltration. For the floating tests this sum should be equal to zero. The heat flux at the inside surface is affected by the resistance to heat flow and the thermal heat capacity of the materials across which heat must flow to the surface as well as the dynamic conditions of the temperature of the outside and inside air. For this reason, heat is simultaneously flowing out of and into different surfaces of the building. The heat flow at the windows is in phase with the temperature potential created by the difference in the outside and inside air temperature because heat storage (mass) of the windows was negligible. The roof and walls are not in phase with this potential

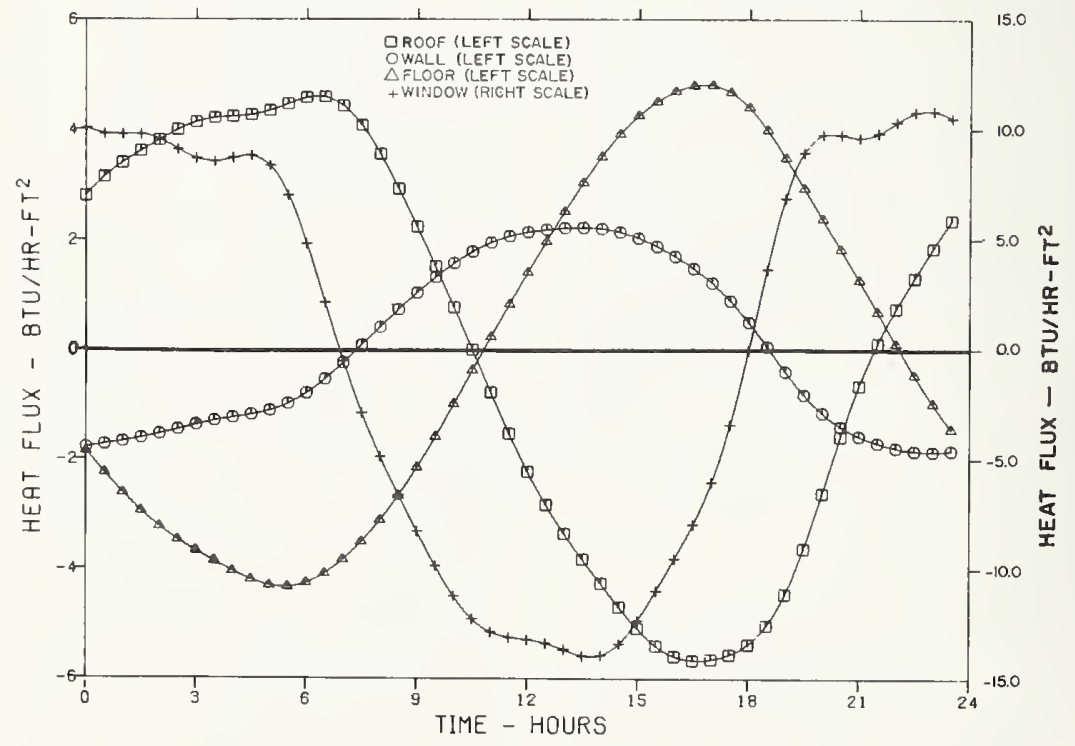

FIgURE 22. Computed variations of the heat flow rates at the inside surfaces of the roof, walls, floor, and the window for the case of no insulation (test 3 ). 


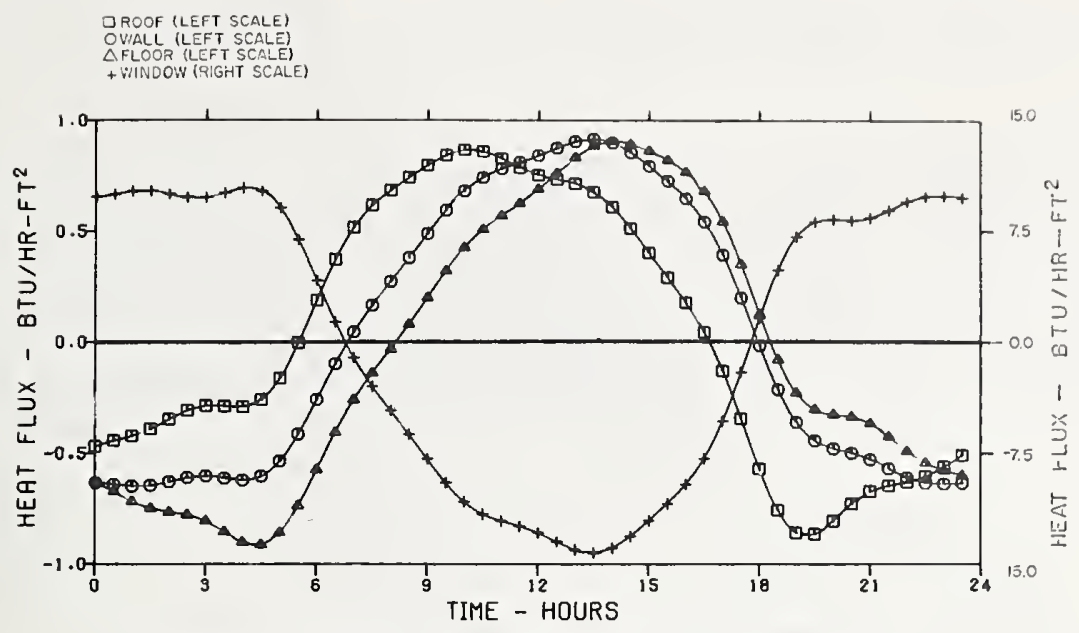

Figure 23. Computed variations of the heat flow rates at the inside surfaces of the roof, walls, floor, and the windows for the case of insulation placed on the outside surfaces of the building (test 5 ).

due to their appreciable heat storage capacity and their minimum values (maximum heat flows into the room) lag behind that for the windows by about 3 and 9 hours, respectively. The roof was approximately one-half the thickness of the walls, and a smaller delay time to reach a maximum or minimum was expected. Heat flow into and out of the floor was approximately in phase with the inside air temperature cycle shown in figure 11. This was as expected because the ground temperature beneath the floor was relatively constant with time.

A similar analysis of heat flow was performed for the case of insulation placed on the outside surfaces (floating test 5). Figure 23 shows the profiles of the heat flow at the inside surfaces for this test condition. With the peak outside air temperature at the fourteenth hour, the delay times for maximum heat flows into the room were 12 and 5 hours for the walls and roof, respectively. The effect of placing insulation on the outside surface was to increase the delay time (from 9 and 3 to 12 and 3) and considerably reduce the amplitude of the heat flux profiles for the wall and roof.

Figure 24 is a plot of deviations of the inside air temperature at each of six points from their instantaneous average (floating test 3 ). As in all previous plots, the peak outside air temperature occurred at the fourteenth hour. Positive deviations signify that the air temperature at that location was higher than the average inside air temperature. On a daily average, the air adjacent to the ceiling was about 2 ${ }^{\circ} \mathrm{F}$ warmer than the air layer next to the floor with the floor being as much as $3^{\circ} \mathrm{F}$ warmer and $8.5^{\circ} \mathrm{F}$ colder than the ceiling during portions of the cycle. The portion of the cycle with the largest floor to ceiling temperature difference (about hour 18) shows a good example of a heated surface facing downward (ceiling) and a cooled surface facing upward (floor) where the air flows adjacent to the two surfaces were in the laminar range thus producing little mixing of air and large vertical temperature gradients. Conversely, the portion of the cycle with the smaller temperature differences (about hour 5) shows an example of a cooled surface facing downward (ceiling) and a heated surface facing upward (floor) where the air flows ad. jacent to the surfaces were more turbulent producing mixing of air by natural convection and smaller vertical temperature gradients. One must conclude from figures 22 to 24 that the indoor convection pat. tern is continually changing, as well as surface coefficients of heat transfer. The same observations can be made from the plots of deviations from the average inside air temperatures given in figures 25 and 26 for insulation placed on the inside (test 4) and the outside (test 5) surfaces, respectively. In these two cases, the vertical temperature gradients are considerably dampened due to the addition of insula. tion and subsequent reductions in variations of the surface temperatures. 


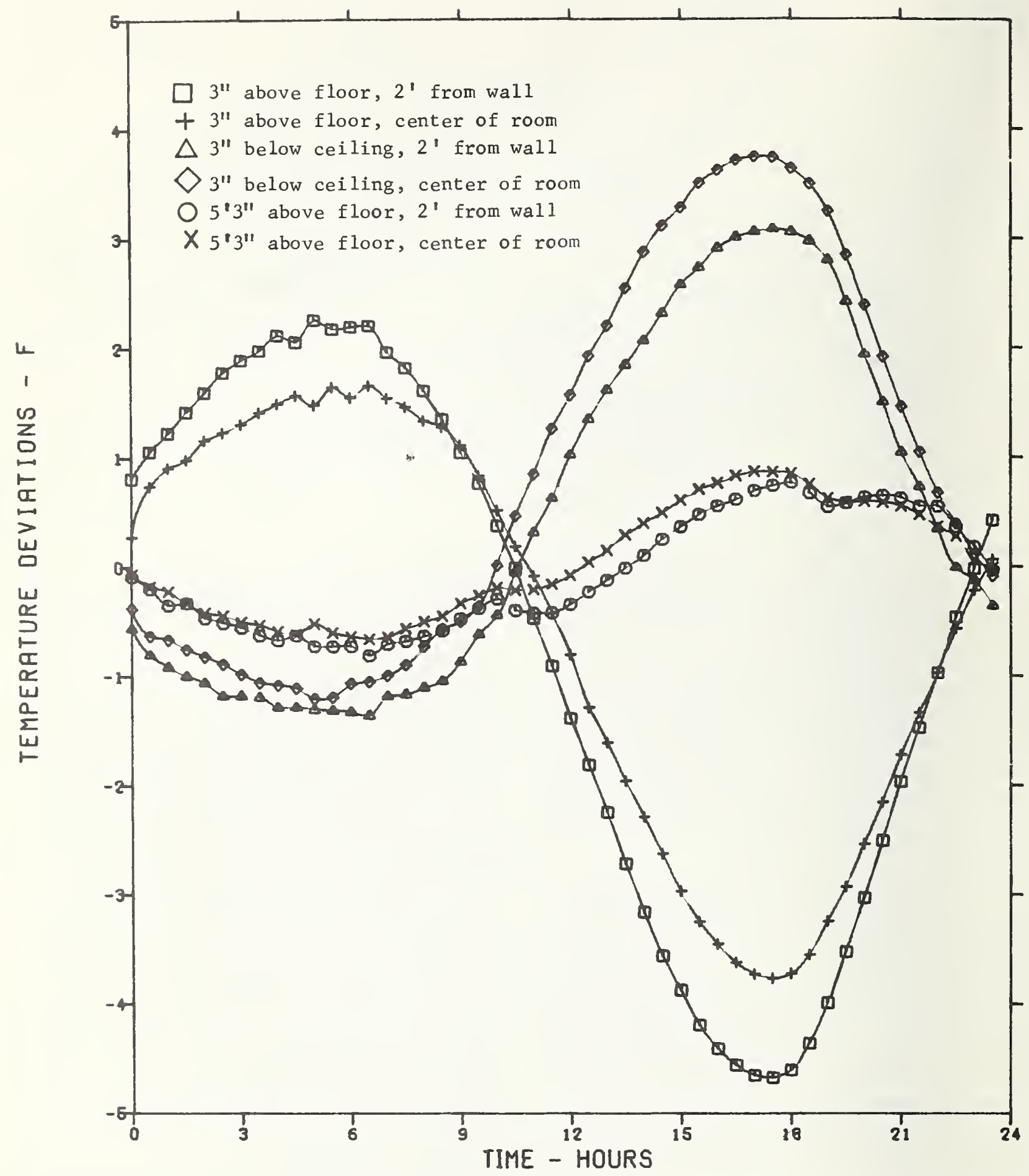

FiguRE 24. Deviations of the inside air temperature from instantaneous average of the six indoor air thermocouples for the case of no insulation (test 3). 


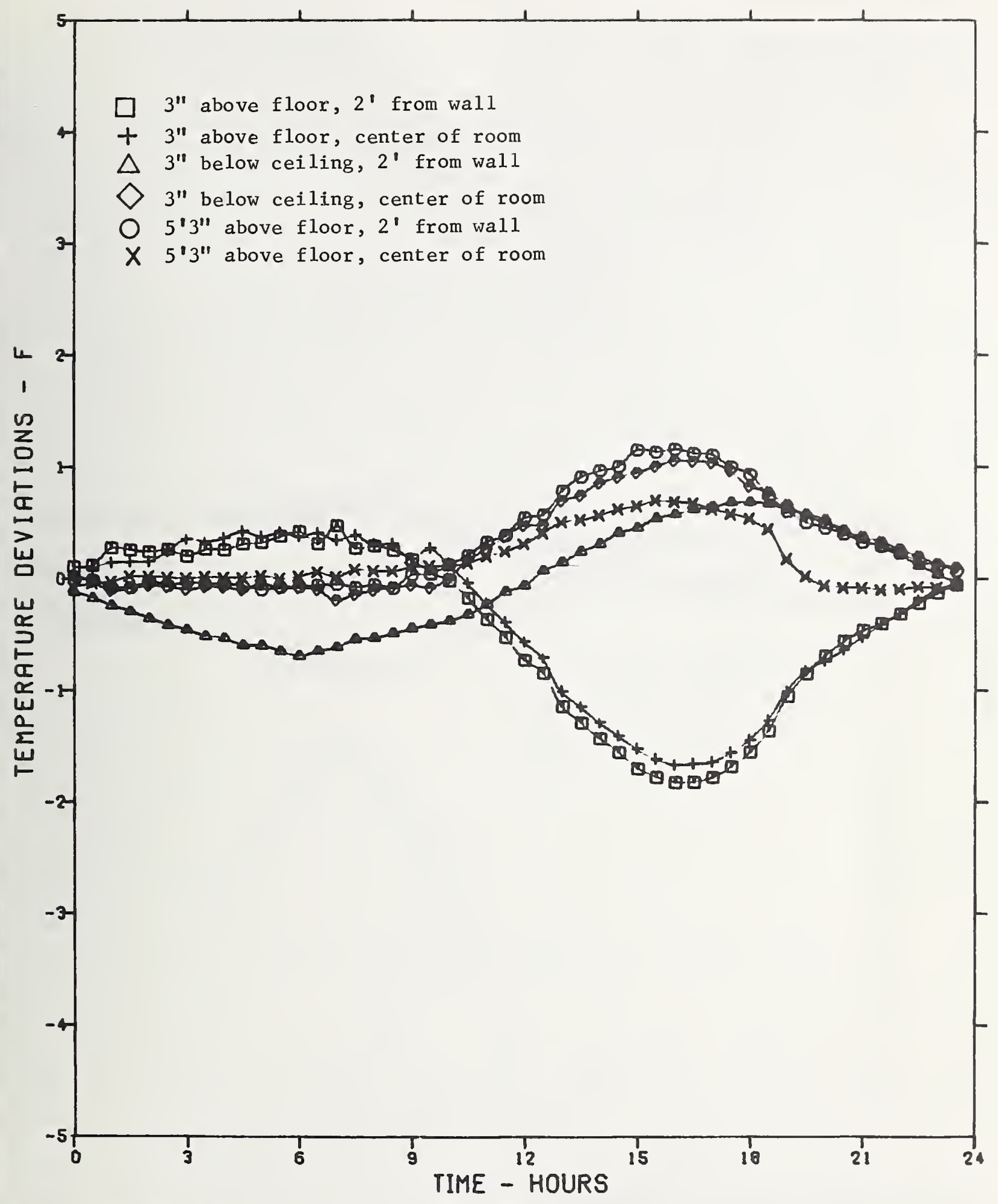

FiguRE 25. Deviations of the inside air temperature from instantaneous average of the six indoor air thermocouples for the case of insulation placed on the inside surfaces of the building (test 4). 


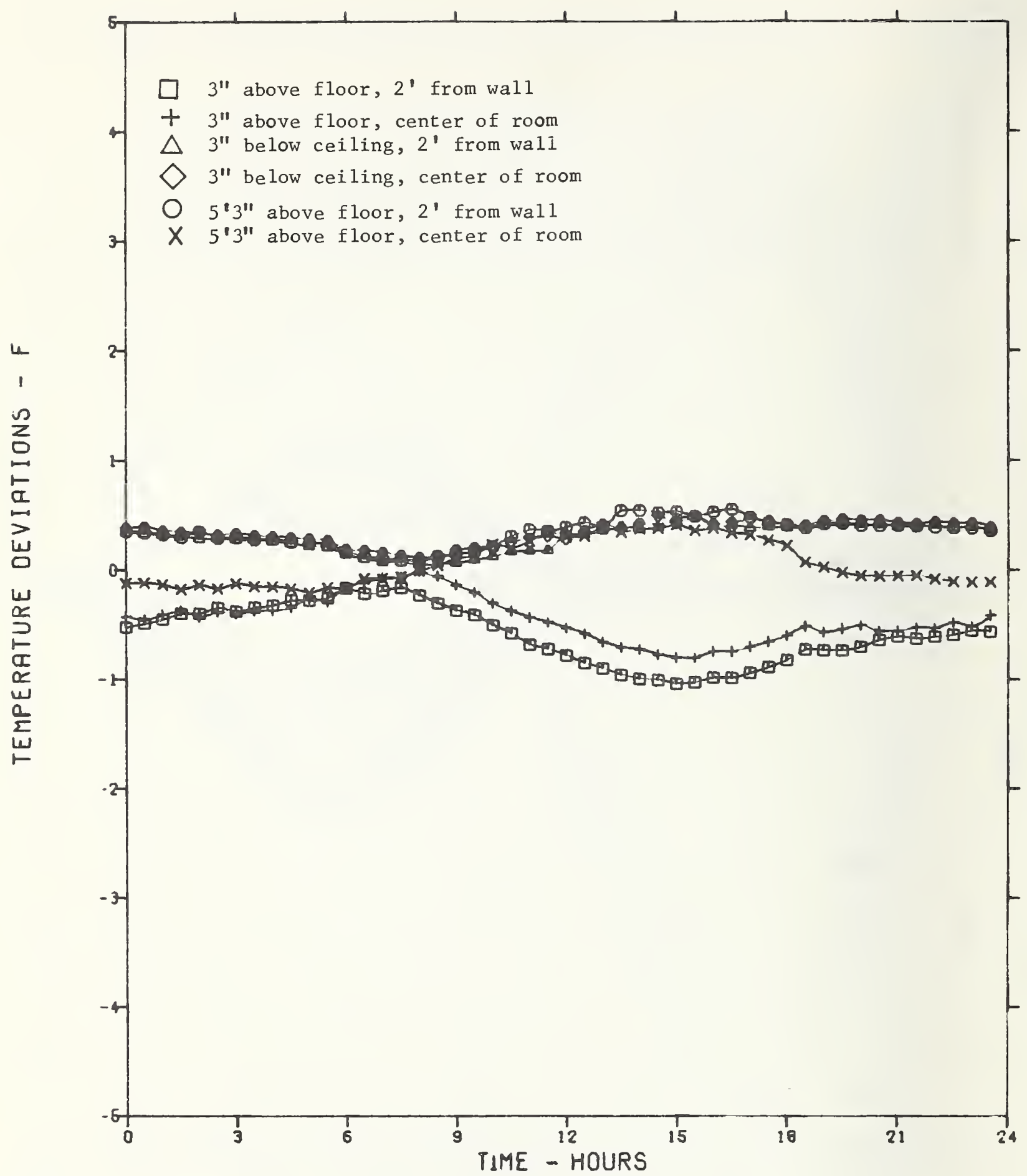

FIGURE 26. Deviations of the inside air temperature from instantaneous average of the six indoor air thermocouples for the case of insulation placed on the outside surfaces of the building (test 5). 


\subsection{Thermostated Tests}

For the thermostated tests, the inside room air temperature was maintained within an approximate $2{ }^{\circ} \mathrm{F}$ band by controlling the heat input to the experimental building. The room air temperature was obtained by averaging the six air temperatures (fig. 5) at each time interval.

Figures 27 through 31 are graphs for tests num. bered 6 to 10 which compare the measured power supplied to the electric heating equipment and the heating load calculated by the Response Factor program over the 24-h outdoor air temperature cycle as shown in each figure. The calculated load was computed by summing the net heat flows through each building component and heat flow due to air infiltration at each time interval. Areas used for computing heat flows were the arithmetic averages of the inside and outside areas of each building component as shown in table 4 . Since both the measured and calculated heating load data contained many small fluctuations due to variations of the inside air tempera- ture, it was necessary to apply a harmonic analysis to each set of heat load data. Only the first eight terms were maintained to give the smoothed curves shown in the graphs.

As shown on figures 27 through 31 , the minimum measured and calculated heating load usually occurred later in the day than the peak outside air temperature (hour 14) because of the effect of the mass of the building and insulation retarding heat flow through building components. Comparing the cases without and with insulation, figure 27 with figures 28 , 29,30 , and 31 , it can be seen that the effect of placing insulation on either the inside or outside surfaces of the building was to substantially reduce the amount of heating needed to maintain a constant inside air temperature. Generally the correlation between computer prediction and the measured heating load profiles is reasonably good. There was less than an 8 percent difference between the maximum computed and measured heating loads for all cases. The average difference was 4.3 percent for the five tests.

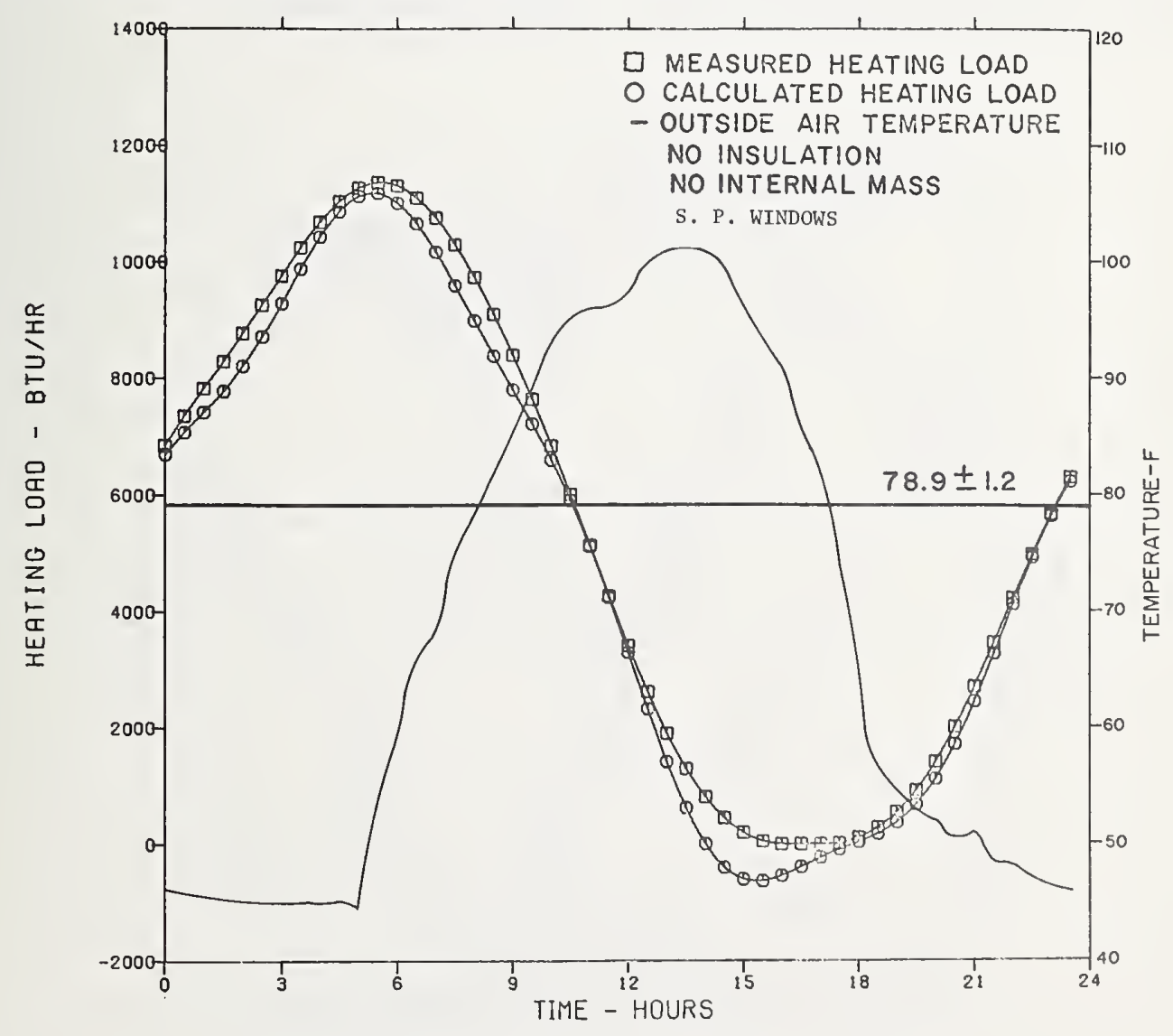

Figure 27. Comparison between the measured and calculated heating loads for test 6 . 
For test 9 (fig. 30) and test 10 (fig. 31), the building was identical but for test 10 the outdoor temperature cycle was changed from $40-100$ to $10-70{ }^{\circ} \mathrm{F}$ and the indoor air temperature was changed from 77.6 to $73.8^{\circ} \mathrm{F}$. The shape of the heating load profiles are similar but for test 9 the maximum and minimum loads were about 2500 and $400 \mathrm{Btu} / \mathrm{h}$, respectively, and for test 10 about 6100 and $3500 \mathrm{Btu} / \mathrm{h}$, respectively. The maximum loads for both tests are lower than the values that would be estimated on the basis of steady-state procedures as is discussed in detail later in this paper.

For the thermostated tests with insulation (tests 7 through 10), the measured heating loads lag the calculated heating loads over part of the 24-h cycle. Consistently, the phase lag occurred on the profiles in the time period between the maximum and minimum loads. Also, some phase lags occurred following the minimum loads. The reasons for these phase lags are not obvious because the phase lags varied from one test to the other and the lag is especially evident in test 9 , figure 30 . It was found during analysis that the calculated heating load was in. fluenced by whether the inside, outside, or average area was used, lack of heat flow allowance for corners and the building foundation, variations of inside air temperature, and heat transfer coefficients at the inside and outside surfaces.

To illustrate the effect of windows on the thermal behavior of the experimental building, calculations were made using the Response Factor method for the cases of seven single-pane windows, seven double-pane windows, and no windows with insulation on the outside surfaces. The outside air temperature cycle used was $40-100^{\circ} \mathrm{F}$ and the inside air temperature was $77.6^{\circ} \mathrm{F}$. Figure 32 shows the computed heating load profiles for the above cases. The peak heating load for single-pane windows was 57 percent higher and occurred approximately $21 / 2$ hours earlier than the case without windows. The peak heating load for double-pane windows was 9 percent lower than single-pane windows. Some validation by measurement of the latter can be seen by comparing the peak heating loads as shown in figures 29 and 30 , about 4 percent difference.

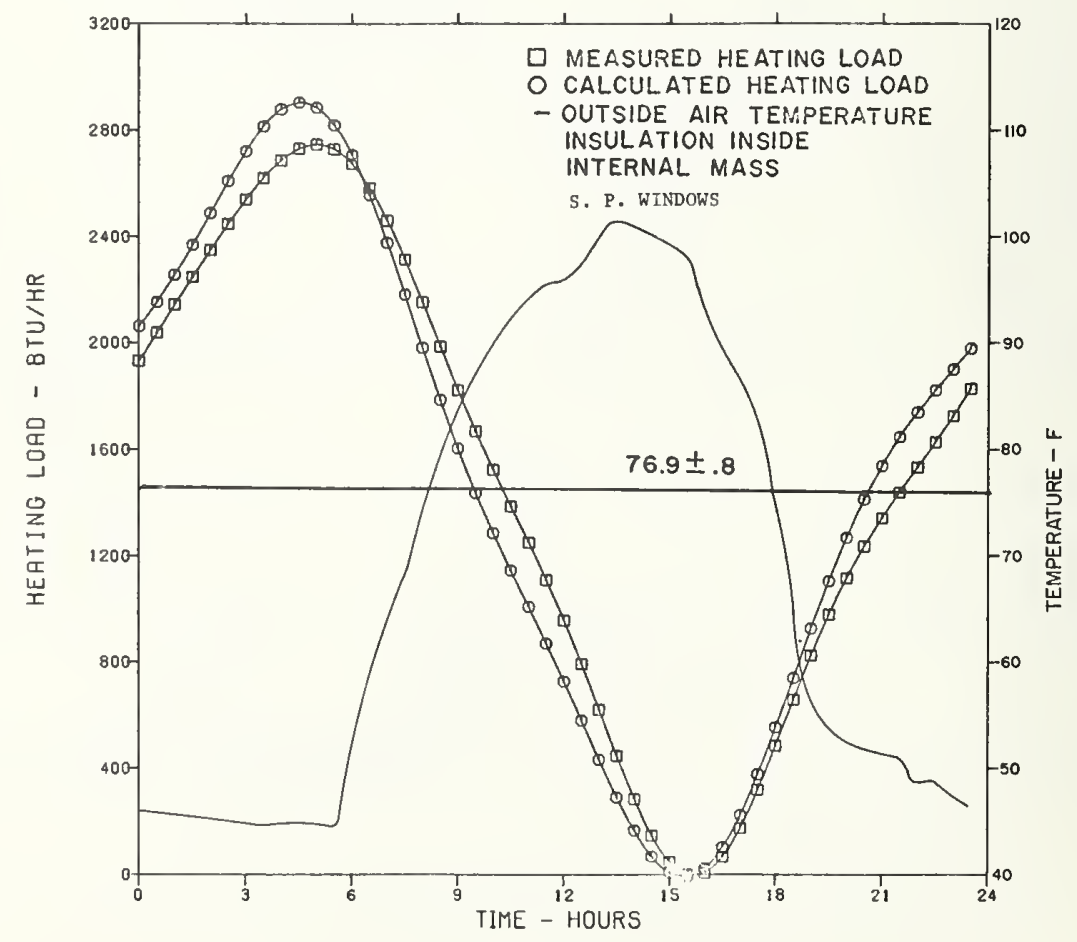

Figure 28. Comparison between the measured and calculated heating loads for test 7 . 


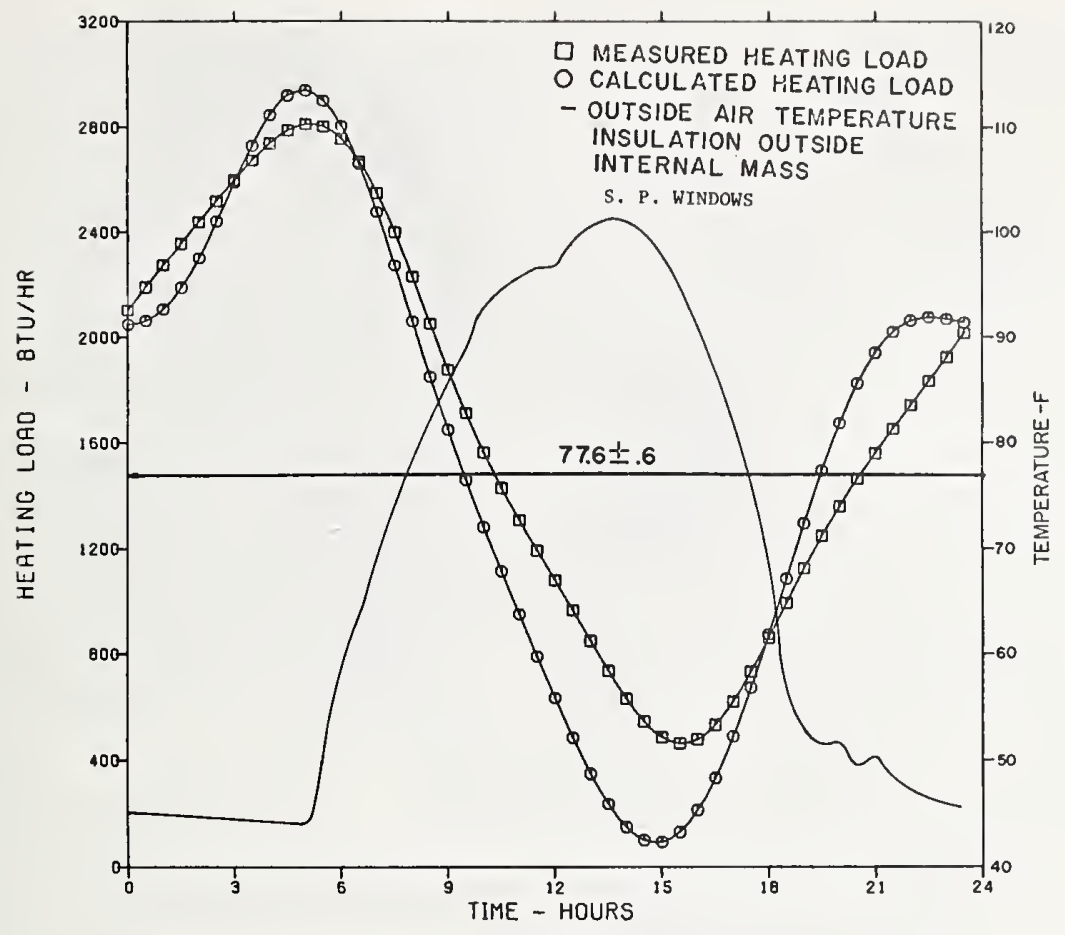

Figure 29. Comparison between the measured and calculated heating loads for test 8 .

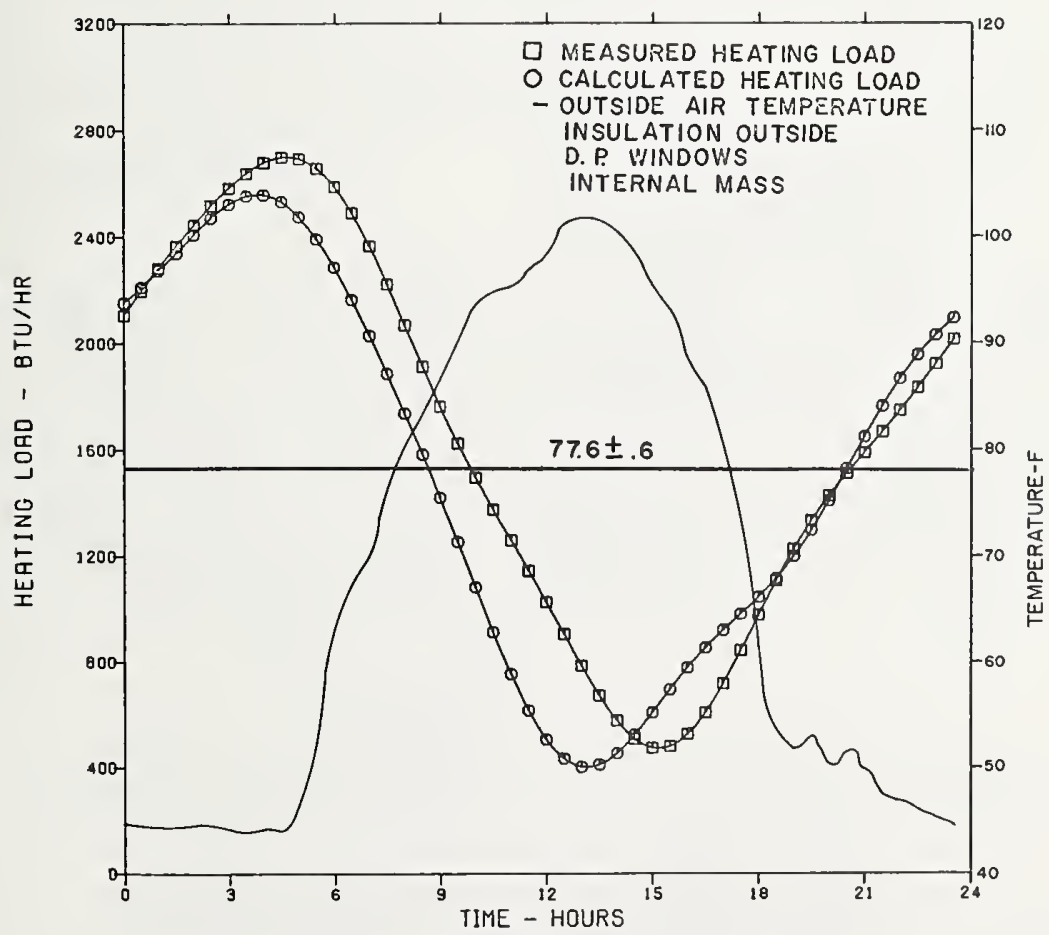

Figure 30. Comparison between the measured and calculated heating loads for test 9 . 


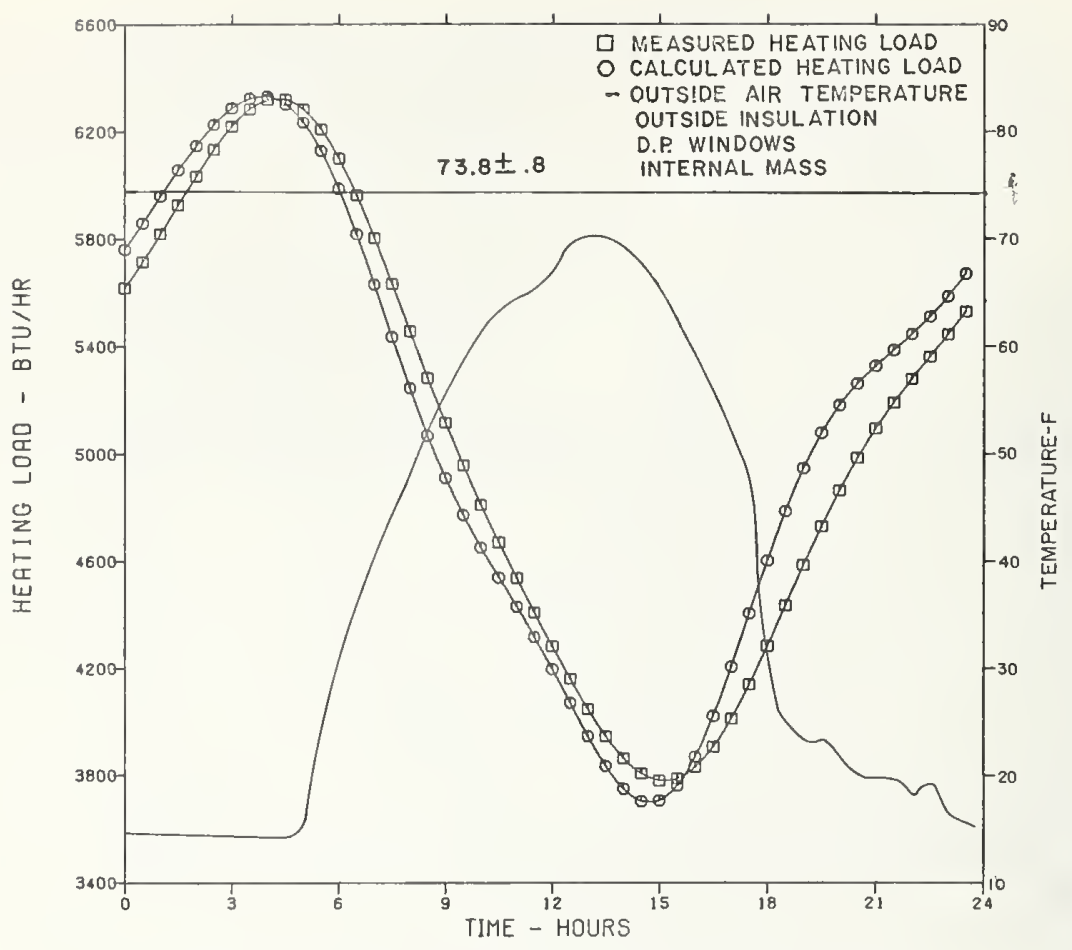

Figure 31. Comparison between the measured and calculated heating loads for test 10 .

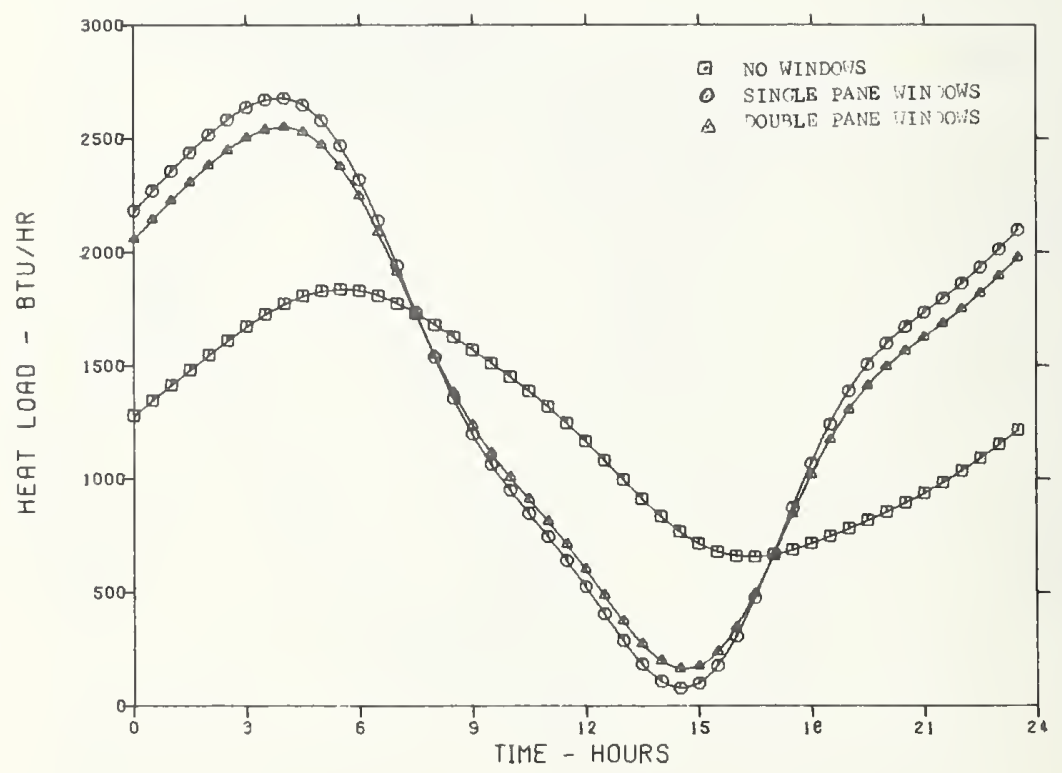

FIGURE 32. Comparison of the calculated heating load profiles for the cases of no windows, single-pane windows, and doublepane windows for the same building. 


\subsection{Heating Load Predictions}

Steady-state methods are usually used for predicting maximum heating loads from which the size of heating equipment is selected. Sometimes this process results in oversizing of heating equipment. To illustrate and compare the steady-state procedure and the dynamic procedure as given by the computer programs in appendices $\mathrm{C}$ and $\mathrm{D}$, table 5 was prepared.

The values listed in the column under SteadyState Method in table 4, were calculated for the experimental building as used in tests 6 through 10 , and for the outside air temperature cycles used during the tests. The steady-state maximum heat flow rate was calculated using the following formula:

$$
\begin{gathered}
q=U_{F} A_{F}\left(T_{i}-T_{g}\right)+\left(T_{i}-T_{0}\right) \Sigma U_{n} A_{n} \\
+1.08 V\left(T_{i}-T_{0}\right)
\end{gathered}
$$

where $q=$ heating load, Btu h $\mathrm{h}^{-1}$

$U_{F}=$ coefficient of transmission for the floor,

$B t u h^{-1} \mathrm{ft}^{-2} \mathrm{~F}^{-1}$

$A_{F}=$ area of the floor, $\mathrm{ft}^{2}$

$T_{i}=$ average inside air temperature, $\mathrm{F}$

$T_{g}=$ average ground temperature, $\mathrm{F}$

$T_{o}=$ outdoor temperature, $\mathrm{F}$

$U_{n}=$ coefficient of transmission for the $n$th surface, Btu h${ }^{-1}, \mathrm{ft}^{-2} \mathrm{~F}^{-1}$

$A_{n}=$ area of the $n$th surface, $\mathrm{ft}^{2}$

$V=$ air infiltration rate, $\mathrm{cfm}$

The first term corresponds to the heat transferred through the floor. The second term is for heat trans. ferred through the walls, windows, and roof. The third term is heat transfer due to air infiltration. When the above equation was used to predict the maximum heating load, the minimum outdoor temperature was used for $T_{0}$. When the above equation was used to calculate the daily average heating load, the daily mean outdoor temperature was used for $T_{0}$.
The maximum and daily average heating loads as calculated using the steady-state and Response Factor methods are presented for comparison with measured values in table 5.

The maximum heat flow rates as calculated by the steady-state method for the conditions during tests $6,7,8,9$, and 10 were $32,63,69,67$, and 29 percent, respectively, higher than the measured rates. The maximum heat flow rates as predicted by the Response Factor method were within 8 percent of the rates measured during the tests. The above high percentages indicate that when steady-state maximum rates are used with the temperature profile of figure 7 to size heating equipment without taking into account the heat capacity effects of the building, considerable oversizing could result.

When comparing daily average heat flow rates between the steady-state method, the Response Factor method, and measured values, table 5 shows that all values are reasonably close to each other for a given test number (about $10 \%$ or less). This was expected because a minimum quantity of heat energy is necessary to maintain the indoor air temperature over a period of 24 hours.

There is no way to make a good comparison between the design heating load that would result from application of the current steady-state procedures in the Guide and Data Book of the American Society of Heating, Refrigerating, and Air-Conditioning Engineers, and the maximum heating load determined by the computer techniques used in this investigation. The design winter outdoor temperature used in the ASHRAE procedure is that temperature for which $971 / 2$ or 99 percent, or some other chosen percentage, of the total hours are less severe in the location under consideration. The procedure does not take into account the effect of sunshine, the mass of the building, of the diurnal temperature pattern, or the relative location of the insulation in the building. Once the design outdoor

TABLE 5. Comparison of maximum and average heating loads

\begin{tabular}{c|c|c|c|c|c|c}
\hline \hline \multicolumn{4}{c|}{ Maximum heat flow rate $(\mathrm{Btu} / \mathrm{h})$} & \multicolumn{2}{|c}{ Daily average heat flow rate $(\mathrm{Btu} / \mathrm{h})$} \\
\hline Test & $\begin{array}{c}\text { Steady- } \\
\text { state } \\
\text { method }\end{array}$ & $\begin{array}{c}\text { Response } \\
\text { factor } \\
\text { method }\end{array}$ & Measured & $\begin{array}{c}\text { Steady- } \\
\text { state } \\
\text { method }\end{array}$ & $\begin{array}{c}\text { Response } \\
\text { factor } \\
\text { method }\end{array}$ & Measured \\
\hline 6 & 15135 & 11558 & 11372 & 4849 & 4899 & 5346 \\
7 & 4470 & 2814 & 2748 & 1365 & 1421 & 1475 \\
8. & 4748 & 3047 & 2811 & 1554 & 1612 & 1664 \\
9 & 4499 & 2525 & 2700 & 1455 & 1515 & 1639 \\
10 & 8150 & 6144 & 6321 & 4981 & 5047 & 5062 \\
\hline
\end{tabular}


temperature is selected, the design heating load is calculated as a steady-state heat transfer problem. There is no way to convert the diurnal temperature cycle used in this investigation into an equivalent ASHRAE design outdoor temperature. Furthermore, it is not possible to select a design winter day in terms of the diurnal temperature pattern using present ASHRAE procedures. Thus the present ASHRAE steady-state procedures constitute an approximate approach to the determination of heating loads that, due to experience and judgment, minimizes the likelihood of serious prolonged underheating of buildings.

\section{Conclusions}

The NBSLD computer program was experimentally verified for predicting the daily indoor air tem. perature as it is influenced by known outdoor temperature conditions and the mass and thermal resistance of the building. Furthermore, when the inside air temperature was thermostated, this program predicted the maximum and daily average heating loads and may therefore be used to size equipment needed to condition the interior of a building and to predict energy requirements. It was shown that steady-state methods of heating load calculations could result in oversizing heating equipment by 30 percent or more for this particular building and imposed exterior conditions if the lowest outdoor temperature was selected as the design temperature. The NBSLD dynamic method takes into account heat storage effects and therefore predicts the maximum heating load more realistically. The maximum percent difference between the computer calculated maximum heating load and measured values was 8 percent, and the average difference was 4.3 percent for the five tests.

The combination of mass in the walls and roof facing the interior with insulation placed on the outer surfaces of the building was very effective in reduc- ing and controlling the variation of the indoor air temperature. This desired effect was also predicted by the computer program. When the inside air temperature was not thermostated and the building floated in response to the outside air temperature condition, placing insulation on the inside building surface reduced the variation of the inside air temperature from $101 / 2$ to $51 / 2^{\circ} \mathrm{F}$. Furthermore, when this insulation was placed on the outside surface of the building, the variation in the inside air temperature was reduced to $2^{\circ} \mathrm{F}$. In addition, comparing cases of no insulation, insulation inside, and insulation outside, the temperature distribution from floor to ceiling on walls and in the indoor air was a minimum when insulation was placed on the outside of the building.

The effect of an internal mass on the thermal behavior of the experimental building was generally small. An internal mass to simulate furnishings may have a greater effect in a less massive building. On the other hand, windows had a significant effect on the computed thermal behavior of the experimental building. For instance, the maximum heating load for the experimental building with windows and insulation was 57 percent higher than the same building with insulation but without windows. Use of storm windows reduced the maximum heating load by 9 percent.

The authors wish to thank H. E. Robinson for his many ideas, conceptual approach, and technical suggestions prior to and during the experimental phases of this investigation. Also, appreciation is expressed to D. R. Showalter, J. D. Allen, J. M. Dungan, and J. W. Grimes for their technical assistance in the installation of the instrumentation and day-to-day operation of the experiments. The very helpful suggestions and comments made during review of this paper by P. R. Achenbach are gratefully acknowledged. 


\section{Appendix A}

\section{Air Infiltration Measurements on the NBS Experimental Building}

\section{Thomas K. Faison}

Thermal Engineering Systems Section, Building Environment Division

Center for Building Technology, Institute for Applied Technology,

National Bureau of Standards, Washington, D.C. 20234 


\section{Introduction}

In the early stages of the project on thermal performance of the experimental building, measurements were made to determine the magnitude of air exchange between the building and the surrounding chamber during the process of cyclic temperature changes. Since wind forces were negligible during the testing period, the major driving force influencing the change of air was the thermal difference between the air inside of the building and that of the surrounding air in the chamber.

\section{Analysis and Instrumentation}

The instrumentation used in the determination of the air exchange rates was developed at the National Bureau of Standards ${ }^{1}$, and the process of measurement was the tracer gas method using helium as the tracer gas.

The rate of change in concentration of a tracer gas caused by exchange or infiltration of outside air under a steady-state temperature difference is expressed by the formula:

$$
-V(d c / d t)=K c
$$

where

$$
\begin{aligned}
& V=\text { volume of enclosure } \\
& c=\text { concentration of tracer gas at time } t \\
& K=\text { average volume of air infiltration per unit time } \\
& \quad \text { for the time interval } \\
& t=\text { time }
\end{aligned}
$$

When $c=c_{0}$ at time $=0$, the solution of eq 1 is as follows:

$$
c=c_{0} e^{-K t / V}
$$

or

$$
K t / V=\log _{e}\left(c_{0} / c\right)
$$

Equation 3 shows that the number of air changes occurring during time $t$ is equal to the natural logarithm of the ratio of the tracer gas concentrations at the beginning and at the end of the time interval.

${ }^{1}$ Coblentz, C. W., and Achenbach, P. R., "Design and Performance of a Portable Infiltration Meter," Transactions, American Society of Heating and Air-Conditioning Engineers, Vol. 63, 1957.

\section{Procedure and Results}

Prior to the test, the apparatus was calibrated and brought into equilibrium with its surroundings, then helium, the tracer gas, was released into the building. As the helium was introduced, it was mixed with the room air by means of a portable fan and the final mixture of air and helium contained about $1 / 2$ percent of helium by volume.

Four helium-sensing elements were distributed within the space. Each sensor was positioned $3 \mathrm{ft}$ above floor level and $4 \mathrm{ft}$ from an outside wall near each of the four corners. Air temperature measurements of the two spaces were recorded during the test.

Initially a test was made to determine the amount of air exchange through the building with the surrounding environmental chamber prior to cutting openings for the glass windows. Later, additional tests were made to determine the rate of air exchange when glass windows were introduced into the building. The windows were of a fixed type and were caulked in place. The door was closed for all tests.

Measurements were made at the time of day when the air temperature in the environmental chamber was lowest and unchanging, providing a maximum temperature difference and air exchange between the inside and outside. Measurements of air exchange were made when the tightly fitting weatherstripped door was normally closed and when all cracks around the door were taped.

For the building without windows, the measured values of air exchange were 0.03 and 0.06 air changes per hour for the conditions of the taped and untaped door, respectively. These air exchange rates for the basic structure are very small. They do provide a minimum value for comparison with other tests and show that heat gain or loss to the building was almost solely by heat conduction and the influence of air leakage for the test without windows was practically negligible.

After the windows were installed, single glass only, additional measurements were made to determine the exchange rate under these conditions. The same procedure was followed and approximately the same temperature difference was observed. Under these conditions, but with the windows installed, the door not taped and no insulation on the walls, the measured value was 0.38 air changes per hour, a sig. nificant increase over the first tests having no window openings. 


\section{Appendix B}

\section{Noise Transmission Measurements of the NBS}

Experimental Building

\section{John S. Forrer}

Applied Acoustics Section, Mechanics Division

Institute for Basic Standards, National Bureau of Standards

Washington, D.C. 20234 



\section{Objectives of Tests}

Measurements were made of the sound attenuation provided by the concrete block experimental building located in the NBS high-bay environmental laboratory in order to establish the feasibility of noise reduction testing in such a space and to determine the sound transmission characteristics corresponding to four different conditions of the building.

\section{Building Variations Tested}

The building construction during the first series of tests was a simple concrete block cubicle with a 20 $\mathrm{ft} \times 20 \mathrm{ft}$ floor plan and a 10-ft-high ceiling (outside dimensions). The walls were made of 8 -in $\times 8$-in $\times$ 16-in solid concrete blocks. A concrete slab floor and a flat 4-in-thick precast concrete slab roof completed the enclosure. A 2-in-thick solid wooden door (foam rubber gasketed) provided the only break in the otherwise solid shell of the building.

The building configurations employed during the noise transmission tests were as follows:

1. Concrete block shell with a single wooden door (described above).

2. Seven 32 -in $\times 40$-in $\times 3 / 32$-in single-pane windows installed as shown in figure 1 (bottom of sills 40 in above floor).

3. 2-in-thick rigid polystyrene thermal insulation applied to the inside walls and ceiling.

4. Insulation removed from inside the building and similar material used to cover the outside walls and roof.

\section{Test Procedures}

Measurements were made in accordance with ASTM E336-67T, Tentative Recommended Practice for Measurement of Airborne Sound Insulation in Buildings. The procedures, referred to in appendix A.1.1 of E336-67T, for determining noise reduction (a measure of the isolation between two enclosed spaces) were followed. This is in contradistinction to the field insertion loss which is typically measured when a complete building is tested out of doors.

Figure B-1 shows the location of each of the five microphones of the receiving room array (inside the

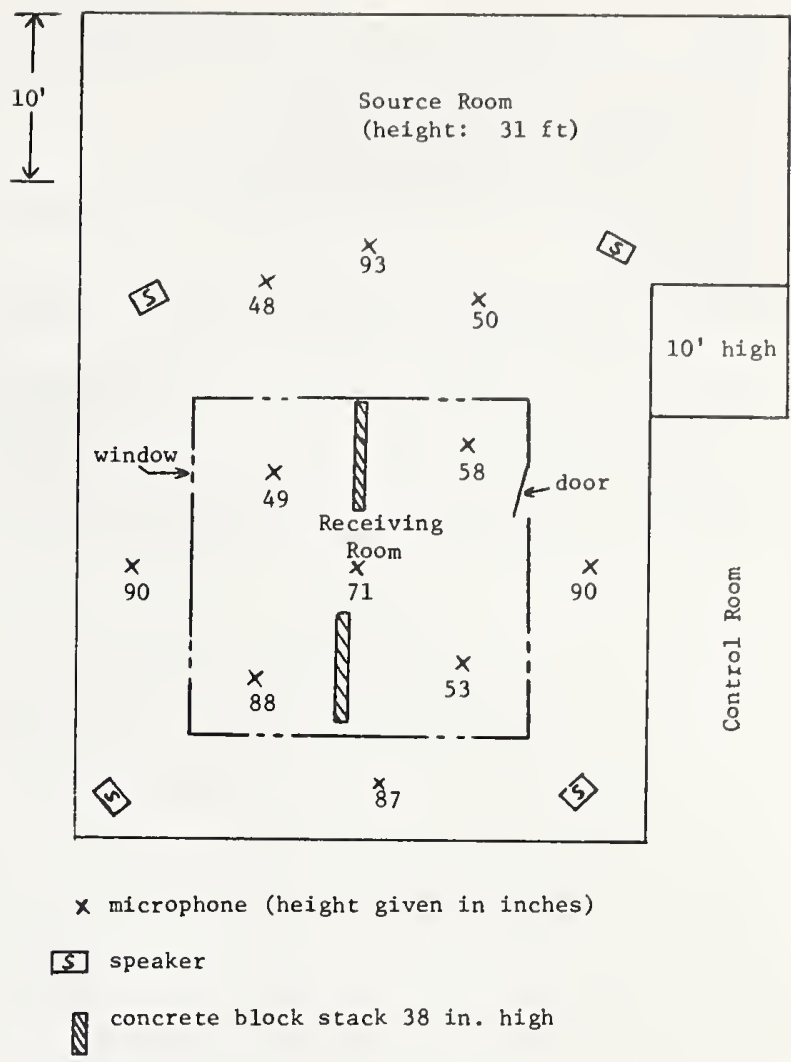

FigURE B-1. Floor plan of NBS High-Bay Environmental Laboratory and experimental building. Microphone and speaker positions used for the noise reduction tests are indicated.

building) and the six microphones of the source room array (outside the building). The microphone systems employed 1 -in pressure-type condenser microphone cartridges with attached preamplifiers. Each array was powered by a six-channel microphone energizer and multiplexer which scanned the microphone array at a rate of five channels per second. The multiplexer output was fed into a one-third octave band-pass filter set. The filtered signal was measured by means of a precision sound level meter or a graphic level recorder (see table B1).

Calibration of the measurement system was performed using a calibrated pistonphone-a precision sound source which produces a sound pressure level of $124 \pm 0.2 \mathrm{~dB}$ at a frequency of $250 \mathrm{~Hz}$ at the microphone diaphragm.

The signal for the noise transmission tests was provided by four speakers energized with pink random noise ${ }^{1}$. These speakers were located opposite

' Pink random noise is white noise passed through a network which weights at $-3 \mathrm{~dB}$ per octave. 
1. Brüel and Kjaer Model 4220 Pistonphone

2. Brüel and Kjaer Model 4132 Pressure Microphone

3. Brïel and Kjaer Model 2619 FET Preamplifiers

4. Brüel and Kjaer Model 221 Microphone Energizer and Multiplexer

5. Brüel and Kjaer Model 1612 Band-pass Filter Set

6. Brüel and Kjaer Model 2204 Precision Sound level Meter (used during design stages 1,2, and 3 ).

7. Brüel and Kjaer Model 2305 Graphic Level Recorder (used during design stages 3 and 4 ).

8. Kudelski (Nagra III) tape recording of pink noise used as signal source in design stages 1,2 , and 3 .

9. Brüel and Kjaer Model 1024. Sine Random Generator used as pink noise source in design stage 4.

* Commercial instruments are identified in this report in order to adequately specify the experimental procedure. In no case does such identification imply recommendations or endorsement by the National Bureau of Standards. nor does it imply that the equipment identified is necessarily the best available for the purpose.

the outside corners of the building as shown in figure B-1. The noise reduction provided by the building at each test frequency was determined by subtracting the one-third octave band sound pressure level measured in the receiving room from the corresponding level measured in the source room.

\section{Results}

The curves plotted in figure B-2 present the measured noise reduction provided by the building for each of the four variations in construction. As shown, the use of windows caused an average loss of sound isolation of about $10 \mathrm{~dB}$ for frequencies above $200 \mathrm{~Hz}$. The addition of thermal insulation either on the inside or the outside improved the acoustic performance but not enough to compensate for the effect of the windows.

Data were gathered at frequencies below $500 \mathrm{~Hz}$ but the short integration times used in the rms detection system, along with difficulties encountered in achieving a uniform sound field in the test space

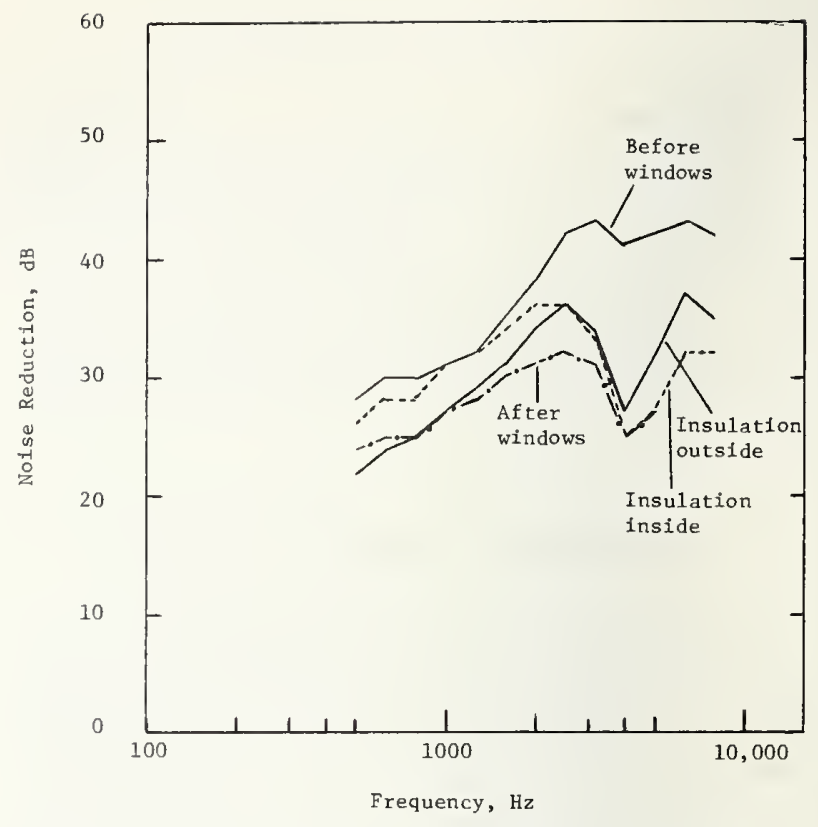

FiguRE B-2. Noise reduction versus frequency for various construction modifications of the experimental building in the High-Bay Environmental Laboratory.

rendered the measurements inconclusive for frequencies below $500 \mathrm{~Hz}$. Specifically, measurements of the sound distribution inside and around the building with the speakers energized revealed differences among the sound pressure levels measured at microphones in the same array of 4-12 dB for frequencies below $200 \mathrm{~Hz}$ in the receiving room and for frequencies below $500 \mathrm{~Hz}$ in the source room. Differences of this magnitude render a spatial average achieved by a five- or six-microphone array of little value.

No attempt was made to compute the sound transmission loss (the difference between the incidence sound intensity level and the transmitted sound intensity level) of the walls of the building or to relate the results of the present tests to laboratory tests on similar walls. The intent of the present work was merely to investigate the feasibility of measuring the noise reduction between one enclosed space contained within another enclosed space. 
Appendix $\mathbf{C}$

Computer Programs (NBSLD) to Obtain Heating and Cooling Loads and to Estimate Room Air Temperature Change Using Thermal Response Factors

\section{Tamami Kusuda}

Thermal Engineering Systems Section, Building Environment Division Center for Building Technology, Institute for Applied Technology National Bureau of Standards, Washington, D.C. 20234 



\section{Introduction}

The NBS computer programs called NBSLD are a group of routines to permit the determination of heating and cooling loads of a room based upon a calculation methodology adopted by the American Society of Heating, Refrigerating, and Air-Conditioning Engineers (ASHRAE) Task Group on Energy Requirements.

For a given 24-hour weather pattern, the program calculates heat exchange due to solar and sky thermal radiation through windows, heat conduction through walls and roofs, heat convection due to air infiltration and internal heat generation. Heat exchange is computed for every hour and later converted into the room heating or cooling load in conjunction with weighting factors. Details of these calculation procedures and the theoretical background for the weighting factors' application are not given here. The calculation procedures are available in the 1971 ASHRAE publication entitled "Procedures for Determining Heating and Cooling Loads for Computerized Calculation of Energy Requirements." These procedures were developed and published by the ASHRAE Task Group on Energy Requirements with the assistance of the National Bureau of Standards and the National Research Council of Canada.

The ASHRAE Task Group procedures incorporate what is considered to be the most up-to-date computation methodology for evaluating the dynamic aspects of building heat conduction by the response factor method. Since the algorithms employed in this procedure are new and rather complex, their use has been limited.

Presented in this report is the general feature of the NBS program of the ASHRAE Task Group algorithms to illustrate the use of this modern and powerful technique on small computers'.

All of the routines are, therefore, written in a close accordance with the ASHRAE Task Group algorithms and made into many subroutines, each of which could be used independently for other programs.

Attached are the Fortran V listings of NBSLD (designed to be run by the NBS UNIVAC 1108 under the version of EXEC II). The program in the form of punched cards or on magnetic tape is available from the Thermal Engineering Systems Section of NBS

1 This document ation is not intended to serve as a User's Gujde or Manual, but rather to describe the program in general. More detailed documentation in the form of a User's Manual will be published subsequently.

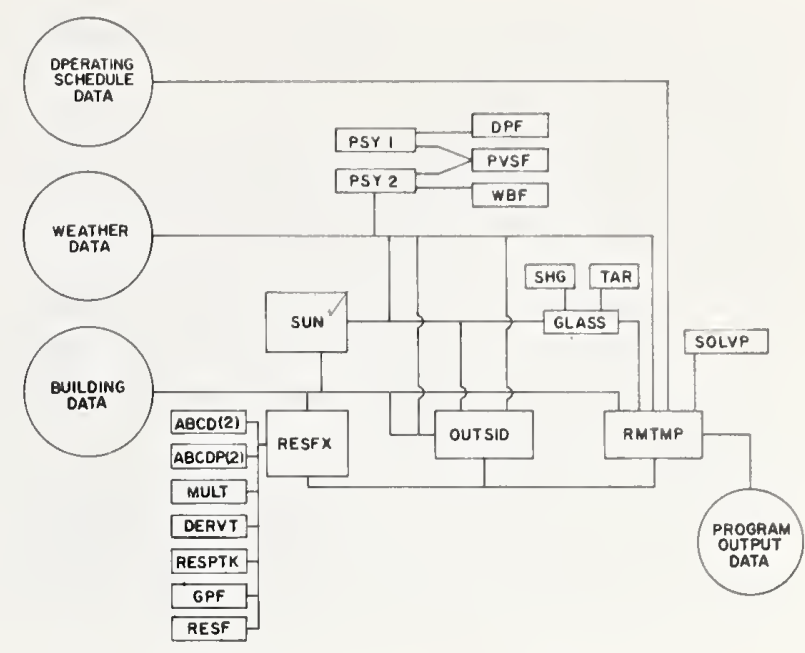

FiguRE C.1. Logic network for NBSLD.

including assistance for its use, if desired. Figure $\mathrm{C}-1$ shows the logic network for NBSLD.

1. ABCD2, ABCDP2, DERVT, GPF, MULT, RESF, RESFX, RESPTK: These routines are parts of a response factor calculation package and are needed for the accurate evaluation of thermal time lag, damping, heat storage in exterior facing surfaces as well as the internal furnishings.

2. DPF: Calculates dew point temperature when the partial vapor pressure is known.

3. GLASS: Calculates solar heat gain through glass when given the shading coefficient, orientation type of glass, type of fenestration.

4. OUTSID: This routine calculates the outside surface temperature and wall heat gain by taking into account solar heating, back radiation to the sky, convective heat loss to the ambient air and transient heat conduction.

5. PSY1: This is a simplified psychrometric routine that determines the thermodynamic properties of moist air when given dry-bulb temperature, wetbulb temperature, and barometric pressure.

6. PSY2: This is the same as PSYl except that the dew point temperature is used instead of the wetbulb temperature.

7. PVSF: This routine determines the saturated vapor pressure as a function of temperature.

8. SHG: This is the ASHRAE routine for calculating solar heat gain through glass.

9. SUN: Calculates basic sun data such as angles, cloud cover, direct and diffuse radiation needed for solar heat gain and solar heating of the building exterior surfaces. 
10. TAR: Calculates transmission and absorption characteristics of glass.

11. WBF: Approximates the wet-bulb temperature when provided with the enthalpy of moist air and the barometric pressure.

12. WF: Determines the cooling load by multiplying the heat gain by the ASHRAE weighting factors. (This routine was not used in this report because it incorporates the basic calculation used for deriving the weighting factors.)

13. RMTMP: Determines the room temperature as a balance of heat gains and cooling capacity of an air conditioning unit. Since this routine is not available in ASHRAE Task Group Algorithms, detail is given in the following pages.

14. SOLVP: Solves simultaneous linear algebraic equations needed in RMTMP.

15. WEATHE, WD, DECODE: This package is a weather decoding program and was not included because the weather input is implicitly defined in the following section on input data.

16. CCM: This routine modifies the solar radiation for a cloudless sky by the instantaneous cloud cover. (This routine is not included.)

17. FO: This routine calculates the outside surface heat transfer coefficients from the weather data. (This routine is not included where the coefficients are considered to be input data.)

\section{RMTMP}

\section{Room Temperature Calculation Routine}

Input: $N S=$ number of heat transfer surfaces in the room

$(S(I), I=1, N S)=$ area of the heat transfer surfaces, $\mathrm{ft}^{2}$

$(M(I), I=1, N S)=$ number of response factor terms for each heat transfer surface

$(I X(I), I=1, N S)=$ index for the thermal storage effect for each heat transfer surface $I X(I)=1$ for thermal storage surface

$I X(I)=0$ for nonthermal storage surfaces such as windows and door

$(C R(I), I=1, N S)=$ common ratio for the thermal response factor of each heat transfer surface

$M(I)=1, C R(I)=0$ if $I X(I)=0$

$((X(I, J), Y(I, J)$ for $I=1, N S), J=1, M(I))$ thermal response factors for each surface

$X(I, 1), Y(I, 1)=$ overall thermal conductance of the nonthermal storage surface and all the other response factor terms should be treated as zero if $I X(I)=0$.

Note: For the calculation of $X(I, J), Y(I, J)$, the surface heat transfer coefficients (both inside and outside) are not included.

$((T \varphi(I, t-J)$ for $I=1, N S), J=1, M(I))=$ outside surface temperature history, ${ }^{\circ} \mathrm{F}$

$((T I(I, t-J)$ for $I=1, N S), J=1, M(I))=$ inside surface temperature history, ${ }^{\circ} \mathrm{F}$

$T A=$ air temperature of the room

$(H(I), I=1, N S)=$ convection coefficient of the interior surface, ${ }^{\circ} \mathrm{F}$

$(F(I, K), I=1, N S), K=1, N S)=$ radiant heat exchange factors between surfaces $I$ and $K$, where $F(I, K)=0$ if $I=K$

$(R(I, t), I=1, N S)=$ heat input per unit indoor surface at time $t$ to the surface, such as solar heat or radiation heat from the lighting, equipment and occupants to the surface

$(E(I), I=1, N S)=$ emissivity of the surface

$Q(I, t-1)=$ heat flow at the Ith surface at the previous time period or time $=(t-1) \Delta$, Btu h-1 $\mathrm{ft}^{-2}$

$\Delta=$ time increment

$t=$ time index for the elasped time $t \Delta$ hours

$C F M L=$ outdoor air leakage, CFM 
$C F M V=$ ventilation air rate, $\mathrm{CFM} /{ }^{\circ} \mathrm{F}$ (at time $t \Delta$ )

$D B(t)=$ outdoor air temperature, ${ }^{\circ} \mathrm{F}$

$T V(t)=$ ventilation air temperature, ${ }^{\circ} \mathrm{F}$ (at time $\left.t \Delta\right)$

QEQUP: convective component of internal heat from equipment, Btu/h

$Q \emptyset C P S$ : convective component of internal sensible heat from occupants, Btu/h

QLITE: convective component of heat from lights suspended in air, Btu/h

1. Basic heat balance equation at the $I$ surface (at time $t \Delta$ )

$$
\begin{array}{r}
Q(I, t)=\sum_{J=1}^{M(I)}\{X(I, J) * T I(I, t-J+1)-Y(I, J) * T \emptyset(I, t-J+1)\}+C R(I) * Q(I, t-1) \\
=H(I) *(T A(t)-T I(1, t))+\sum_{K=1}^{N s} G(I, K) *(T I(K, t)-T I(I, t))+R(I, t)
\end{array}
$$

where $G(I, K)=4 * E(I) * F(I, K) *(T A+460))^{3 * 0.174 E-8}$

2. Total heat balance for the room air

$$
\begin{aligned}
& \sum_{I=1}^{N s} S(I)^{*}(T I(I, t)-T A(t))+1.08 * C F M \\
& *(D B(t)-T A(t)) \\
& +1.08 * C F M V^{*}(T V(t)-T A(t)) \\
& +Q E Q U P+Q O C P S+Q I I T E=0
\end{aligned}
$$

3. Letting matrix elements

$$
\begin{aligned}
& A(I, I)=X(I, 1)+H(I)+\sum_{K=1}^{N s} G(I, K) \\
& A(I, K)=-C(I, K), A(K, I)=-G(K, I), \text { for } I=1, N S \text { and } K=1, N S \\
& A(I, N s+1)=-H(I) \\
& B(I)=-\sum_{J=2}^{M(I)} X(I, J) * T I(I, t-J)+\sum_{J=1}^{M(I)} Y(I, J) * T \emptyset(I, t-J)-C R(I)^{*} Q(I, t-1)+R(I, t) \\
& A(N s+1, K)=S(K) * H(K) \text { for } K=1, N s \\
& A(N s+1, N s+1)=-1.08 *(C F M I+C F M V)-\sum_{K=1}^{N s} H(K) * S(K) \\
& B(N s+1)=-Q E Q U P-Q \emptyset C P S-Q L I T E-1.08 *\left(C F M L^{*} D B(t)+C F M V^{*} T V(t)\right)
\end{aligned}
$$

$T I(I, t)$ and $T A$ can be obtained by solving the following $N s+1$ simultaneous equations

$\left[\begin{array}{c}A(1,1), A(1,2) \ldots A(1, N s+1) \\ A(2,1), A(2,2) \ldots A(2, N s+1) \\ \cdot \\ \cdot \\ A(N s, 1), A(N s, 2) \ldots A(N s, N s+1) \\ A(N s+1,1), A(N s+1,2) \ldots A(N s+1, N s+1)\end{array}\right] *\left[\begin{array}{c}T I(1, t) \\ T I(2, t) \\ \cdot \\ \cdot \\ \cdot \\ T I(N s, t) \\ T A\end{array}\right]=\left[\begin{array}{c}B(1) \\ B(2) \\ \cdot \\ \cdot \\ \cdot \\ B(N s) \\ B(N s+1)\end{array}\right]$




\section{Input Data Needed for the Fortran Listing of NBSLD}

Input data needed for the heating/cooling load calculation are listed on the following pages but not necessarily in the card reading sequence of the Fortran version listed in this report.

\author{
Building Number (BLDGNO) \\ Ceiling Height (HT) \\ Floor Area (AG) \\ Number of Floors (NØFLR) \\ Number of Occupants (QCU) \\ Winter Window Overall Heat Transfer Coeffi- \\ cient (UGW) \\ Ground Floor Heat Transfer Coefficient (UG) \\ Air Change Per Hour (AIRCHG) \\ Latitude (LAT) \\ Longitude (LØNG) \\ Time Zone Number (TZN) \\ Month (MØNTH) \\ Day (DAY) \\ Elapsed Hour Since Midnight of January lst \\ (ELAPS)
}

Electric Power to the Light Watts Per Square Foot of Floor (QLITY)

Electrical Power to Equipment, Watts Per Square Foot of Floor Area (QEQPX)

Ventilation Air Rate (CFMV)

Air Leakage Rate (CFML)

Maximum Temperature of the Design Day (DBMAX)

Daily Temperature Range of the Design Day (RANGE)

Design Indoor Temperature Condition (DBIN)

Design Outdoor Wet-Bulb Temperature (WBMAX)

Design Indoor Wet-Bulb Temperature (WBID)

Design Winter Outdoor Temperature (DBMWT)

Design Summer Ground Temperature (TG)

Design Winter Ground Temperature (TGW)

Total Number of Exterior Surfaces to be Considered for the Heat Gain Calculation (NEXP)

Index for the Room Temperature Calculation

Index for the Standard ASHRAE Task Group Calculation in the Special and Detailed NBS Calculation

Repeat the following cards for NEXP times

Type of Heat Transfer Exposures (ITYPE)

1. Roofs

2. Walls
3. Windows

4. Doors

5. Floors

Type of Response Factors to be Used (IRF)

1. Heavy roof construction

2. Light weight roof

3. Heavy weight exterior walls

4. Light weight exterior walls

5. Heavy ceiling/floor

6. Light ceiling/floor

7. Heavy partition wall

8. Light partition wall

$U$ Value of the Exposures $(U)$

Area of the Exposures (A)

Orientation of the Exposures $(A Z W)$

0 . South facing

90. West facing

180. North facing

-90. East facing

Radiant Heat Exchange Factors Among
Exposure Surfaces

If the construction of roof, wall and floor is nonstandard, the following information is needed in addition to the standard data indicated above.

$$
\text { Roof, Wall, Floor Data }
$$

1 Time increment of the temperature data

2 Number of roof layers (NR)

3 Thermal resistance of the roof inside surface

$4 l, \kappa, \rho, c$, and resistance of the lst layer counted from inside surface .... (NR-2) Cards

5 Thermal resistance outside surface of the roof

6 Description of the lst layer of the roof

7 Description of the $2 d$ layer of the roof

8 Description of the NRth layer of the roof

9 Number of wall layers (NW)

10 Thermal resistance of the inside surface

$11 l, \kappa, \rho, c$ and resistance of the lst layer counted from inside (NW-2) Cards

12 Thermal resistance of the outside surface layer

13 Description of the 1st layer of the wall

14. Description of the 2d layer of the wall

15 Description of the NWth layer of the wall

16 Number of layer of the floor and the semiinfinite layer (NF) index (if basement floor)

17 Thermal resistance of the inside surface $l, \kappa, \rho$, $c$ and Res of the lst layer of the floor counted from the inside surface

$l, \kappa, \rho, c$ and Res of the 2d layer of the floor $(\mathrm{NF}-1)$ Cards

$19 \kappa, \rho$, and $c$ of the earth . . if basement floor

20 Description of the 1st layer

21 Description of the 2d layer

22 Description of the NFth layer 
BASE HEATING/EOOLING LOAD CALCULATION PROGRAM

INCLUDING THE ROOM TEMPERATURE CHANGE PREDICTIONS

$I=E X P O S U R E$ NUMBER, I=1,2, -NEXP

ITYPE (1).EXPOSURE TYPE NUMBER

1 ROOF

2 EXPOSED WALLS

3 WINDOWS

4 DOORS

5 GROUND HEAT TRANSFER SURFACES

6 FURNISHINGS,PARTITION WALLS PARTY WALLS AND FLOOR/CEILINGS

7 OPEN SURFACE

8 EXPOSED FLOORS

PB BAROMETRIC PRESSURE IN OF HG

ITEMP = TEMPERATURE RISE INDEX

IHT(I) HEAT TRANSFER INDEX

AVEHTG-OAVERAGE HEAT GAIN FOR SITE

TSITHT-OTOTAL SITE HEAT GAIN FOR 24 HOURS

IHT $=-1$ GLASS SURFACE (TRANSPARENT)

IHT $=0$ OPAQUE

IHT 1 OTHERWISE

QI--HEAT FLOW THROUGH EACH EXPOSURE

QSUM--SENSIBLE HEAT GAIN

QTLAT=-LATENT HEAT GAIN

TOTHT--TOTAL HEAT GAIN

QC--SENSIBLE COOLING LOAD

SITEQS--ENTIRE SITE SENSIBLE HEAT GAIN

SITEQL-OENTIRE SITE LATENT HEAT GAIN

SITETH--ENTIRE SITE TOTAL HEAT GAIN

BLDMAX--BUILDING MAX HEAT GAIN

QSUMT--AVERAGE HEAT GAIN

SITELD-OENTIRE SITE COOLING LOAD

SITMAX--SITE MAX HEAT GAIN

AVESIT--SITE AVERAGE HEAT GAIN

SQWINT-OSITE HEAT LOSS

IRF (I) RESPONSE FACTOR NUMBER APPLICABLE TO THE SURFACE.

ABSP (I) SURFACE SOLAR HEAT COEFFICENT

SHADE (I) SHADING COEFFICIENTS

U(I) EXPOSURE U VALUE

UT(I) $=-U$ VALUE WITHOUT EXTERNAL SURFACE RESISTANCE

H(I) EXPOSURE EXTERIOR SURFACE THERMAL CONDUCTANCE

A(I) EXPOSURE AREA

WAZ(I) WALL AZIMUTH ANGLE MEASURED CLOCKWISE FROM SOUTH

TG--GROUND TEMPERATURE FOR COOLING LOAD CALCUATION

TV = VENTILATION AIR TEMPERATURE

UG--GROUND HEAT TRANSFER COEFFICIENT

AG=-GROUND HEAT TRANSFER SURFACE ( $=0$ WHEN NO GROUND FLOOR)

TGW--WINTER GROUND TEMP

DBMWT-OWINTER OUTDOOR TEMP

LAT = LATITUDE DEGREE

LONG=LONGITUDE DEGREE

TZN--TIME ZONE NUMBER

MONTH-OMONTH OF YEAR

DAY $=D A Y$

QLITX-OMAXIMUM LIGHTING LOAD IN WATT/FT2

QEQPX - MAX EQUIP LOAD IN WATT/FT2

NEXP--NUMBER OF EXTERIOR. HEAT TRANSFER SURFACES

BLDGNO--BUILDING NUMBER

HT- BUILDING OR DWELLING UNIT HEIGHT

QPSX - MAX OCCUPANT SENSIBLE LOAD BTU/HR,PERSON

QPLX--MAX OCCUPANT LATENT LOAD BTU/HR,PERSON

DP-DEWPOINT TEMP, $F$

QCU $-M A X$ NUMBER OF OCCUPANTS 
ELAPS =DAYS ELAPSED SINCE JAN. 1

UGLAS- -WINTER GLASS HEAT TRANSFER COEFFICIENT

HI- - - INNER SURFACE CONVECTIVE HEAT TRANSFER COEFFICIENT

HR INNER SURFACE RADIATIVE HEAT TRANSFER COEFFICIENT

G,GG RADATION HEAT EXCHANGE SURFACES SHAPE FACTORS

$X, Y, Z$ RESPONSE FACORS

THESE RESPONSE FACTORS SHOULD NOT INCLUDE OUTSIDE SURFACE

THERMAL RESISTANCE WHEN ITEMP•EQ,O

THEY SHOULD NOT INCLUDE BOTH THE OUTSIDE AND INSIDE THERMAL

RESISTANCES WHEN ITEMP.EQ. 1

CFML AIR LEAKAGE

CFMV VENTILATION

R A FRACTION OF LIGHTING POWER THAT GOES INTO FLOOR

DBMAX DESIGN OUTDOOR DRY -BULB TEMPERATURE

RANGE DAILY RANGE OF THE OUTDOOR TEMPERATURE

WBMAX DESIGN OUTDOOR WET-BULB TEMPERATURE

WBID DESIGN INDOOR WET-BULB TEMPERATURE

DBIN DESIGN INDOOR DRY-BULB TEMPERATURE

ITK INDEX TO CALCULATE ROOM TEMPERATURE RISE WHEN NOT AIR CONDIT ITK $=1$ WHEN NOT AIR CONDITIONED

ITEMP INDEX TO USE ASHRAE WEIGHTING FACTOR

IF ITEMP $=0$ ASHARE WEIGHTING FACTOR

COMMON $/ C C / X(10,100), Y(10,100), Z(10,100), I T Y P E(10), I H T(10), I R F(10$

1), $\operatorname{ABSP}(10), \mathrm{U}(10), \mathrm{H}(10), \mathrm{HI}(10), A(10), \mathrm{UT}(10), \operatorname{TOS}(10,48), \operatorname{TS}(10,48), \mathrm{G}$

$2(10,10)$, TOY (48), DB (24), QLITE (24), QEQUP (24), QOCPS (24), QI (10),CR (10)

3. NR (10), QGLAS $(10,24)$, ITHST

DIMENSION $X X(100,10), Y Y(100,10), Z Z(100,10)$, TNEW(24), TIX(24), TI (49)

1, QOCUP (24), QTL (24), XDUM (100), YDUM $(100), Z$ ZUM $(100), \operatorname{TDUM}(100), 00(10)$

REAL LG( 8$), L X(8), L I S(8), Q G(8), Q X(8), Q I S(8), Q G Z(8), Q X Z(8), \operatorname{QISZ}(8), S$

1 ITEQS (24), SITEQL (24), SITETH( 24), SITELD( 24), TIF (10)

DIMENSION QLITX(24), QEQUX (24), QDESIN (10,24), QPEOPL (24), QDES (10)

DIMENSION QSUN $(10,24), Q S K Y(10,24), \operatorname{SHADE}(10), A Z W(10)$

DIMENSION NAMEBD (6), VT (10),DR(10), MR (10), QGX(10)

DIMENSION DBNBS( 24$) / .26, .20, .15, .10, .05, .0, .03, .1, .19, .30, .43, .57$,

$1.69 \cdot .80, .90 \cdot .96 \cdot .99 \cdot 1 \cdot 0 . .97 \cdot .90, .75 \cdot .57 \cdot .43 \cdot .33 /$

REAL LAT.LONG, MONTH,NOFLR

DIMENSION LTYPE (10), GG(10,10:

COMMON /SOL/ LAT,LONG TZN.WAZ,WT, CN,DST , LPYR,S(35)

READ $(5,900)$ QLITX

READ $(5,900)$ QEQUX

READ $(5,900)$ QOCUP

SIGMA $=0.1714 E-8$

$H R=4 . *(535$.**3)*SIGMA

DO 790 IJKLMN $=1,20$

READ $(5,910$, END $=800)$ NAMEBD

READ $(5,880)$ IROT.ISKIP

IF (NAMEBD (1) ,EQ.' ') GO TO 800

IF (ISKIP.NE.O) GO TO 30

DO $10 \quad I=1.10$

DO $10 \mathrm{~J}=1,100$

$X(I, J)=0$.

$Y(I, J)=0$.

$10 \quad z(I, J)=0$.

DO $20 \quad J=1,24$

$\operatorname{SITEQS}(J)=0$.

$\operatorname{SITEQL~}(J)=0$.

$\operatorname{SITETH}(J)=0$.

SITELD $(J)=0$.

20 CONTINUE

SQWINT $=0$.

CALL RESFX $(X, Y, Z, X X, Y Y, Z Z, M R, D R, V T, 10)$

WRITE $(6,820)$ 
$P B=29.92$

READ $(5,900)$ LAT,LONG, TZN, MONTH, DAY,ELAPS, UG, UGLAS

WRITE $(6,850)$

WRITE (6,840) LAT,LONG,TZN, MONTH,DAY,ELAPS, UG,UGLAS

READ (5.900) QLITY,QEQPX,CFMVDCFML

WRITE $(6,860)$

WRITE $(6,840)$ QLITY, QEQPX,CFMV.CFML

READ (5,900) DBMAX,RANGE,DBIN,WBMAX,WBID, OBMWT,TG,TGW,TV

WRITE $(6,870)$

WRITE (6,840) DBMAX,RANGE, DBIN,WBMAX,WBID, DBMWT, TG,TGW,TV

CALL PSY1 (DBMAX,WBMAX,PB.DP,PV,WOUT,HOUT, VOUT, RHOUT)

CALL PSYI (DBINOWBID.PB.OPID,PV,WID.HIND,VIN口RHIN)

WV=WOUT

WIN=WID

WAEWOUT

TIO=DBIN

30 READ $(5,900)$ ROOMNO,HT, AG, NOFLR, QCU, AIRCHG

WRITE $(6,830)$

WRITE $(6,840)$ ROOMNO,HT, AGPNOFLR, QCU,AIRCHG

READ (5,890) NEXP.ITKOITEMP ITHST

DO $110 \quad I=1$. NEXP

READ (5,920) ITYPE(I), IRF (I),U(I),A (I) , AZW (I) ,DUM, SHADE (I), ABSP (I)

READ (5,900) (G(I,J) OJ $=1$, NEXP)

LTYPE (I) $=$ ITYPE (I)

IF (ITYPE (I),EQ.7) GO TO 110

$K=I R F(I)$

IF $(Y(K, 1) \cdot G T \cdot 1 \cdot) \quad \operatorname{IRF}(I)=10$

$N R(I)=M R(K)$

$\mathrm{UT}(\mathrm{I})=\mathrm{VT}(\mathrm{K})$

CR (I) $=D R(K ;$

IF (NR(I), GT.48) NR(I) $=48$

IF (ITYPE(I),EQ.3) ABSP(I) $=0$.

IF (ITYPE (I),EQ.5) ABSP(I) $=0$.

IF (ITYPE(I),EQ.6) ABSP(I) $=0$.

IHT $(I)=1$

IF (ITYPE(I),EQ,3) IHT(I) $=-1$

$H(I)=4.08$

$H I(I)=0.542$

IF (ITYPE(I),EQ.6) $H(I)=0$.

IF (ITYPE(I).EQ.5) HI $(I)=0.162$

IF (U(I)) $40,40,50$

40 RUE1./UT (I)+1./HI (I)

IF (ITYPE (I),NE.6) RU=RU+1./H(I)

$U(I)=1 \cdot / R U$

50 CONTINUE

IF $(X(K, 2)) 120,60,110$

60 IF $(H(I)) 70 \cdot 80,70$

$70 \quad R=1 \cdot / U(I)-1 \cdot / H(I)$

GO TO 90

$80 \quad R=1 . / U(I)$

$90 \quad U T(I)=1 \cdot / R$

IF (ITEMP.NE.0) UT (I) $=1 \cdot /(R-1 \cdot /(H I(I)+0.9))$

100 UT $(I)=100$.

110 CONTINUE

WRITE $(6,1170)$

DO $120 \quad I=1$. NEXP

$A Z W(I)=A Z W(I)+I R O T$

IF (AZW(I),GT.180,) AZW(I) $=A Z W(I)=360$ 。

WRITE $(6,930)$ I ITYPE(I),IHT(I),IRF(I),ABSP(I), U(I),H(I),A I),AZW( 1I) . SHADE (I) , UT (I)

120

CONTINUE 


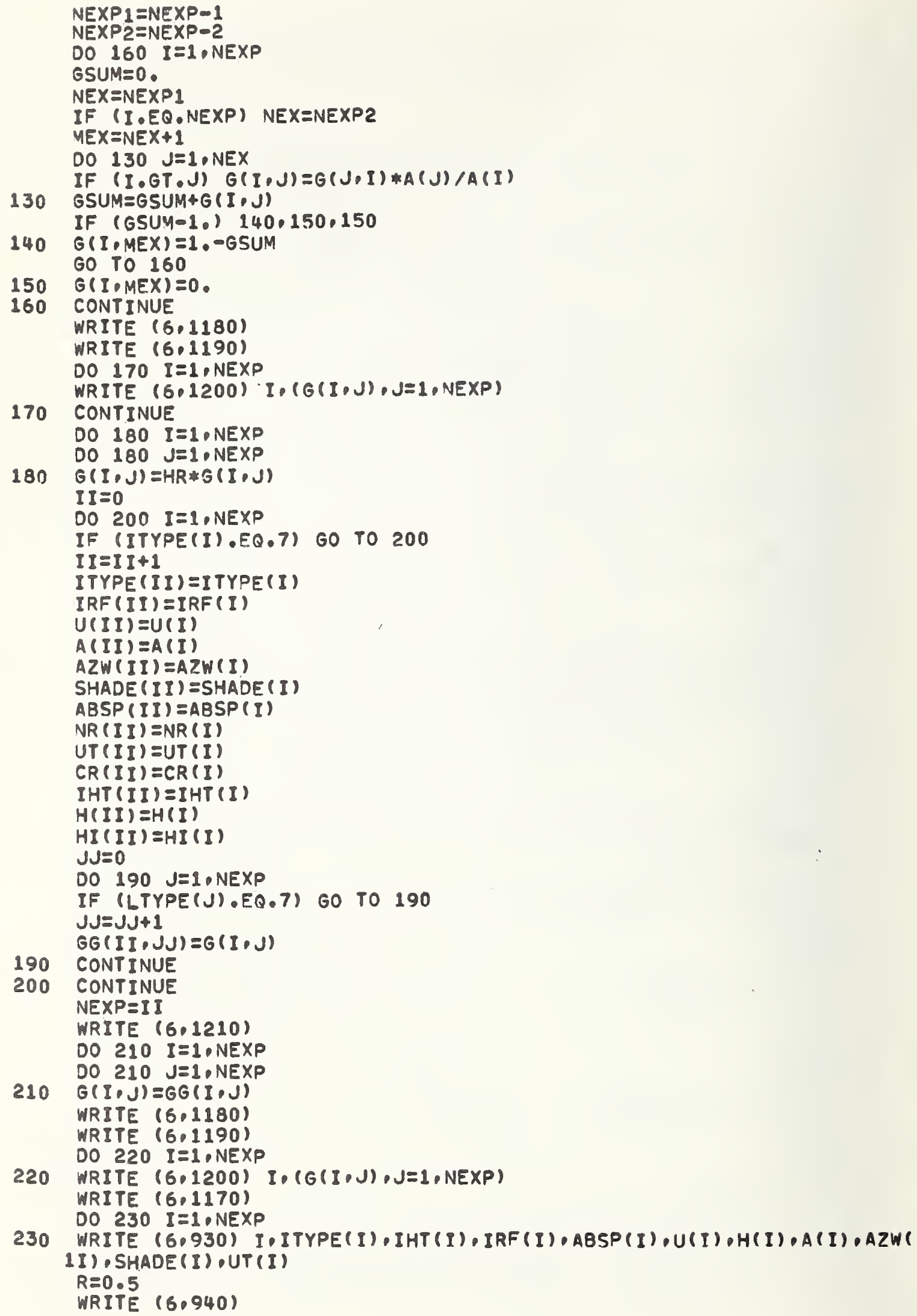




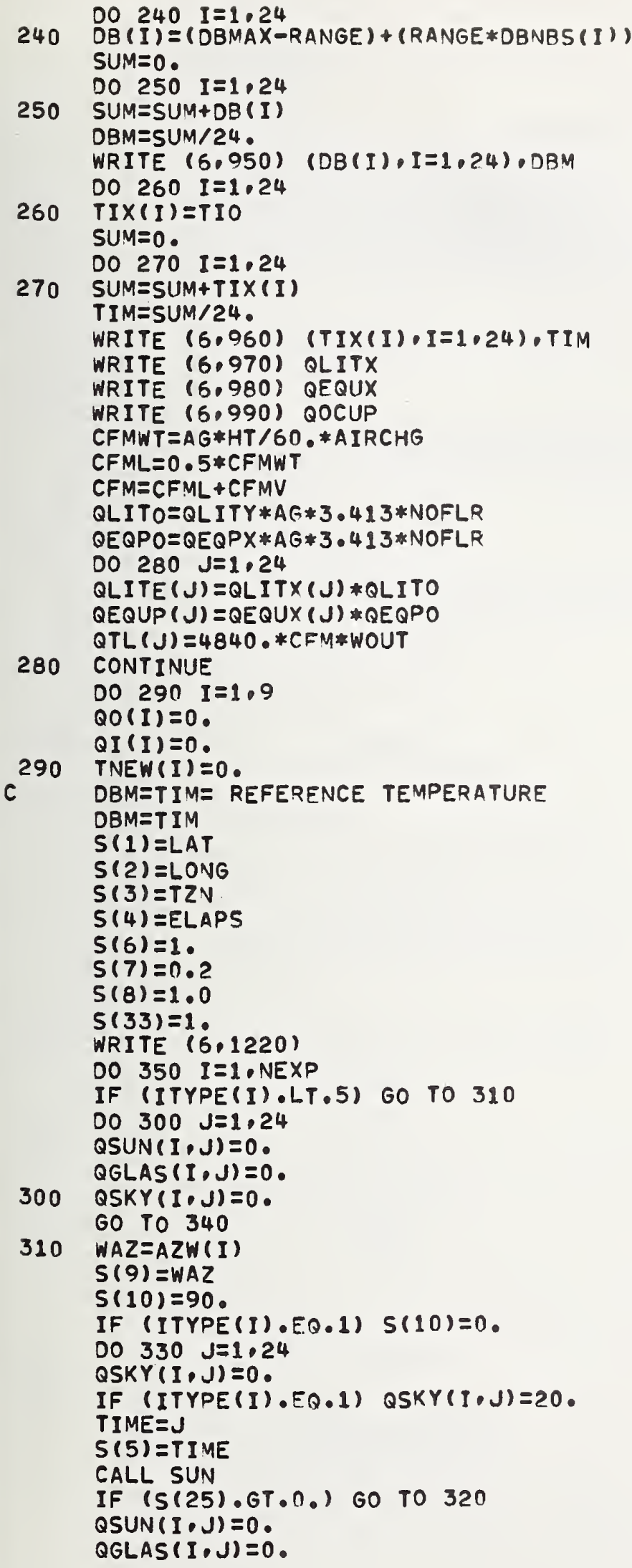


GO TO 330

320 QSUN $(I, J)=S(25) * A B S P(I)$

$\operatorname{QGLAS}(I, J)=0$

IF (IHT(I).GT.0) GO TO 330

CALL GLASS (SHADE (I), 1.,1.,QGLAS (I,J))

330 CONTINUE

340 WRITE $(6,1000)$ I

WRITE $(6,1010)$ (QSUN(I,J),J $=1,24)$

350 WRITE $(6,1010)$ (QGLAS $(I, J), J=1,24)$

$00360 \quad j=1.24$

$T I(J)=T I X(24-J+1)-T I M$

DO $360 \quad I=\{$. NEXP

$360 \operatorname{TOS}(I \cdot J)=D B(24-J+1)=D B M$

DO $370 \quad J=25.49$

$T I(J)=T I(J-24)$

DO $370 \quad I=1$. NEXP

$370 \operatorname{TOS}(I, J)=\operatorname{TOS}(I, J-24)$

IF (ITEMP.NE.0) GO TO 390

Do $380 \quad L=1.8$

$L G(L)=0$.

$L X(L)=0$ 。

$\operatorname{LIS}(L)=0$.

$Q G(L)=0$.

$Q \times(L)=0$.

380 QIS $(L)=0$.

390 CONTINUE

DO $400 \quad I=1$. NEXP

$00400 \mathrm{~J}=1.48$

400 TIS $(I, J)=0$.

$T A=T I M$

DO $720 \quad \mathrm{~N}=1.7$

IF (N.NE. 7$)$ GO TO 410

QSUMT $=0$.

BLDMAX $=0$.

410 CONTINUE

DO $720 \quad N K=1.24$

DO 440 I $=1$. NEXP

DO 420 NTTE2.4B

420 TOY (NTT) $=T O S$ (I.NTT-1)

DO 430 NTT $=2.48$

430 TOS (IDNTT) $=$ TOY (NTT)

440 CONTINUE

IF (ITEMP.NE.0) GO TO 490

$T A=T I X(N K)$

DO $450 \quad L=2,8$

$Q G Z(L)=Q G(L-1)$

$Q \times Z(L)=Q \times(L-1)$

$\operatorname{QISZ}(L)=Q \operatorname{IS}(L-1)$

450 CONTINUE

DO $460 \quad L=2.8$

$Q G(L)=Q G Z(L)$

$Q \times(L)=Q \times Z(L)$

$\operatorname{QIS}(L)=Q I S Z(L)$

460 CONTINUE

DO 470 NTT $=2.49$

$470 \operatorname{TOY}(N T T)=T I(N T T-1)$

DO 480 NTT $=2,48$

$480 T I(N T T)=T O Y(N T T)$

SUMQG $=0$.

490 CONTINUE

DO $540 \quad I=1$. NEXP

$K=I R F(I)$ 
DO $500 \quad J=1.48$

$\operatorname{XDUM}(J)=X(K, J)$

$\operatorname{YDUM}(J)=Y(K, J)$

$\operatorname{ZOUM}(J)=Z(K, J)$

$\operatorname{TOUM}(J)=\operatorname{TOS}(I, J)$

IF (ITYPE(I),EQ,6) $\operatorname{TOUM}(J)=\operatorname{TIS}(I, J)$

IF (ITYPE (I),EQ.5) TDUM(J) $=T G-T I M$

IF (ITEMP.NE,O) TI(J)=TIS(I,J)

IF (TOUM(J).GT.100,.OR.TI(J).GT.100.) GO TO 760

500 CONTINUE

$U X=U(I)$

IF (H(I)) $520,520,510$

$510 R X=1 . / U(I)-1 . / H(I)$

$U X=1 . / R X$

520 CONTINUE

CALL OUTSID (XDUM, YDUM,ZOUM,CR (I),UX,H(I),DB(NK),TIM,QO(I), QI (I), Q

ISUN (I D NK) , QSKY (I, NK) , TDUM, TI, TNEWO, TA I I TEP)

DO $530 \mathrm{~J}=1.48$

$530 \operatorname{TOS}(I, J)=\operatorname{TDUM}(J)$

TNEW $(I)=T N E W O+T I M$

540 CONTINUE

QOCPS $(N K)=Q O C U P(N K) * 10, *(100 .-T A) * Q C U$

QOCPL $=10 * *(T A-60) * Q O C U P,(N K) * Q C U$

IF $(T A-100)$.

550 QOCPS $(N K)=0$.

$Q O C P L=400, * Q O C U P(N K) * Q C U$

GO TO 580

560 IF $(T A-60) 570,$.

570 QOCPS $(N K)=400 *$ QOCUP (NK) *QCU

QOCPL $=0$.

580 QPEOPL $(N K)=Q O C P L$

SUML $=Q T L(N K)-4840$.*CFM*WIN+QOCPL QTLAT $=-5 U M L$

C QSUM INSTANTANEOUS HEAT GAIN

C SUMQC INSTANTANEOUS SOLAR HEAT GAIN

C QI CONDUCTION HEAT TRANSFER

QSUM $=1.08 * C F M L *(T A-D B(N K))+1.08 * C F M V *(T A-T V)-Q L I T E(N K)-Q E Q U P(N K)=Q$

10 CPS (NK)

DO $590 \quad I=1$, NEXP

$590 \quad Q S U M=Q S U M+A(I) *(Q I(I)-Q G L A S(I, N K))$

IF (N.NE.5) GO TO 650

IF (NK.NE.1) GO TO 600

WRITE $(6.1020)$ NAMEBD

600 CONTINUE

WRITE $(6,1030)$ NK, (TNEW(I), I $=1,9), D B(N K)$

IF (ITEMP) $720,720.650$

610 IF (NK.NE.1) GO TO 620

WRITE $(6.1040)$ NAMEBD

620 CONTINUE

TOTHT $=Q L+Q T L A T$

WRITE $(6,1050)$ NK, $(Q I(I), I=1,0), Q S U M, Q T L A T, Q L, T O T H T$

DO $630 I=1$. NEXP

$\operatorname{QDESIN}(I, N K)=Q I(I) * A(I)$

630 CONTINUE

$S I T E Q S(N K)=S I T E Q S(N K)+Q S U M$

SITEQL (NK) $=5 I T E Q L(N K)+Q T L A T$

$\operatorname{SITETH}(N K)=S I T E T H(N K)+T O T H T$

$\operatorname{SITELD}(N K)=S I T E L D(N K)+Q L$

IF (QL.GT.BLDMAX) GO TO 640

BLDMAX $=Q L$

TOTHTX $=$ TOTHT 


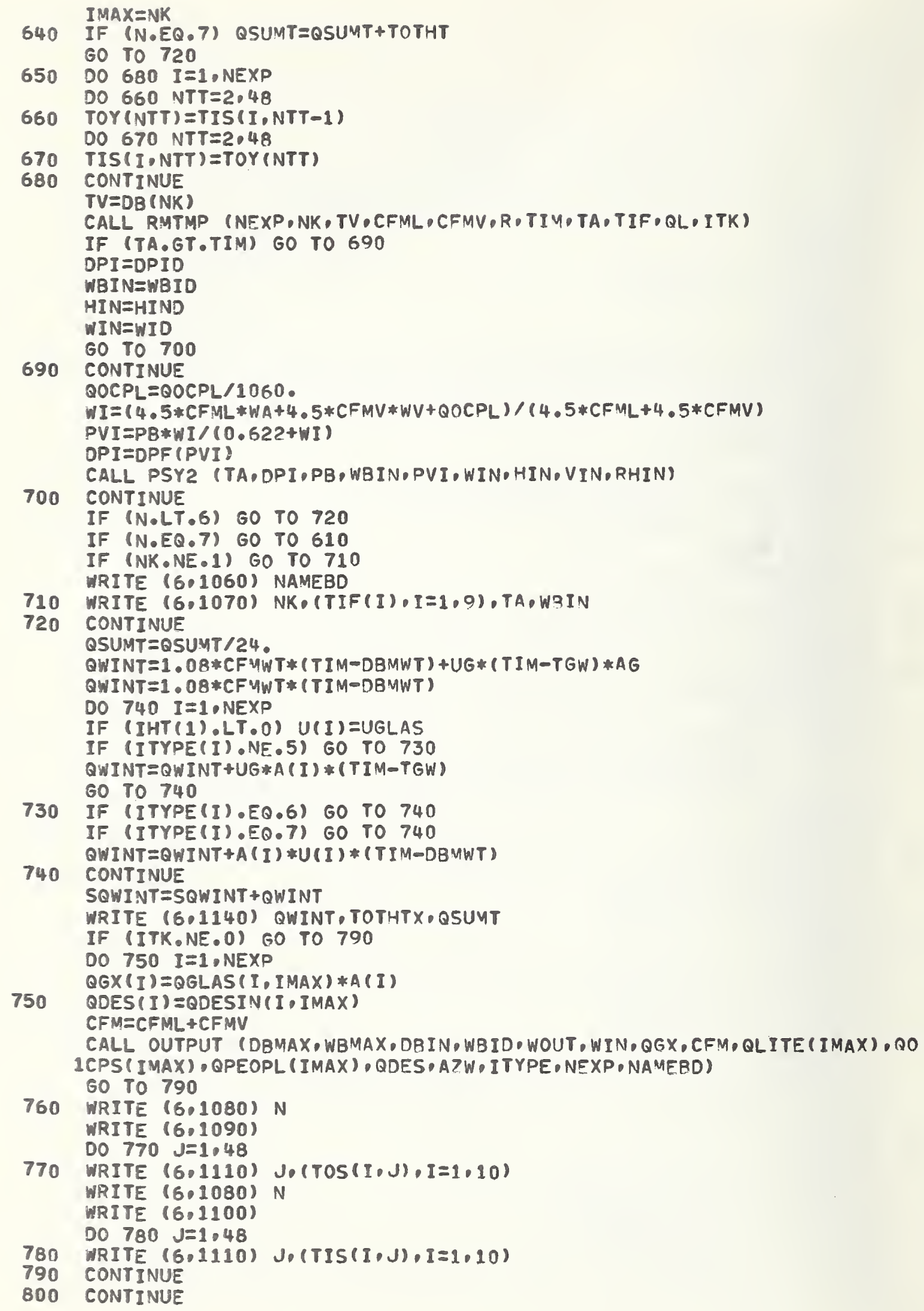


WRITE $(6,1120)$

WRITE $(6,1130)$

SITMAX $=0$.

TSAVE $=0$.

TSITHT $=0$.

DO $810 \quad I=1.24$

SQLLD $=S I T E Q L(I)+S I T E L D(I)$

TSITHT $=$ TSITHT+SITETH(I)

IF (SITETH(I).LT.SITMAX) SITMAX SSITETH(I)

IF (SQLLD.LT.TSAVE) TSAVESSQLLD

WRITE (6.1150) I.STTEQS (I),SITEQL(I),SITETH(I),SITELD(I), SQLLD

810 CONTINUE

AVEHTG $=T S I T H T / 24$.

WRITE $(6.1160)$ SQWINT.SITMAX,AVEHTG,TSAVE

WRITE $(6,1120)$

c STOP

820

830

840

850

860

870

880

890

900

910

920

930

940

950

960

970

980

990

1000

1010

1020 FORMAT (1H120X EXPOSURE SURFACE TEMPERATURE, DEGREES F FOR 16 A6// $17 X \cdot$ TIME: $5 X \cdot(1) \cdot 7 X \cdot(2) \cdot 7 x \cdot(3) \cdot 7 X \cdot(4) \cdot 7 x \cdot(5) \cdot 7 x \cdot(6) \cdot 7 X \cdot(7) \cdot 7 x \cdot(8) \cdot 7 X$ $5 \cdot(9)\left(7 \times \cdot D B^{\circ}\right)$

1030 FORMAT (I10.10F10.2)

1040 FORMAT (1H130X6A6///7X'TIME'14X EXPOSURE HEAT FLUX O40X. HEAT GAIN

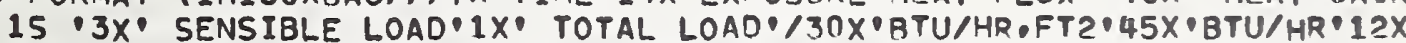
2'BTU/HR $5 X$ 'BTU/HR $/ 10$ 'B1X'SENSTBLE' $3 X$ 'LATENT / $14 X \cdot(1) \cdot 4 X \cdot(2) \cdot 4 X \cdot(3$ 3) 4 X $(4), 4 X \cdot(5) \cdot 4 X \cdot(6) \cdot 4 X \cdot(7) \cdot 4 X \cdot(8) \cdot 4 X \cdot(9) \cdot 7 X$ HEAT: $7 X \cdot$ HEAT?/1

1050 FORMAT (I10.997.2.4X.4G10.4)

1060 FORMAT (1H120X' INSIDE SURFACE TEMPERATURE. DEGREE F FOR 16 AG//7X' 1TIME: $5 X \cdot(1) \cdot 7 X \cdot(2) \cdot 7 X \cdot(3) \cdot 7 X \cdot(4) \cdot 7 X \cdot(5) \cdot 7 x \cdot(6) \cdot 7 X \cdot(7) \cdot 7 X \cdot(8) \cdot 7 X \cdot(9$ 5) $7 X X+T A \cdot T A \cdot 8 X \cdot W B \cdot / 1$

1070 FORMAT $(I 10.11 . F 10.2)$

1080 FORMAT ( 1 CONVERSION ERROR AT $N=$ II10)

1090 FORMAT $(10$ TOS $)$

1100 FORMAT $(10$ TIS')

1110 FORMAT $(110.10 F 10.2)$

1120 FORMAT (1HI)

1130 FORMAT (30X'SITE SUMMARY//7X'TIME'9X OHEAT GAINS'15X'TOTAL HEAT $4 X$ 1'COOLING LOAD'7X'TOTAL'/22X'BTU/HR'19X'BTU/HR'9X'BTU/HR'7X'COOLING

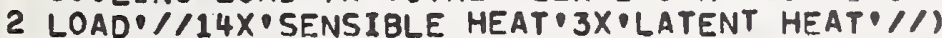

1140 FORMAT (//// HEAT LOSS 10X'COOLING LOAD'7X'AVERAGE HEAT GAIN'3X// 
$11 \times 3(610.4 \cdot 10 X))$

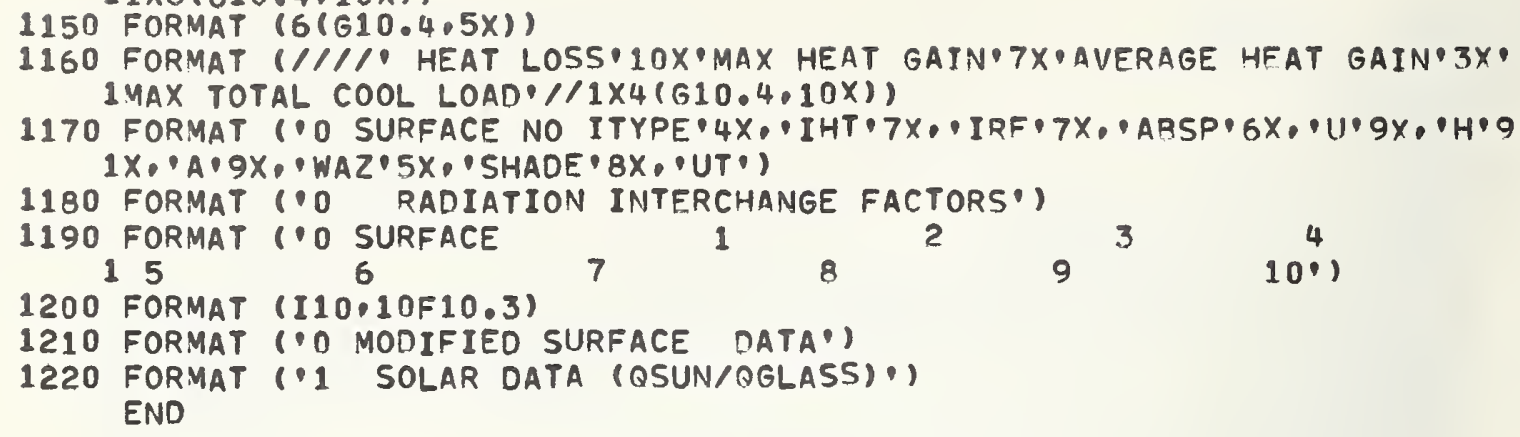


SUBROUTINE DERVT $(A \cdot B, C, D, A P, B P, C P, D P, A P P, B P P, C P P, D P P, N)$

DIMENSION $A(N), B(N), C(N), D(N), A P(N), B P(N), C P(N), D P(N), A T(10), B T(10$

1).CT(10),DT(10),ATT $(10), B T T(10), C T T(10), D T T(10)$

DO $30 \quad I=1, N$

DO $20 \mathrm{~J}=1, \mathrm{~N}$

IF (I.EQ.J) GO TO 10

$A T(J)=A(J)$

$B T(J)=B(J)$

CT $(J)=C(J)$

$\operatorname{DT}(J)=D(J)$

GO TO 20

10

$A T(J)=A P(J)$

$B T(J)=B P(J)$

$C T(J)=C P(J)$

$\operatorname{OT}(J)=D P(J)$

20 CONTINUE

30 CALL MULT (AT,BT,CT,DT,ATT(I),BTT(I),CTT(I),DTT(I),N)

APP $=A T T(1)$

$B P P=B T T(1)$

$C P P=C T T(1)$

DPP $=D T T(1)$

DO $40 I=2, N$

$A P P=A P P+A T T(I)$

$B P P=B P P+B T T(I)$

$C P P=C P P+C T T(I)$

$40 \quad D P P=D P P+D T T(I)$

RETURN

END

FUNCTION DPF (PV)

C THIS SUBROUTINE CALCULATES DEW-POINT TEMPERATURE FOR GIVEN VAPOR PRE $Y=\operatorname{LOG}(P V)$

IF (PV.GT.0.1836) GO TO 10

$D P F=71 \cdot 98+24 \cdot 873 * Y+0 \cdot 8927 * Y * Y$

GO TO 20

$10 \quad$ DPF $=79.047+30 \cdot 579 * Y+1 \cdot 8893 * Y * Y$

20 RETURN

END

SUBROUTINE GLASS (SHDCF,GLTYP,GLAZE,SHGF)

DIMENSION TR (9), SH(25)

COMMON /SOL/ LAT.LONG,TZN,WAZ,WT,CN,DST,LPYR,S(35)

$\operatorname{TR}(7)=S(19)$

$T R(8)=G L T Y P$

$T R(9)=G L A Z E$

CALL TAR (TR)

$S H(1)=S(24)$

$\mathrm{SH}(2)=S(22)$

$\mathrm{SH}(3)=5(23)$

$S H(4)=S(19)$

$\mathrm{SH}(5)=0.5$

$\mathrm{SH}(6)=0.5$

$\mathrm{SH}(7)=0.25$

$S H(8)=0$.

$\mathrm{SH}(9)=0.7$

$S H(10)=1.0$

$S H(11)=S H D C F$

$S H(12)=T R(1)$ 
$S H(13)=T R(2)$

$S H(14)=T R(3)$

$S H(15)=T R(5)$

$S H(16)=T R(4)$

$S H(17)=T R(6)$

CALL SHG (SH)

$S H G F=S H(18)$

RETURN

END

SUBROUTINE GPF $(U, Z L, Z)$

DIMENSION Z(1)

$P I=4$. * ATAN (1.)

SOTPI $=S Q R T$ (PI)

$P I 2=2 . / P I$

$E B=0.001$

$D B=0.1$

WRITE $(6,30)$

WRITE $(5,40)$

$Z(1)=2 * Z L * S Q R T(U) / S Q T P I$ $Z Z=Z(1)$

$Z(2)=Z(1) *(5 Q R T(2)-.2 \cdot)$

DO $10 K=3.50$

$Z K=K$

$10 \quad Z(K)=Z(1) *(5 Q R T(Z K)-2 \cdot * 5 Q R T(Z K-1)+5 Q R T(Z K-2 \cdot))$

DO $20 K=1.50$

20 WRITE $(6,50) \quad K, Z(K)$

C

RETURN

C

c

30

40

50

FORMAT $150 H O$ RESPONSE FACTORS FOR SEMI-INFINTTE BED FORMAT $(50 \mathrm{HO}$ K $Z(K)$

FORMAT (1I10.3F10.5)

END

SUBROUTINE MULT (A,B,C,D,AT,BT,CT,DT,N)

DIMENSION $A(N), B(N), C(N), D(N)$

$A T T=A(1)$

$B T T=B(1)$

$C T T=C(1)$

DTT $=D(1)$

IF (N.LT.2) GO TO 20

DO $10 \quad J=2 \cdot N$

$A T=A T T * A(J)+B T T * C(J)$

$B T=A T T * B(J)+B T T * D(J)$

$C T=C T T * A(J)+D T T * C(J)$

$D T=C T T * B(J)+D T T * D(J)$

ATT $=A T$

BTT $=B T$

CTT $=C T$

10 DTT $=D T$

GO TO 30

20 ATEATT

$B T=B T T$

$C T=C T T$

DT $=D T T$

30 RETURN

END 
SUBROUTINE OUTPUT (DB,WB,DBI,WBI,WA,WI, QGX,CFML, QLITE, OOCS , QOCL, R, IWAZ, ITYPE, NEXP, NAME)

DIMENSION Q(10),WAZ(10), ITYPE(10), NAME (6), QGX(10)

QWS $=0$.

QWW=0.

QHN=0.

QWE $=0$.

$Q G S=0$.

QGE $=0$.

QGW=0.

BGN $=0$.

QDS $=0$.

$Q D W=0$.

$Q D E=0$.

QDN $=0$.

WRITE $(6,20)$ (NAME $(I), I=1,6)$

WRITE $(6,30)$ DB.WB.WA

WRITE $(6,40)$ DBI.WBI.WI

$D B D=D B=D B I$

$W D=W A-W I$

WRITE $(6.50)$

WRITE $(6,60)$ DBD WD

DO $10 I=1$, NEXP

$Q(I)=-Q(I)$

II I I TYPE (I)

IF (II.EQ.3) $Q(I)=Q(I)+Q G X(I)$

IWAZ $=W A Z(I)$

IF (II.EQ.1) $Q R O O F=Q(I)$

IF (II.EQ.5) $Q F L O O R=Q(I)$

IF $(I I . E Q .6)$ QFLOOR=QFLOOR+Q(I)

IF (II.EQ.2.AND.IWAZ,EQ.0) QWS $=Q(I)$

IF (II.EQ.2.AND.IWAZ.EQ.90) QWW=Q(I)

IF (II.EQ,2.AND.IWAZ,EQ, -90) QWE=Q(I)

IF (II.EQ.2.AND.IWAZ,EQ,180) QWN $=Q(I)$

IF (II.EQ.3. AND. IWAZ,EQ.0) $Q G S=Q(I)$

IF (II.EQ.3.AND. IWAZ,EQ.90) QGW=Q(I)

IF (II.EQ,3.AND.IWAZ,EQ,-90) $Q G E=Q(I)$

IF (II.EQ.3.AND.IWAZ,EQ.180) QGN $=Q$ (I)

IF (II.EQ,4.AND.IWAZ,EQ.0) QDS $=Q(I)$

IF (II.EQ.4. AND. IWAZ.EQ.90) QDW $=Q$ (I)

IF (II,EQ,4,AND.IWAZ,EQ, -90$) \quad Q D E=Q(I)$

10 IF (II,EQ.4,AND.IWAZ,EQ,180) QDN $=Q(I)$

WRITE $(6,350)$

WRITE $(6,70)$ QROOF

WRITE $(6,80)$ QWS

WRITE $(6.90)$ QWE

WRITE $(6,100)$ QWW

WRITE $(6,110)$ QWN

WRITE $(6,180)$

WRITE $(6.190)$ QDS

WRITE $(6.200)$ QDE

WRITE $(6.220)$ NDW

WRITE $(6.210)$ QDN

WRITE $(6,120)$ QFLOOR

WRITE $(6,130)$

WRITE $(6,140)$ QGS

WRITE $(6,150)$ QGE

WRITE $(6,160)$ QGN

WRITE $(6.170)$ QGW

QINFIL $=1.08 * C F M L * D B D$

WATT $=Q L I T E / 3.415$

WRITE $(6,340)$ 
$S U M=Q R O O F+Q W S+Q W E+Q W W+Q W N+Q F L O O R+Q D S+Q D E+Q D W+Q D N+Q G S+Q G W+Q G E+Q G N$ WRITE $(6.270)$ SUM

WRITE $(6.230)$

WRITE $(6.250)$ WATT,QLITE

WRITE $(6,260)$ QOCS

WRITE $(6,240)$ CFML,DBD, QINFIL

WRITE $(6,340)$

$S U M=S U M+Q L I T E+Q I N F I L+Q O C S$

WRITE $(6,280)$ SUM

QINFIL $=4840$ * WD*CFML

WRITE $(6.320)$ CFML,WD.QINFIL

WRITE $(6,330)$ QOCL

WRITE $(6,340)$

SUML $=Q$ INFIL+QOCL

WRITE $(6.290)$ SUML

SUMT $=$ SUM+SUML

WRITE $(6,300)$

WRITE $(6.310)$ SUMT

C

RETURN

20

30

40

50

60

70

80

90

100

110

120

130

140

150 .

160

170

180

190

200

210

220

230

240

250

260

270

280

290

300

310

320

330

340

350

FORMAT (1H110X'SUMMARY OF CALCULATIONS FOR'6A6)

FORMAT 1 OO OUTDOOR CONDITIONS..... FF.1. DBOF10.1. 'WBOF10.4. HUMI 1DTY RATIO०)

FORMAT ('O SPACE CONDITIONS.......'F5.1, DBOF10.1, WB'F10.4.'HUMI 1OTY RATIO')

FORMAT $(24 \times 0-\infty-0-1,20 \times 10-\infty-\infty)$

FORMAT $($ OO DIFFERENCE............. F5.1,F25.4)

FORMAT (' ROOF $=\left(36 X_{0} F 10.0\right.$ )

FORMAT (" SOUTH WALL $\left.=36 X_{0}, F 10,0\right)$

FORMAT (" EAST WALL $=336 \times 010.0$ )

FORMAT (" NORTH WALL $=36 \times, F 10.0$ )

FORMAT (" WEST WALL $=336 \times, F 10.0$ )

FORMAT (" FLOOR $=$ (36X,F10.0)

FORMAT ("O SOLAR HEAT GAIN AND TRANSMISSION THROUGH GLASS')

FORMAT (" SOUTH $=(36 \times, F 10.0$ )

FORMAT (" EAST $=36 X_{0} F 10.0$ )

FORMAT (" NORTH $=36 \times 0$ F10.0)

FORMAT (" WEST $\left.=36 X_{0} F 10.0\right)$

FORMAT ('ODOORS')

FORMAT (? SOUTH $=36 \times, F 10.0)$

FORMAT (" EAST $=36 \times, F 10.0)$

FORMAT (" NORTH $\left.=33 X_{0} F 10.0\right)$

FORMAT (1 WEST $=(36 \times, F 10.0)$

FORMAT (०O INTERNAL LOAD')

FORMAT (" INFILTRATIONOF10.0, OCFMX 1.08 X 'F10.1.F13.0)

FORMAT ( LIGHTS F10.10.X 3.41=123X,F10.0)

FORMAT (POPEOPLE $\left.=.37 X_{0} F 10.0\right)$

FORMAT $(48 X, F 10.0)$

FORMAT $(10$ TOTAL SENSIBLE SPACE LOAD.20X,F10.0)

FORMAT 100 TOTAL LATENT SPACE LOAD' $20 \mathrm{X}=+1++$

1)

FORMAT (" GRAND TOTAL LOAD $30 \times, F 10.0)$

FORMAT ('OINFTLTRATION'F5.1.'CFM X $\left.4840 \times 0 F 6.40^{\circ}=010 \times 0 F 10.0\right)$

FORMAT (" PEOPLE $=227 \times, F 20.0)$

FORMAT $\left(50 X_{0} 00-\infty-\infty-\infty-\infty\right)$

FORMAT (1HO)

END 
SUBROUTINE OUTSID $\left(X, Y, Z, C R, U X_{P} F O, D B, T I Y_{P}, Q O, Q I, Q S U N, Q S K Y, T O, T I, T O N\right.$ 1EW.TA. ITEMP)

DIMENSION TO(1),TI(1),X(1),Y(1),Z(1)

$X N U M=Q S U N-Q S K Y+F O *(D B-T I M)$

10 IF $(X(2)) \quad 50.10 .50$

10 IF (FO) $20,20 \cdot 30$

20 TONEWETO(1)

GO TO 40

30 TAM $=T A-T I M$

TONEW $=(X N U M+U X * T A M) /(U X+F O)$

40 CONTINUE

OO=UX*(TAM-TONEW)

IF (ITEMP.EQ•O) $Q I=Q O$

TO $(1)=$ TONEW

RETURN

$50 \quad$ SUMZ $=0$.

SUMY $=Y(1) * T I(1)$

SUMX $=X(1) * T I(1)$

SUMXY $=0$.

DO $60 \mathrm{~J}=2,48$

SUMY $=S U Y Y+Y(J) * T I(J)$

SUMX $=S U M X+X(J) * T I(J)$

SUMXY $=S U M X Y+Y(J) * T O(J-1)$

$60 \quad$ SUMZ $=S U M Z+Z(J) * T O(J-1)$

$X N U M=S U M Y-S U M Z+C R * Q O+X N U M$

TONEW $=X N U M /(Z(1)+F O)$

70 IF (FO) $70,70,80$

TONEW=TO(1)

80 TO $(1)=$ TONEW

SUMZ $=$ SUMZ $+Z(1) * T O(1)$

SUMXY $=S U M X Y+Y(1) * T O(1)$

$Q O=S U M Y-S U M Z+C R * Q O$

IF (ITEMP,EQ.ก) $Q I=S U M X-S U M X Y+C R * Q I$

RETURN

END

SUBROUTINE PSY1 (OB,WB,PB,OP,PV,W,H,V,RH)

C THIS SUBROUTINE CALCULATES VAPOR PRESSURE (PV), HUMIDITY RATIO (W)

6 ENTHALPY (H), VOLUME(V) , RELATIVE HUMIDITY RH) AND DEW-POINT

C TEMPERATURE WHEN THE DRY-BULB TEMPERATURE (DB), WET-BULB TEMPERATURE

C (WB) AND BAROMETRIC PRESSURE(PB) ARE GIVEN

PVP $=P V S F(W B)$

IF $(D B-W B) 30 \cdot 30,10$

10 WSTAR $=0.622 * P V P /(P B-P V P)$

IF $(W B-32) 20,20,$.

$20 \quad P V=P V P=5.704 E-4 * P B *(D B-W B) / 1.8$

GO TO 50

$30 \quad P V=P V P$

GO TO 50

$40 \quad C D B=(D B-32) /$.

$C W B=(W B-32) /$.

$H L=597 \cdot 31+0.4409 * C D B-C W B$

$C H=0.2402+0.4409 * W S T A R$

$E X=(W S T A R-C H *(C D B-C W B) / H L) / 0.622$

$P V=P B * E X /(1,+E X)$

$50 \quad W=0.622 * P V /(P B-P V)$

$V=0.754 *(D B+459.7) *(1+7000 * W / 4360) / P B$

$H=0.24 * D B+(1061+0.444 * D B) * W$

$D P=D P F(P V)$

$R H=P V / P V S F(D B)$

RETURN

END 
SUBROUTINE RESF (XX,YY,ZZ,IRUN)

THIS PROGRAM IS DEVELOPED BY T.KUSUDA OF THE NATIONAL RUREAU OF

STANDARDS FOR CALCULTING THE THERMAL RESPONSE FACTORS FOR

COMPOSITE WALLS,FLOORS, ROOFS, BASEMENT WALLS, BASEMENT FLOORS

AND INTERNAL FURNISHINGS OF SIMPLE SHAPES

RESPONSE FACTORS ARE USED IN THE FOLLOWING MANNER

$X, Y, Z$ ARE RESPONSE FACTORS

$Q I=X * T I-Y * T O * G M A$ INSIDE WHERE $R$ IS MINIMIIM

$Q O=Y * T I-Z * T O$ OUTSIDE WHERE $R$ IS MAXIMUM

$T I$ INSIDE TEMPERARURE WHERE $R$ IS MINIMUM

TO OUTSIDE TEMPERATURE WHERE $R$ IS MAXIMUM

$K$ THERMAL CONDUCTIVITY

$G$ THERMAL DIFFUSIVITY

L THICKNESS

IN=0 FINITE THICK WALL

IN=1 SEMI-FINITE WALL

IN $=2$ SOLIO OBJECT

IF RESPONSE FACTORS OF THE SOLID CYLINDER OR SPHERE OF HOMOGENEOUS

PROPETY ARE DESIRED. TREAT THE PROBLEM OF MULTILAYER BUT WITH THE

IDENTICAL PROPERTIES FOR ALL THE LAYERS EXCEPT THE. RADIUS

REAL $K(10), G(10), L(10), K G$

DIMENSION $X(100), Y(100), Z(100), C(10), D(10), \operatorname{RES}(10), \operatorname{RMK}(10,4)$

DIMENSION RMKG(4), F $(100), X X(100,1), Y Y(100,1), Z Z(100,1), F F(100,20)$

10 READ $(5.240)$ DELTAT

IRUN $=0$

20 READ $(5.230)$ NLAYR,IN

IF (NLAYR.EQ.0) GO TO 200

IRUN $=$ IRUN+I

IF (NLAYR.GT.10) GO TO 200

NNLAYR $=$ NLAYR+1

IF (NLAYR,EQ,0) GO TO 40

DO $30 \quad I=1$. NLAYR

30 READ $(5,240)$ L(I ),K (I),D(I),C (I),RES(I)

IF (IN.EQ.2.AND.IM.EQ.0) GO TO 50

C READ K.RHO. AND C OF GROUND IF INEI

C FOLLOWING ARE GROUND THERMAL CONDUCTIVITY, DENSITY AND SP.HT IF

C

40

C

IN=2, OTHERWISE THE SAME PROPERTIES OF THE INTERNAL SLAB

IF (IN,NE, O) READ $(5,240) \quad K G, D G, C G$

AG THERMAL DIFFUSIVITY OF EARTH

IF (IN,NE,O) $A G=K G / C G / D G$

IF (NLAYR,EQ.0) GO TO 100

IF (IN.EQ.2) READ $(5,330)$ (RMKG $(J), J=1,4)$

50 DO $60 \quad I=1$.NLAYR

$60 \operatorname{READ}(5,330)(R M K(I, J), J=1,4)$

IF $(I N, E Q .1)$ READ $(5.330)$ (RMKG $(J), J=1,4)$

DO $90 \quad I=1$.NLAYR

IF (L(I)) $80,70 \cdot 80$

$70 \quad G(I)=0$.

$K(I)=1 . / R E S(I)$

GO TO 90

80

$G(I)=K(I) / C(I) / D(I)$

90 CONTINUE

100 WRITE $(6,350)$

CALL RESPTK (K,L, G, AG,KG, X, Y, Z, NLAYR,DELTAT,NRT, CR,UT, IN,F)

WRITE $(6.220)$ IRUN

WRITE $(6,360)$

WRITE $(6.250)$

WRITE $(6,260)$

WRITE $(6,210)$

IF (NLAYR.EQ.0) GO TO 130

IF (IN.EQ.2.ANN.IM.NE.0) WRITE $(6,370) \quad K G, D G, C G,(R M K G(J), J=1,4)$

DO $120 I=1$. NLAYR

IF (L(I) $120,110 \cdot 120$ 
120 WRITE $(6,270)$ I,L(I),K(I),D(I),C(I),RES(I), (RMK (I,J),J=1,4)

130 WRITE $(6,290)$ OELTAT

WRITE $(6,280)$ UT

WRITE $(6,300)$

WRITE $(6,210)$

IF $(I N, N E \cdot 0)$ GO TO 150

WRITE $(6.310)$

$X X(1, I R U N)=F L O A T(N R T)$

$Y Y(1, I R U N)=F L O A T(N R T)$

$Z Z(1, I R U N)=F L O A T(N R T)$

$X X(2, I R U N)=C R$

$Y Y(2, I R U N)=C R$

$Z Z(2, I R U N)=C R$

$X X(N R T+3, I R U N)=U T$

DO $140 \mathrm{~N}=1$. NRT

$X X(N+2, I R U N)=X(N)$

$Y Y(N+2 \cdot I R U N)=Y(N)$

$Z Z(N+2, I R U N)=Z(N)$

$J N=N-1$

140 WRITE $(6,320)$ JNo $X(N), Y(N), Z(N)$

GO TO 190

150 WRITE $(6,380)$

IF (IN.EQ.1) GO TO 170

IF (IN.EQ.2) GO TO 170

$X X(1, I R U N)=F L O A T(N R T)$

$X X(2, I R U N)=C R$

$X X(N R T+3, I R U N)=U T$

DO $160 \mathrm{~N}=1$. NRT

$J N=N-1$

$X(N)=-x(N)$

$X X(N+2, I R U N)=X(N)$

160 WRITE $(6,390)$ JNOX(N)

GO TO 190

170 DO $180 \quad \mathrm{~N}=1$, NRT

$J N=N-1$

$F F(N+2, I R U N)=F(N)$

180 WRITE $(6,390)$ JN, $F(N)$

$F F(1, I R U N)=F L O A T(N R T)$

$F F(2, I R U N)=C R$

$F F(N R T+3, I R U N)=U T$

190 WRITE $(6.210)$

WRITE $(6.210)$

WRITE $(6.340) \quad C R$

GO TO 20

200 RETURN

C

C

c

210 FORMAT (2HO)

220 FORMAT (10H1 IRUN= I10)

230 FORMAT (1017)

240 FORMAT (1OF7.0)

250

260

FORMAT $177 \mathrm{HO}$ LAYER

1I) DESCRIPTION

$L(I) \quad K(I)$

(I)

C(I)

RESI

FORMAT $177 \mathrm{H}$ NO

1 OF LAYERS

) )

270 FORMAT $(116,1 F 11.3,1 F 10.3 .1 F 10.2,1 F 10.3 .1 F 8.2 \cdot 2 \times \cdot 4 A 6)$

280 FORMAT $(58 \mathrm{HO}$

1 U $=1 F 7.3$ )

THERMAL CONDUCTANCE 


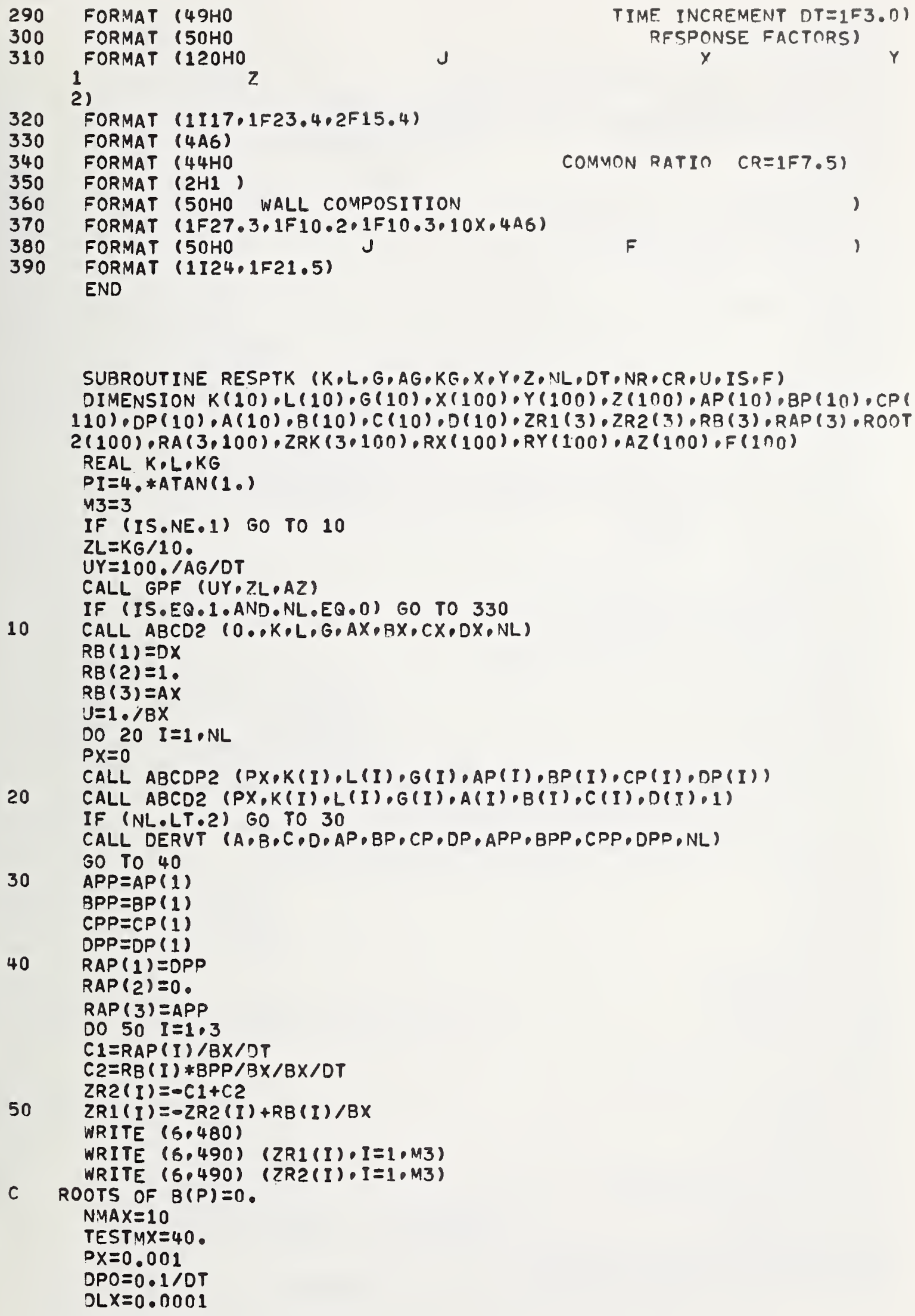


$N=0$

WRITE $(6,500)$

60

$D L=D P O$

70

$C A L L A B C D 2(P X, K, L, G, A X, B X, C X, D X, N L)$

$P X P=P X+D L$

$C A L L A B C D 2(P X P, K, L, G, A X P, B X P, C X P, D X P, N L)$

IF $(B X * B X P) \quad 90,110,80$

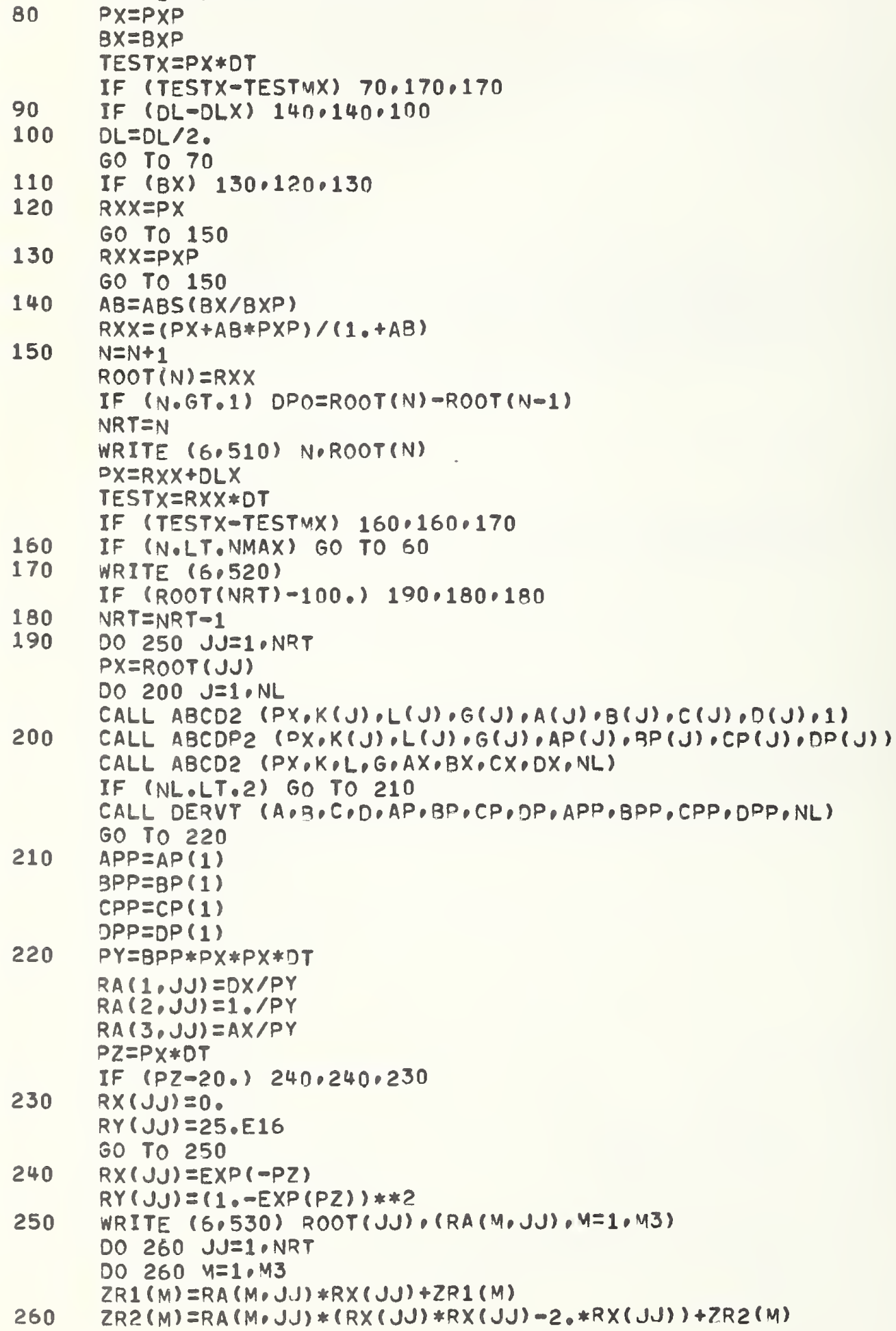

80 
$I I=1$

II I $=2$

WRITE $(6.540)$

WRITE $(6,550)$

IF $(Z R 1(2), L T \cdot 0) \quad Z R 1(2)=0$.

WRITE $(6,560)$ II. $(Z R I(M), M=1, M 3)$

WRITE $(6,560)$ III, $(Z R ?(M), M=1, M 3)$

DO $270 \quad n=1, M 3$

$Z R K(M \cdot 1)=Z R 1(M)$

$27 U \quad Z R K(M \cdot 2)=Z R 2(M)$

NT $=100$

DO $300 \quad N=3$.NT

$N R=N$

$280 \quad Z R K(M \circ N)=0$.

DO $290 \quad M=1 \cdot M 3$

DO 290 JJIEI NRT

$P Z=(R \times(J))) * * N$

$290 \quad Z R K(M, N)=Z R K\left(M_{0} N\right)+P Z * R Y(J J) * R A(M, J J)$

WRITE $(6,560) \quad N \cdot(Z R K(M, N), M=1, M 3)$

IF $(N . L T .5)$ GO TO 300

TEST $1=Z R K(1, N) / Z R K(1, N-1)$

TEST2 $=Z R K(1, N-1) / Z R K(1, N-2)$

TEST $3=A B S\left(T E S T_{1}-T_{E S T}\right)$

IF (TEST3-0.00001) 310.310 .300

300 CONTINUE

310 DO $320 \quad N=1$. NR

$X(N)=Z R K(1, N)$

$Y(N)=Z R K(2, N)$

$320 \quad Z(N)=Z R K(3, N)$

CRETEST?

WRITE (6.570) CR

IF (IS.EQ.2) GO TO 450

IF (IS.NE.I) GO TO 470

330 IF $(N L . E Q .0)$ GO TO 390

$G F=2 * K G / S Q R T$ (DT*AG*PI)

IF $(N R \cdot L T \cdot 50)$ GO TO 350

DO $340 J=50$. NR

$Z J=J$

$340 \quad A Z(J)=G F *(S Q R T(Z J)-2 . * S Q R T(Z J-1)+.S Q R T(Z J-2)$.

$N R R=N R$

GO TO 370

350 DO 360 JVNR, 50

$z(J+1)=z(J) * C R$

$X(J+1)=X(J) * C R$

$360 \quad Y(J+1)=Y(J) * C R$

VRR $=50$

370 DO $380 \mathrm{~J}=1$, NRR

$380 \quad F(J)=X(J)-Y(J) * Y(J) /(Z(J)+A Z(J))$

$N R=N R R$

SO TO 410

390

DO $400 \quad J=1, N R$

400

$F(J)=A Z(J)$

410 WRITE $(6,580)$

CR1 $=1$.

DO $430 \mathrm{~J}=1.50$

$C R=F(J+1) / F(J)$

TESTCR $=A B S(C R-C R 1)$

$420 \quad$ CR1 $=C R$

$C R 1=C R$
$J J=J-1$

430 WRITE $(5,590)$ JJPF(J)

$440 \quad N R=J$ 
$C R=C R 1$

GO TO 470

450

WRITE $(6,580)$

DO $460 \mathrm{~J}=1$. NR

$F(J)=X(J)+Z(J)-2 * Y(J)$

$J J=J-1$

460 WRITE $(6,590)$ JJPF(J)
470 RETURN

480

490

500

510

520

530

540

550

FORMAT $150 H O$ DESIDUES AT $P=0$

)

FORMAT (3F20.6)

FORMAT $(50 \mathrm{HO}$ ROOTS OF $B(P)=0$

)

FORMAT $(110.1 F 20.6)$

FORMAT ( 50 HO RESUDUES AT P=ROOT(N)

)

FORMAT (4F20.5)

FORMAT (5OHO RESPONSE FACTORS OF FINTTE SLAB

,

FORMAT (12OHO

1

560

FORMAT (I $10.3 F 20.6)$

570

580

590

FORMAT ( 1 OHO

FORMAT $150 \mathrm{HO}$

$C R=1 F 10.6)$

FORMAT (1I10.1F20.5)

$J$

$x(J)$

$Y(J)$

END

SUBROUTINE RMTMP (NEXP,NX,TV,CFML,CFMV,R,TIM,TA,TIF, QL,ITK)

COMMON /CC/ $X(10.100), Y(10.100), Z(10.100)$, ITYPE (10), IHT (10), IRF (10

1), ABSP (10),U(10),H(10),HI (10),A(10),UT (10), TOS $(10,48), T$ IS $(10,48), G$

$2(10,10)$, TOY (48), DB (24), QLITE (24), QEQUP (24), QOCPS (24), QI (10),CR (10)

3.NR (10), OGLAS $(10,24)$, ITHST

DIMENSION $A A(20,20), B B(20), T T(20)$, TIF $(20), A 2(20,20), B 2(20), B 3(20)$, 1 GSUM(20)

$D B N X=D B(N X)-T I M$

TUETV TIM

NEXP2 $=N E X P+1$

DO $10 \quad I=1$. NEXP2.

$B B(I)=0$.

$B 2(I)=0$.

DO $10 \mathrm{~J}=1$. NEXP?

$A 2(I, J)=0$.

$10 \quad A A(I, J)=0$.

$S H G=0$.

HSUM $=0$.

ASUM $=0$.

ASUMT $=0$.

DO $70 I=1$, NEXP

$S H G=S H G+Q G L A S(I \circ N X) * A(I)$

ASUMT $=A S U M T+A(I)$

$\operatorname{GSUM}(I)=0$.

DO $20 \mathrm{~J}=1, \mathrm{NEXP}$

20

$\operatorname{GSUM}(I)=\operatorname{GSUM}(I)+G(I \cdot J)$

IF (ITYPE (I).NE・3) ASUM $=A S U M+A(I)$

HSUM $=H S U M+H I(I) * A(I)$

$I R=I R F(I)$

$C R X=C R(I)$

IF $(X(I R, 2)) \quad 40.30,40$

$X(I R, 1)=U T(I)$

$Y(I R, I)=U T(I)$

$C R X=0$.

$Z(I R, 1)=U T(I)$

40

$A A(I, I)=X(I R, I)+H I(I)+\operatorname{GSUM}(I)$

60 
DO $50 \mathrm{~J}=1$ - NEXP

IF $(I, E Q, J)$ GO TO 50

$A A(I, J)=-G(I, J)$

50

CONTINUE

$A A(I, N E X P 2)=-H I(I)$

SUMY $=Y(I R, 1) * \operatorname{TOS}(I, 1)$

SUMX $=0$.

DO $60 \mathrm{~J}=2,48$

SUMY $=S U M Y+Y(I R, J) * \operatorname{TOS}(I, J)$

$60 S$ SUMX $=S U M X+X(I R, J) * T I S(I, J)$

$B 3(I)=S U M Y-C R X * Q I(I)-S U M X$

$70 \quad A A(N E X P 2, I)=A(I) * H I(I)$

OLT $=Q L I T E(N X) / A S U M T * R$

DO $80 \quad I=1$, NEXP

SHF $=S H G / A S U M$

IF (ITYPE(I),EQ.3) SHF $=0$.

$80 \quad B B(I)=B 3(I)+S H F+Q L T$

$A A(N E X P 2 \cdot N E X P 2)=-1.08 *(C F M L+C F M V)-H S U M$

SUM $=1.08 *(C F M L * D B N X+C F M V * T U)+Q O C P S(N X)+Q E Q U P(N X)+Q L I T E(N X) *(1,-R)$

$B B(N E X P 2=-S U M$

NEXP3 $=N E X P 2+1$

DO $90 \quad I=1$. NEXP2

$B 2(I)=B B(I)$

DO $90 \mathrm{~J}=1, \mathrm{NEXP2}$

$90 \quad A 2(I, J)=A A(I, J)$

IF (ITHST.NE.0) GO TO 100

CALL SOLVP (NEXP2, NEXP3,AA,BB,TT, 20)

$T A=T T(N E X P 2)+T I M$

IF $(I T K . N E . O)$ GO TO 110

IF (TA-TIM) $110,110,100$

TA $=$ TIM

CALL SOLVP (NEXP,NEXP2,A2,B2,TT, 20 )

$110 Q L=S U M-1.08 *(C F M L+C F M V) *(T A-T I M)$

SUMQ $=0$.

DO $140 \quad I=1$, NEXP

$K=I R F(I)$

$\operatorname{TIS}(I \cdot 1)=\operatorname{TT}(I)$

TEST $=A B S(T T(I))$

IF (TEST.GT.100.) GO TO 150

$Q I(I)=X(K, I) * T T(I)-B 3(I)$

If $(x(k, 2)) 130,120 \cdot 130$

120

$Q I(I)=U(I) *(T A-D B(N X))$

$130 \quad \operatorname{TIF}(I)=T T(I)+T I M$

140 SUMQ $=S U M Q+A(I) * H I(I) *(T A-T I F(I))$

$Q L=-Q L+S U M Q$

RETURN

150 CONTINUE

WRITE $(6,170)$

DO $160 \quad I=1$. NEXP2

160 WRITE $(6,180)$ (A2(I,J),JI, NEXP2), B2(I),TT(I)

RETURN

c

C

C

170 FORMAT ('0 ROOM TEMPERATURE MATRIX')

180 FORMAT $(12 F 10.3)$

END 
REAL LONG,LAT

SH(1) = INTENSITY OF DIRECT NORMAL SOLAR RADIATION

SH(2) =INTENSITY OF DIFFUSE SKY RADIATION

SH $(3)=$ INTENSITY OF GROUND REFLECTED DIFFUSE RADIATION

$S H(4)=C O S I N E$ OF INCIDENCE OF DIRECT SOLAR RADIATION

SH(5)=FORM FACTOR BETWEEN THE WINDOW AND THE SKY

SH(6)=FORM FACTOR BETWEEN THE WINDOW AND THE GROUND

SH(7) =THERMAL RESISTANCE AT OUTSIDE SURFACE

SH $(8)=$ THERMAL RESISTANCE AT THE AIR SPACE (DOUBLE GLAZING)

SH $(9)=$ THERMAL RESISTANCE AT THE INNER SURFACE

SH(10) =SUNLIT AREA FACTOR

SH(11) =SHADING COEFFICIENT NON-ZERO VALUE WILL BE GIVEN ONLY WHEN THE WINDOW IS SHADED BY DRADES OR BLINDS OR IF IT HAS AN INTERPANE SEPARATION OF MORE THAN 1=INCH

SH(12) =TRANSMISSION FACTOR FOR DIRECT RADIATION

SH $(13)=T R A N S M I S S I O N$ FACTOR FOR DIFFUSE RADIATION

SH(14) =ABSORPTION FACTOR FOR DIRECT RADIATION (OUTER PANE)

SH(15) =ABSORPTION FACTOR FOR DIRECT RADIATION (INNER PANE)

SH $(16)=A B S O R P T I O N$ FACTOR FOR DIFFUSE RADIATION(OUTER PANE)

SH $(17)=A B S O R P T I O N$ FACTOR FOR DIFFUSE RADIATION (INNER PANE)

SH $(18)=S O L A R$ HEAT GAIN

COMMON /SOL/ LAT,LONG,TZN,WAZ,WT,CN,DST,LPYR,S(35)

REAL NI, NO

$N I=(S H(7)+S H(8)) /(S H(7)+S H(8)+S H(9))$

$\mathrm{NO}=(\mathrm{SH}(7)) /(\mathrm{SH}(7)+\mathrm{SH}(8)+\mathrm{SH}(9))$

$D=S H(10) * S H(1) * S H(4) *(S H(12)+N O * S H(14)+N I * S H(15))$

$D D=(S H(2) * S H(5)+S H(3) * S H(6)) *(S H(13)+N O * S H(16) * N I * S H(17))$

IF (SH(11)) $20,10,20$

10

$\mathrm{SH}(18)=D+D D$

GO TO 30

20

$S H(18)=(D+D D) * S H(11)$

30 RETURN

END

SUBROUTINE SOLVP $(M, N, C, D, X, I)$

C

C

c

$10 \quad A(I X, I Y)=C(I X, I Y)$

THIS IS A ROUTINE FOR SOLVING SIMULTANEOUS LINEAR EQUATIONS THE ROUTINE WAS DEVELOPED BY B.A. PEAVY OF NBS

ROUTINE FAILS WHEN ANY OF THE DIAGONAL ELEMENTS IS ZERO

DIMENSION A $(100,101), C(I, 1), D(1), X(1)$

DO 10 IX $X=1 . M$

DO 10 IY $=1, M$

DO 20 IZ $=1 . \mathrm{M}$

$20 \quad A(I Z, N)=D(I Z)$

$L=1$

$30 \quad A A=A(L, L)$

DO $40 \quad K=L, N$

$40 \quad A(L, K)=A(L, K) / A A$

DO $60 K=1, M$

IF $(K \cdot E Q \cdot L)$ GO TO 60

$A A=-A(K, L)$

50 DO 50 IAEL,N

$50 \quad A(K, I A)=A(K, I A)+A A * A(L, I A)$

60 CONTINUE

$L=L+1$

IF (L.LE,M) GO TO 30

70

DO 70 IP $=1, M$

$X(I P)=A(I P, N)$

RETURN

END 
SUBROUTINE SUN

DIMENSION AO(5)/.302,-.0002.358.44,.1717.0.09n5/.A1(5)/-22.93,.419

$17.24 .52,-.0344,-.0410 / . A 2(5) /-.229,-3.2265,-1.14, .0032, .0073 / . A 3(5$ 2) $/-.243,-.0903,-1.09, .0024, .0015 / .81(5) / 3.851,-7.351, .58,-.0043, \cdots$ $30034 / . \mathrm{B} 2(5) / .002,-9.3912,-.18,0.00 .0004 / .83(5) /-.055,-.3361, .28,-$. $4008,-.0006 /$

COMMON /SOL/ LAT,LONG,TZN,WAZ,WT,CN,DST,LPYR,S(35)

REAL LATD, LONG, MERID.LOND

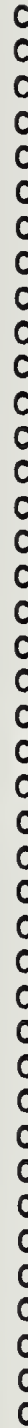

$S(1)=$ LATITUDE, DEGREES $\left(+N O R T H_{0}-S O U T H\right)$

$S(2)=$ LONGITUDE, DEGREES (+WEST, -EAST $)$

$S(3)=$ TIME ZONE NUMBER

ATLANTIC STANDARD TIME

EASTERN

CENTRAL MOUNTAIN

PACIFIC

RD
4
5
6
7
8

DAYLIGHT SAVING TIME

$S(4)=$ DAYS(FROM START OF YEAR)

$S(5)=$ TIME,HOUR AFTER MIDNIGHT)

$S(6)=$ DAYLIGHT SAVING TIME INOICATOR

$S(7)=$ GROUND REFLECTIVITY

$S(B)=$ CLEARNESS NUMBER

$S(9)=$ WALL AZIMUTH ANGLE, DEGREES FROM SOUTH

$S(10)=W A L L$ TILT ANGLE, DEGREES FROM HORIZON

$S(11)=S U N$ RISE TIME (HOURS AFTER MIDNIGHT)

$S(12)=S U N$ SET TIME

$S(13)=\cos 2$

$S(14)=\operatorname{Cos} N$ DIRECTION COSINES

$S(15)=\cos (S)$ DIRECTION COSINES

DIRECTION COSINES)

$S(16)=A L P H A$ DIRECTION COSINES NORMAL TO SURFACE

$S(17)=B E T A$

$S(18)=$ GAMMA

$S(19)=\operatorname{COS}(E T A) \operatorname{COSINE}$ OF INCIDENCE ANGLE

$S(20)=S O L A R$ ALTITUDE ANGLE

$S(21)=S O L A R$ AZIMUTH ANGLE

$S(22)=D I F F U S E$ SKY RADIATION ON HORIZONTAL SURFACE

$S(23)=D I F F U S E$ GROUND REFLECTED RADIATION

$S(24)=D I R E C T$ NORMAL RADIATION

$S(25)=$ TOTAL SOLAR RADIATION INTENSITY

$S(26)=$ DIFFUSE SKY RADIATION INTENSITY

$S(27)=$ GROUND REFLECTED DIFFUSE RADIATION INTENSITY

$S(28)=S U N$ DECLINATION ANGLE.DEGREES

$S(29)=E Q U A T I O N$ OF TIME - HOURS

$S(30)=A$ SOLAR FACTOR

$S(31)=\quad$ SOLAR FACTOR

$S(32)=$ SOLAR FACTOR

$S(33)=\quad$ CLOUD COVER MODIFIER

S(34) INTENSITY OF DIRECT SOLAR RADIATION ON SURFACE $S(35)$ HOUR ANGLE.DEGREE

$P I=3.1415927$

$X=2 * P I / 366 * * S(4)$

$\operatorname{coc}=\cos (x)$

$c_{2}=\cos (2 * x)$

$c 3=\cos (3 * x)$

$S 1=\operatorname{SIN}(x)$

$\operatorname{S2}=\operatorname{SIN}(2 * x)$

$S 3=\operatorname{SIN}(3 * x)$

DO $10 \quad K=1.5$

$K S=(K-1)+28$

$10 S(K S)=A 0(K)+A 1(K) * C 1+A 2(K) * C 2+A 3(K) * C 3+B 1(K) * S 1+B 2(K) * S 2+B 3(K) * S 3$

$S(29)=S(29) / 60$.

LATD $=S(1)$

LONG $=S(2)$ 
MERID $=15 * S(3)$

LOND $=$ LONG $-M E R I D$

$Y=S(28) * P I / 180$.

$Y Y=L A T D * P I / 180$.

$H P=-T A N(Y) * T A N(Y Y)$

$T R=12 / P I * A C O S(H P)$

$S(11)=(12-T R)-S(29)+L O N D / 15$.

$S(12)=24 \cdot-S(11)$

$H=15 *(5(5)-12+5(3)+5(29)-S(6))-S(2)$

$S(35)=H$

S13 $=\operatorname{SIN}(Y Y) * S I N(Y)+\operatorname{COS}(Y Y) * \operatorname{COS}(Y) * \operatorname{COS}\left(H * P I / 180_{0}\right)$

$S(13)=513$

$H P 1=180 * A \operatorname{COS}(H P) / P I$

$X 1=A B S(H P 1)$

$\times 2=A B S(H)$

IF $(X 1-x 2) \quad 130,20,20$

$20 \quad S(14)=\cos (Y) * S I N(H * P I / 180$.

$S(15)=S Q R T(1 .-S(13) * S(13)-S(14) * S(14))$

STEST $=5(15)$

STESTI $=\operatorname{COS}(H * P I / 180)-.T A N(Y) / T A N(Y Y)$

30

IF (STEST1) $40,30,30$

GO TO 50

$40 \quad S(15)=-S T E S T$

$50 \quad S(20)=A S I N(S(13))$

IF $(S(15)) 70 \cdot 60,60$

$60 S(21)=A S I N(S(14) / \operatorname{COS}(S(20)))$

GO TO 80

$70 \quad S(21)=P I-A S I N(S(14) / \operatorname{Cos}(S(20)))$

$80 \quad S(20)=180 * * S(20) / P I$

$S(21)=180 \cdot * S(21) / P I$

$S(24)=S(30) * S(8) * S(33) * \operatorname{EXP}(-S(31) / S(1.3))$

$S(22)=S(32) * S(24) / 5(8) / 5(8)$

$S(23)=5(7) *(5(22)+5(24) * S(13))$

$W T=S(10) * P I / 180$.

$S(16)=\cos (W T)$

$W A=S(9) * P I / 180$.

$S(16)=\cos (W T)$

$S(17)=\operatorname{SIN}(W A) * \operatorname{SIN}(W T)$

$S(18)=\operatorname{Cos}(W A) * S I N(W T)$

$S(19)=S(16) * S(13)+S(17) * S(14)+S(18) * S(15)$

$S(34)=S(24) * S(19)$

$Y=0.45$

If $(S(19)+0.2) \quad 100,100,90$

$90 \quad Y=0.55+0.437 * S(19)+0.313 * S(19) * 2$

100 IF $(S(19)) \quad 110,110,120$

$110 \quad S(19)=0$.

$S(34)=0$.

120 CONTINUE

$S(26)=S(22) * Y$

$S(27)=5(23) *(1-5(16)) / 2$.

$S(25)=S(34)+S(26)+S(27)$

$130 \quad$ DO $140 \quad J=14.26$

$140 \quad S(J)=0$.

$S(34)=0$

150 RETURN

END 
SUBROUTINE TAR (TR)

REAL A1 (6)/0.01154.0.77674.03.94657.8.57881,-8.38135.3.0118B/

REAL A2 (6)/0.01636,1.40783,-6.79030,14.37378,-13.83357.4.92439/

REAL A3 (6) /0.01837.1.92497.-8.89134.18.40197.-17.48648.6.17544/

REAL A4(6)/0.09902.2.35417,-10.4715.21.24322,-19.95978.6.09964/

REAL A5(6)/0.01712,3.50839,-13.8639.26.34330, $-23.84846 .8 .17372 /$

REAL AG(6)/0.01406,4.15958,-15.0628.27.18492,-23.82518,8.03650/

REAL A $(6) / 0.01153,4.55946,-15.4329,26 \cdot 70568,-22.87993 .7 .57795 /$

REAL AB (6)/0.00962.4.91911.-15.4714.25.86516,-21.69106.7.08714/

REAL T1 $(6) /=0.00885,2.71235,-0.62062,-7.07329 \cdot 9.75995,-3.89922 /$

REAL T2 $(6) /-0.01114 \cdot 2.39371,0.42978,-8.98262 \cdot 11.51798,-4.52064 /$

REAL T $3(6) /=0.01200 \cdot 2.13036,1.13833,-10.07925 \cdot 12.44161,-4.83285 /$

REAL T $4(6) /=0.01218,1.90950 \cdot 1.61391,-10.64872 \cdot 12.83698,-4.95199 /$

REAL T5 $(6) /=0.01056 \cdot 1.29711 \cdot 2.28615,-10.37132 \cdot 11.95884,-4.548 .80 /$

REAL T6 $(6) /=0.00835,0.92766,2.15721,-8.71429,9.87152 \cdot-3.73328 /$

REAL T7(6)/-0.00646,0.682561 1.82499,-6.95325,7.80647,-2.94454/

REAL T8(6)/ $/ 0.00496,0.51043,1.47607,-5.41985,6,00546,-2.28162 /$

REAL AO1 (6) /0.01407.1.06226, $-5.59131 .12 .15034,-11.78092 .4 .20070 /$

REAL AO2 $(6) / 0.01819 \cdot 1 \cdot 862770=9.24831 \cdot 19.49443 .-18.56094 \cdot 6.53940 /$

REAL AO3(6)/0.01905.2.47900,-11.7427.24.14037,-22.64299.7.89954/

REAL AO4(6)/0.01862.2.96400,-13.4870,27.13020,-25.11877.8.68895/

REAL AO5 (6)/0.01423.4.14384,-16.66709.31.30484,-27.81955.9.36959/

REAL AOG $(6) / 0.01056,4.71447,-17.33454 .30 .91781,-26.63898,8.79495 /$

REAL AO7 $(6) / 0.00819 .5 .01768,-17.21228 .29 .46388,-24.76915 \cdot 8.05040 /$

REAL AO8 (6) /0.00670.5.18781.-16.84820.27.90292.-22.99619.7.38140/

REAL AI $1(6) / 0.00228 \cdot 0.345590-1.19908 \cdot 2 \cdot 22336,-2.05287,0.72376 /$

REAL AI2(6)/0.00123,0.29788, $=0.92256,1.58171,-1.40040,0.48316 /$

REAL AI $3(6) / 0.00061,0.260170=0.72713 \cdot 1 \cdot 14950,-0.9713800 .32705 /$

REAL AI 4 (6) / $0.00035,0.229740=0.58381,0.84626,-0.67666,0.22102 /$

REAL AI5 $(6) /-0.00009,0.15049,-0.27590,0.25618,-0.12919,0.02859 /$

REAL AI6 (6) / $/ 0.00016,0.10579,-0.15035,0.06487,0.02759,-0.02317 /$

REAL AI $7(6) /-0.00015,0.07717,-0.09059,0.00050,0.06711,-0.03304 /$

REAL AIB $(6) /-0.00012,0.05746,-0.05878,-0.01855,0.06837,-0.03191 /$

REAL TO1 $(6) /-0.00401,0.74050 .7 .20350,-20.11763,19.68824,-6.74585 /$

REAL TO2 $(6) /=0.00438,0.57818,7.42065,-20.26848,19.79706,-6.79619 /$

REAL TO3 $(6) /-0.00428,0.45797 .7 .41367,-19.92004 \cdot 19.40969,-6.66603 /$

REAL TD4 $(6) /=0.00401,0.36698,7.27324,-19.29364,18.75408,-6.43968 /$

REAL TO5 $(6) /=0.00279 .0 .16468,6.17715,-15.84811,15.28302 .-5.23666 /$

REAL TDG $(6) /=0.00192,0.08180 .4 .94753,-12.43481,11.92495,-4.07787 /$

REAL TOT(6)/ $/ 0.00136,0.04419,3.87529,-9.59069 \cdot 9.16022,-3.12776 /$

REAL TDB $(6) /-0.00098,0.02576,3.00400,-4.33834 \cdot 6.98747,-2.38328 /$

DIMENSION TR $(9), A(8,6), T(8,6), A O(8,6), A I(8,6), T D(8,6)$

TR(1) = TRANSMISSION FACTOR -OIRECT

TR $(2)=$ TRANSMISSION FACTOR .DIFFUSE

$T R(3)=$ ABSORPTION FACTOR ODIRECT, OUTER

$T R(4)=$

$\operatorname{TR}(5)=$

$\operatorname{TR}(6)=$

COSINE OF INCIDENT ANGLE

$T R(8)=T Y P E$ OF GLASS

$T R(9)=I D$ CODE FOR THE GLAZING

ID $=1$ SINGLE GLAZING

ID $=2$ DOUBLE GLAZING

DO $10 \mathrm{~J}=1.6$

$A(1, J)=A 1(J)$

$A(2, J)=A 2(J)$

$A(3,7)=A 3(7)$

$A(4, J)=A 4(J)$

$A(5, J)=A 5(J)$

$A(6, J)=A G(J)$

$A(7, J)=A 7(J)$

$A(8, J)=A B(J)$ 
$T(1, j)=T I(J)$

$T(2, j)=T 5(J)$

$T(3, J)=T 3(J)$

$T(4, J)=T 4(\mathrm{~J})$

$T(5, J)=T 5(J)$

$T(6, J)=T 6(J)$

$T(7, J)=T 7(J)$

$T(8, J)=T 8(J)$

$A O(1, J)=A 01(J)$

$A O(2 \cdot J)=A 02(J)$

$A O(3, J)=A 03(J)$

$A O(4, J)=A O 4(J)$

$A O(5, J)=A O 5(J)$

$A O(6, J)=A 06(J)$

$A O(7, J)=A 07(J)$

$A O(8, J)=A O B(J)$

$\operatorname{AI}(1, J)=A I 1(J)$

$A I(2, J)=A I 2(J)$

AI $(3, J)=A I 3(J)$

$\operatorname{AI}(4, \mathrm{~J})=\operatorname{AI} 4(\mathrm{~J})$

$\operatorname{AI}(5, J)=\operatorname{AIS}(\mathrm{J})$

$A I(6, J)=A I G(J)$

$\operatorname{AI}(7, J)=A I 7(J)$

$A I(B, J)=A I B(J)$

$\operatorname{TD}(1, J)=T D 1(J)$

$\operatorname{TO}(2, J)=T D 2(J)$

$\operatorname{TD}(3, \mathrm{~J})=\operatorname{TD} 3(\mathrm{~J})$

$\operatorname{TO}(4, \mathrm{~J})=\operatorname{TD} 4(\mathrm{~J})$

$\operatorname{TD}(5, J)=\operatorname{TDS}(J)$

$\operatorname{TD}(6, J)=\operatorname{TD} 6(J)$

$\operatorname{TD}(7, J)=\operatorname{TD} 7(J)$

10

$T O(B, J)=T D 8(J)$

\section{ETA $=T R(7)$}

\section{$L=T R(8)$}

$I D=T R(9)$

IF (ID.EQ.2) GO TO 30

$T R(1)=T(L, 1)$

$T R(2)=T(L, 1) / 2$.

$\operatorname{TR}(3)=A(L, 1)$

$T R(4)=A(L, 1) / 2$.

DO $20 \mathrm{~J}=2.6$

$T R(1)=T R(1)+T(L, J) *(E T A * *(J-1))$

$T R(2)=T R(2)+T(L, J) /(J+1)$

20

$\operatorname{TR}(3)=\operatorname{TR}(3)+A(L, J) *(E T A *(J-1))$

$\operatorname{TR}(4)=T R(4)+A(L, J) /(J+1)$

$T R(5)=0$

$T R(6)=0$

GO TO 50

$30 \quad T R(1)=T D(L, 1)$

$T R(2)=T O(L, 1) / 2$.

$T R(3)=A O(L, 1)$

$T R(4)=A O(L, 1) / 2$.

$\operatorname{TR}(5)=A I(L, 1)$

$\operatorname{TR}(6)=A I(L, 1) / 2$.

DO $40 \mathrm{~J}=2,6$

$X=E T A * *(J-1)$

$T R(1)=T R(1)+T D(L \cdot J) * X$

$T R(2)=T R(2)+T D(L, J) /(J+1)$

$\operatorname{TR}(3)=\operatorname{TR}(3)+A O(L, J) * X$

$T R(4)=T R(4)+A O(L, J) /(J+1)$

$T R(5)=T R(5)+A I(L, J) * X$

$40 \quad \operatorname{TR}(6)=T R(6)+A I(L \cdot J) /(J+1)$ 
END

FUNCTION WBF (H०PB)

C THIS PROGRAM APPROXIMATES THE WET-BULB TEMPERATURE WHEN

C ENTHALPY IS GIVEN

IF $(P B-29.92) 10.30 .10$

$10 \quad Y=L O G(H)$

IF $(H . G T \cdot 11.758)$ GO TO 20

$W B F=0.6041+3.4841 * Y+1.3601 * Y * Y+0.97307 * Y * Y * Y$

GO TO 100

$20 \quad W B F=30.9185-39.68200 * Y+20.5841 * Y * Y-1.758 * Y * Y * Y$

GO TO 100

$30 W B 1=150$.

PV1 $=$ PVSF (WB1)

$W 1=0.622 * P V 1 /(P B-P V 1)$

$X 1=0.24 * W B 1+(1061+0.444 * W B 1) * W 1$

$Y_{1}=H-X_{1}$

$40 \quad W B 2=W B 1-1$

PV2 =PVSF (WB2)

$W 2=0.622 * P V 2 /(P B-P V 2)$

$X 2=0.24 * W B 2+(1061+0.444 * W B 2) * W 2$

$\mathrm{Y} 2=\mathrm{H}-\mathrm{X} 2$

IF $(Y 1 * Y 2) 90,60,50$

$50 W B 1=W B 2$

$Y_{1}=Y_{2}$

GO TO 40

60 IF (Y1) 80.70 .80

70 WBF $=W B 1$

GO TO 100

$80 \quad W B F=W B 2$

GO TO 100

$90 Z Z=A B S(Y 1 / Y 2)$

$W B F=(W B 2 * Z+W B 1) /(1+Z)$

100 RETURN

END

SUBROUTINE WF (QG,QX,QIS,LG,LX,LIS, QL)

C THIS ROUTINE TAKES HEAT GAINS TO HEAT LOSS BY WEIGHTING FACTOR

C QG=-HISTORY OF SOLAR HEAT GAIN

C QX-AHISTORY OF LONG WAVE LENGTH HEAT GAIN

C QIS--HISTORY OF LIGHTING POWER INPUT

REAL QG $(8), Q X(B), Q I S(B), L G(8), L X(8), L I S(8)$

REAL AG $(8) / 0.2060,-0.3989,0.2247,-0.0245,-0.0026,-0.0006,-0.000 ? 0-$

$10.0001 /$

REAL BG(8)/1.000,-2.4586.2.0078,-0.5447.0.0.0.0.10.1

REAL $A X(8) / 0.6258,-1.2492,0.7932,=0.1573,=0.0003,0, \cdots 0,0.1$

REAL $B X(8) / 1,000,-2.0676,1.3651,00.2837,0,0,00,0.1$

REAL AIS $(8) / 0.2902,00.1866,0,00,00,0,0 ., 0.1$

REAL BIS $(8) / 1.000,-0.8781,0,10,00,10,00,00 . /$

DIMENSION QZG (B), QZX $(8), Q Z I S(8)$

DO $10 \quad L=2,8$

$\theta Z G(L)=L G(L-1)$

$Q Z X(L)=L \times(L-1)$

$\operatorname{QZIS}(L)=L I S(L-1)$ 
DO $20 \quad L=2,8$

$L G(L)=Q Z G(L)$

$L X(L)=Q Z X(L)$

20

$\operatorname{LIS}(L)=Q Z I S(L)$

CONTINUE

SUMAG $=A G(1) * Q G(1)$

SUMBG $=0$.

SUMAX $=A X(1) * Q X(1)$

SUMBX $=0$.

SUMAIS $=A I S(1) * Q I S(1)$

SUMBIS $=0$.

DO $30 \quad L=2.8$

SUMAG $=$ SUMAG $+A G(L) * Q G(L)$

SUMBG $=S U M B G+B G(L) * L G(L)$

SUMAX $=$ SUMAX $+A X(L) * Q X(L)$

SUMBX $=$ SUMBX+BX $(L) * L X(L)$

SUMAIS = SUMAIS+AIS (L) *QIS (L)

30

SUMBIS=SUMBIS+BIS (L)*LIS (L)

CONTINUE

$L G(I)=S U M A G-S U M B G$

$L X(1)=$ SUMAX - SUMBX

LIS $(1)=$ SUMAIS - SUMBIS

$Q L=L G(1)+L X(1)+L I S(1)$

RETURN

END

SUBROUTINE ABCDPZ (Z,K,L,G,AP,BP,CP,DP)

REAL $K \cdot L$

$P I=4 . * A T A N(1$,

IF (G) $30,30,10$

$10 \quad P P=P I / 4 . / G$

IF (Z) $40,40,20$

20

$Z Q=S Q R T(Z / G)$

$Z Q L=2 Q * L$

$X=L * L * 0.5 / 6$

$R E S=L / K$

CO=SIN $(Z Q L)$

$C 1=\cos (Z Q L)$

$S 1=C O / Z Q L$

$S 2=(51-C 1) / Z Q L / Z Q L$

$A P=X * 51$

$B P=X * R E S * S 2$

$C P=X *(S 1+C 1) / R E S$

$D P=X * 51$

30

GO TO 50

$B P=0$.

$C P=0$.

$D P=0$.

GO TO 50

40 CONTINUE

$X=L * L * 0.5 / G$

$A P=X$

$S P=X * L / K / 3$

$C P=K / L * X *$ ? 。

$D P=X$

GO TO 50

50

RETURN

END 
SUBROUTINE RESFX $(X, Y, Z, X X, Y Y, Z Z, N R, C R, U T, N E X P)$

DIMENSION $X X(100,10), Y Y(100,10), Z Z(100,10), X(10,100), Y(10,100)$

DIMENSION $Z(10,100), N R(10), C R(10), U T(10)$

DO $10 \mathrm{~K}=1 \cdot 10$

DO $10 \quad J=1.100$

$X X(J, K)=0$

$Y Y(J, K)=0$

$10 \quad Z Z(J, K)=0$

CALL RESF (XX,YY,ZZ,IRUN)

DO $30 K=1$. NEXP

$I=K$

IF $(K, G T \cdot I R U N)$ GO TO 30

$X(I, 1)=X X(3, K)$

$Y(I, 1)=Y Y(3, K)$

$Z(I, I)=Z Z(3, K)$

$N R(I)=X X(1, K)$

$C R(I)=X X(2, K)$

JUJ $=N R(I)+3$

$U T(I)=X X(J J J \cdot K)$

$\operatorname{NMAX}=N R(I)$

DO $20 \mathrm{~J}=2$. NMAX

$J 3=J+2$

$J 2=J+1$

$X(I, J)=X X(J 3, K)-X X(J 2, K) * C R(I)$

$Y(I, J)=Y Y(J 3, K)=Y Y(J 2, K) * C R(I)$

$20 \quad Z(I, J)=Z Z(J 3, K)=Z Z(J 2, K) * C R(I)$

30 CONTINUE

RETURN

END 



\section{Appendix D}

Computer Program Used in Evaluation for the Experimental Building T. Kusuda and D. M. Burch

Thermal Engineering Systems Section, Building Environment Division Center for Building Technology, Institute for Applied Technology National Bureau of Standards, Washington, D.C. 20234 

C THIS PROGRAM CHECKS THE NBS INSIDEOUT HOUSE

C $X X, Y Y, Z Z$ ARE RESPONSE FACTORS CALCULATED BY RESPTK

C WHICH HAS BEEN DEVELOPED BY T. KUSUDA OF NBS

c

$X, Y, Z$ ARE AUGUMENTED RESPONSE FACTORS TO SHORTEN THE CALCULATION

A(1) AREA OF THE ROOF IN SQ.FT

A(2) AREA OF THE WALLS IN SQ. FT

$A(3)$ AREA OF THE FLOOR IN SQ. FT

A(4) AREA OF THE INTERNAL FURNISHINGS

CFM AIR LEAKAGE IN CU.FT. PER MINUTE

UD OVERALL HEAT TRANSFER COEFFICIENT OF THE DOOR

AD AREA OF THE DOOR IN SQ.FT.

UW OVERALL HEAT TRANSFER COEFFICIENT FOR WINDOWS

AW TOTAL WINDOW AREA SQ.FT.

TG GROUND TEMPERATURE IN F

TA ASSUMED INITIAL AIR TEMPERATURE AT TIME TERO IN $F$

PARAMETER $R=4, S=100, T=48, U=T+1, V=2 * T$

DIMENSION $X(R, S), Y(R, S), Z(R, S), X X(S, R), Y Y(S, R), Z Z(S, R), C R(R), Q(R)$,

$1 T O(S), T I(S), T O X(T), A(R), S U M(R), \operatorname{TOY}(S), T I M E(T), T I X(T), B(R)$

3001 DO $700 \quad k=1, R$

DO $700 \quad J=1 \cdot S$

$X X(J, K)=0$.

$Y Y(J, K)=0$.

$700 \quad Z Z(J, K)=0$.

CALL RESF(IRUN,XX,YY,ZZ,DEL)

DO 1 I $=1$. IRUN

$X(I, I)=X X(3, I)$

$Y(I, I)=Y Y(3, I)$

$Z(I, 1)=Z Z(3, I)$

$C R(I)=X X(2 . I)$

NMAX $=X X(1, I)$

DO $1 J=2$. NMAX

$J 3=J+2$

$\mathrm{J}=\mathrm{J}=\mathrm{J}+1$

$X(I, J)=X X(J 3, I)-X X(J 2, I) * C R(I)$

$Y(I, J)=Y Y(J 3, I)-Y Y(J 2, I) * C R(I)$

$1 \quad Z(I, J)=Z Z(J 3, I)-Z Z(J 2, I) * C R(I)$

603 WRITE $(6.605)$

100 FORMAT $(11 F 7.0)$

3000 READ $(5.100)$ RUN

WRITE $(6.8007)$ RUN

8007 FORMAT $(1 \mathrm{HI} \cdot$ RUN NO $=\cdot F 10.0)$

IF(RUN) $6000.6000,7000$

7000 DEN $=0$.

DO $102 \quad I=1, T$

$\operatorname{TIME}(I)=D E N$

$102 \quad D E N=D E N+D E L$

READ(5.101) (TOX (I), I $=1, T)$

READ(5,101) (TIX(I), I I I,T)

$R E A D(5,100)(A(I), I=1, R), C F M, U D, A D, U W, A W, T G, T A$

101 FORMAT (12F6.1)

WRITE $(6,4000)$

4000 FORMAT $(30$ HO OUTDOOR TEMPERATURE CYCLE WRITE $(6,609)(T O X(I), I=1, T)$

IF $(T I X(1)) 8001,8002,8001$

8001 WRITE $(6,8003)$

WRITE $(6,609) \quad(T I X(I), I=1, T)$

NTI $I=1$

8003 FORMAT( $1 \mathrm{HO}^{\circ}$ INSIDE AIR TEMPERATURE CYCLE')

609 FORMAT $(12 F 10.2)$

$8 \cap 02$ NTI $=0$ 


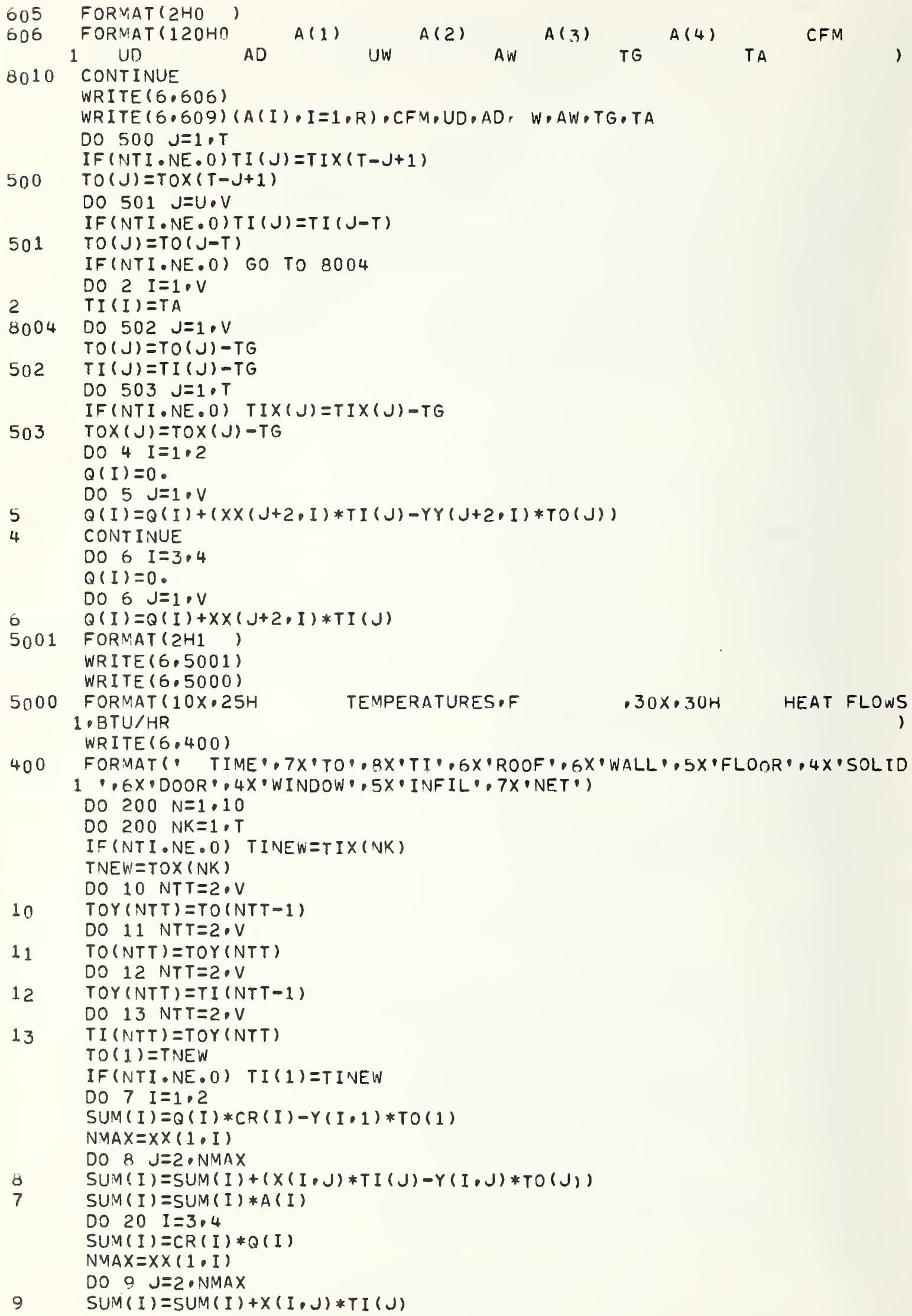




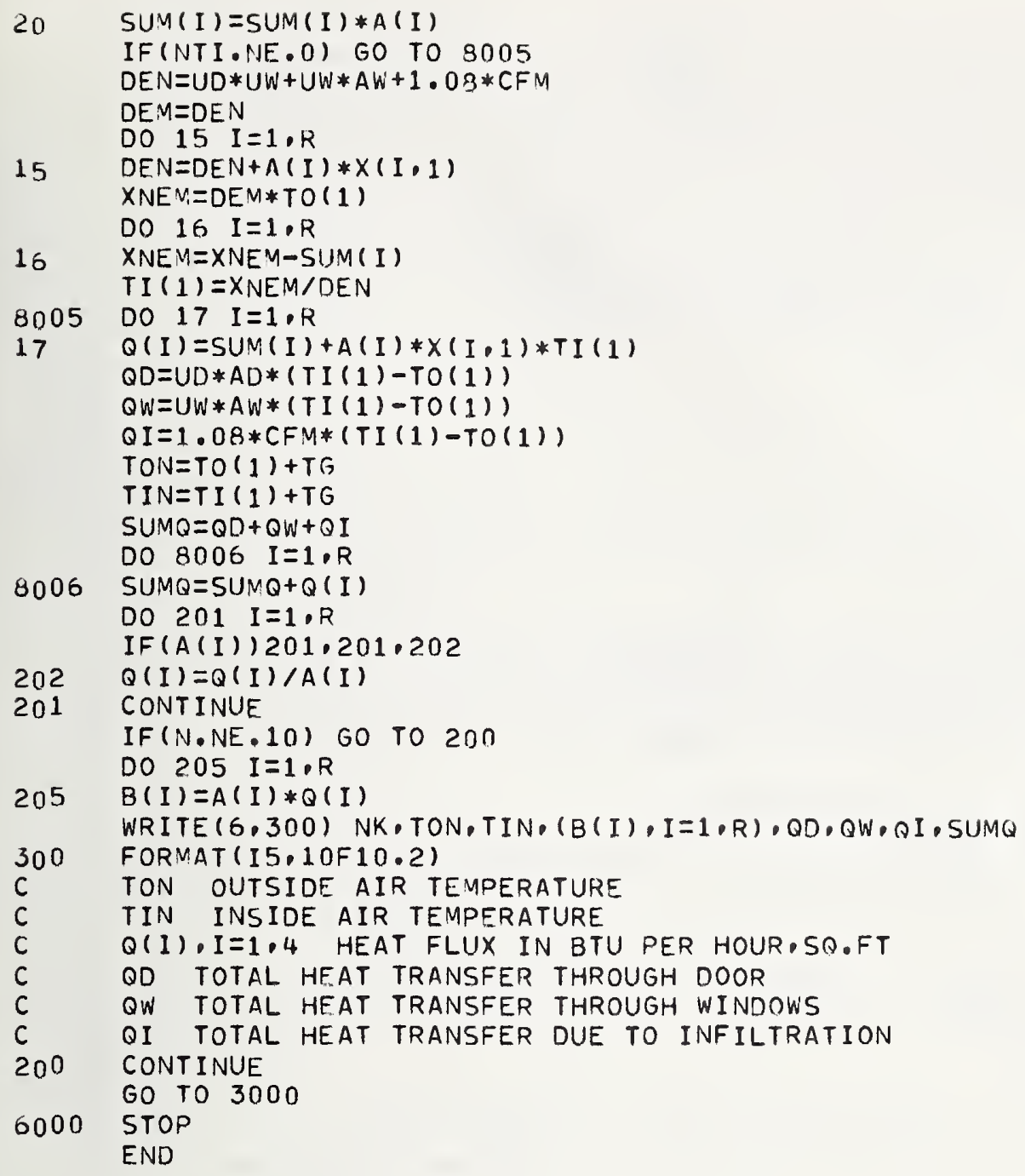


SUBROUTINE RESF (IRUN, XX,YY,ZZ,DELTAT)

C THIS PROGRAM IS DEVELOPED BY T.KUSUDA OF THE NATIONAL BUREAU OF

STANDARDS FOR CALCULTING THE THERMAL RESPONSE FACTORS FOR

COMPOSITE WALLS,FLOORS, ROOFS. BASEMENT WALLS BASEMENT FLOORS

AND INTERNAL FURNISHINGS OF SIMPLE SHAPES

RESPONSE FACTORS ARE USED IN THE FOLLOWING MANINER

$X, Y, Z$ ARE RESPONSE FACTORS

$Q I=X * T I-Y * T O * G M A$ INSIDE WHERE R IS MINIMUM

$Q O=Y * T I-Z * T O$ OUTSIDE WHERE $R$ IS MAXIMUM

TI INSIDE TEMPERARURE WHERE R IS MINIMUM

TO OUTSIDE TEMPERATURE WHERE $R$ IS MAXIMUM

K THERMAL CONDUCTIVITY

$G$ THERMAL DIFFUSIVITY

L THICKNESS

IM=0 OR BLANK PLANE WALL

IM=1 CYLINDRICAL WALL

IM=2 SPHERICAL WALL

IN=0 FINITE THICK WALL

IN $=1$ SEMI-FINITE WALL

IN $=2$ SOLID OBJECT

IF RESPONSE FACTORS OF THE SOLID CYLINDER OR SPHERE OF HOMOGEINEOUS PROPERTY ARE DESIRED. TREAT THE PROBLEM OF MULTILAYER BUT WITH THE IDENTICAL PROPERTIES FOR ALL THE LAYERS EXCEPT THE RADIUS

IF IHEAT $=0$ NO TEMPERATURE DATA THUS NO HEAT CALCULATION

IF IHEAT 1 PERIODIC BOUNDATRY CONDITIONS

400 FORMAT(2HO)

PARAMETER $S=100 \cdot T=10 \cdot U=T+1, T V=2 * T$

REAL $K(T), G(T), L(T), K G$

DIMENSION $X(S), Y(S), Z(S), C(T), D(T), R(U), R E S(T), R M K(T, T), R M K G(T)$, $I F(S), X X(S, T V), Y Y(S, T V), Z Z(S, T V)$

1 FORMAT (10I7)

2 FORMAT (10F7.0)

100 FORMAT $(14$ HO EXPOSURE NO= I10)

101 FORMAT(77HO LAYER L(I)

1) DESCRIPTION

$K(I)$

(I)

$C(I)$

RESI I

102 FORMATI 77 H NO

2 OF LAYERS

103 FORMAT ( $16 \cdot 1 \mathrm{~F} 11 \cdot 3 \cdot 1 \mathrm{~F} 10 \cdot 3 \cdot 1 \mathrm{~F} 10 \cdot 2 \cdot 1 \mathrm{~F} 10 \cdot 3 \cdot 1 \mathrm{~F} 8 \cdot 2 \cdot 2 \times \cdot 4 \mathrm{A6})$

104 FORMAT ( $58 \mathrm{HO}$

$3 U=1 F 7.3)$

105 FORMAT $149 \mathrm{HO}$

106 FORMAT $150 \mathrm{HO}$

107 FORMAT $1120 \mathrm{HO}$

1

THERMAL CONDUCTANCE

TIME INCREMENT DT $=1 F 3.1$,

RESPONSE FACTORS $x$

108 FORMAT (1I17.1F23.4.2F 15.4)

112 FORMAT (4A6)

117 FOR 1 AT $(44 \mathrm{HO}$

700 READ $(5.2)$ DELTAT

IRUN $=0$

300 READ $(5,1)$ NLAYR, NTEST, IM, IN

IF (NLAYR•EQ.0) GO TO 800

$I R U N=I R U N+1$

IF( ILAYR.GT.10) GO TO 600

NNLAYR=ALAYR+1

IF (NLAYR.EQ.0) GO TO 500

DO $200 \quad I=1$. NLAYR

$200 \operatorname{READ}(5 \cdot 2) \mathrm{L}(\mathrm{I}) \cdot \mathrm{K}(\mathrm{I}) \cdot D(I) \cdot C(I) \cdot \operatorname{RES}(I)$

IF (IN.EQ.2.AND.IM.EQ.0) GO TO 301

500 IF (IN.NE.0) READ $(5,2) K G, D G, C G$

$I F(I N, N E \cdot 0) \quad A G=K G / C G / D G$

IF (NLAYR・EQ.0) GO TO 501

IF $(I M \cdot E Q \cdot 0)$ GO TO 301 
$\operatorname{READ}(5,2)(R(I), I=1 \cdot N N L A Y R)$

GO TO 302

$301 R(1)=10$.

DO $303 I=2$. NNLAYR

$303 R(I)=R(I-1)+L(I)$

302 IF (IN.EQ.2. AND.IM.NE. O) READ $(5,112)(\operatorname{RMKG}(J), J=1,4)$

DO $113 \quad I=1$. NLAYR

$113 \operatorname{READ}(5,112)(\operatorname{RMK}(I, J), J=1,4)$

$\operatorname{IF}(I N \cdot E Q \cdot 1) \operatorname{READ}(5,112)(\operatorname{RMKG}(J), J=1,4)$

DO $109 \mathrm{I}=1$. NLAYR

IF (L (I) ) 110.111 .110

$111 G(I)=0$.

$K(I)=1 \cdot \operatorname{RES}(I)$

GO TO 109

$110 G(I)=K(I) / C$ (I) $/ D(I)$

109 CONTINUE

501 GMA $=(R(N N L A Y R) / R(1)) * * I M$

CALL RESPTK (K,L,R, G, AG,KG,X,Y,Z,NLAYR,DELTAT,NRT, CR,UT, IM, IN,F)

$X X(1 \cdot I R U N)=F L O A T(N R T)$

$Y Y(1, I R U N)=F L O A T(N R T)$

$Z Z(1, I R U N)=F L O A T(N R T)$

$X X(2, I R U N)=C R$

$Y Y(2, I R U N)=C R$

$Z Z(2 \cdot I R U N)=C R$

$X X(N R T+3, I R U N)=U T$

$Y Y(N R T+3 \cdot I R U N)=U T$

$Z Z(N R T+3 \cdot I R U N)=U T$

WRITE $(6.100)$ IRUN

IF (IM.EQ.0) WRITE $(6.701)$

701 FORMAT $(50 H 0$ PLANE WALL

IF (IM.EQ.1) WRITE $(6.702)$

702. FORMAT (5OHO CYLINDRICAL WALL

IF (IM.EQ.2) WRITE $(6.703)$

703 FORMAT $(50 H O$ SPHERICAL WALL

WRITE $(6.101)$

WRITE $(6.102)$

WRITE $(6.400)$

IF (NLAYR,EQ.0) GO TO 502

IF (IN.EQ.2. AND.IM.NE.0)WRITE $(6,120) K G, D G, C G,(R M K G(J), J=1,4)$

DO $202 I=1$, NLAYR

IF (L(I)) 202.203 .202

$203 K(I)=0$.

202 WRITE (6,103) I,L(I),K(I),D(I),C(I),RES(I), (RMK (I,J),J=1,4)

IF (IN.EQ.1)WRITE $(6,120) K G, D G, C G,(R M K G(J), J=1,4)$

120 FORMAT (1F27.3.1F10.2,1F10.3.10X,4A6)

502 CONTINUE

IF (IN.NE.0) GO TO 1535

DO $114 \mathrm{~N}=1$. NRT

$J N=N-1$

$X X(N+2, I R U N)=X(N)$

$Y Y(N+2, I R U N)=Y(N)$

$Z Z(N+2, I R U N)=Z(N)$

114 CONTINUE

GO TO 504

1535 CONTINUE

555 FORMAT (5OHO

IF (IN.EQ.1) GO TO 9999

GO TO 9998

9999 SIGIV=1.0

GO TO 505

Y998 IF(IN.EQ.2.AND.IM.EQ.0) GO TO 9997 
GO TO 9996

9997 SIGN $=-1.0$

GO TO 505

9996 CONTINUE

DO $506 \mathrm{~N}=1$, NRT

$J N=N-1$

$X(N)=-X(N)$

$X X(N+2, I R U N)=X(N)$

506 CONTINUE

GO TO 504

505 DO $509 \quad N=1$,NRT

$X X(N+2, I R U N)=S I G N * F(N)$ $J N=N-1$

509 CONTINUE

508 FORMAT (1124, 1F21.5)

504 CONTINUE GO TO 300

600 CONTINUE

800 RETURN

END 
SUBROUTINE RESPTK $(K, L, R, G, A G, K G, X, Y, Z, N L, D T, N R, C R, U, I M, I S, F)$

C CALCULATES RESPONSE FACTORS BY MAKING USE OF THICKNESS, THERYAL

C CONDUCTIVITY, DENSITY. AND SPECIFIC HEAT OF EACH LAYER OF

C COMPOSITE WALL

DIMENSION $K(10), L(10), R(10), G(10), X(100), Y(100), 2(100), A P(10) \cdot B P(1$

$10), C P(10), D P(10), A(10), B(10), C(10), D(10), Z R 1(3), Z R 2(3), R B(3), R A P(3$

2) $\operatorname{ROOT}(100), R A(3,100), Z R K(3,100), R X(100), R Y(100), A Z(100)$

3. $F(100)$

REAL K०L,KG

$P I=3.1415927$

$M 3=3$

IF (IS.EQ.2.AND.IM.NE. 0$) \quad M 3=1$

IF (IS.NE.1) GO TO 613

$608 Z L=K G / R(N L+1)$

$U Y=R(N L+1) * * 2 / A G / D T$

CALL GPF (UY,ZL,IM,AZ )

IF (IS.EQ.1.AND.NL.EQ.0) GO TO 901

613 CALL $A B C D 2(0, . K, L, R, G, A X, B X, C X, D X, I M, N L)$

$R B(1)=D X$

$R B(2)=1$.

$R B(3)=A X$

$U=1 \cdot / B X$

DO $1 \quad I=1 \cdot N L$

$P X=0$

CALL ABCDP2 (PX,K(I),L(I),R(I),G(I),AP(I),BP(I),CP(I),DP(I),IM)

$1 C A L L \quad A B C D 2(P X, K(I), L(I), R(I), G(I), A(I), B(I), C(I), D(I), I M, 1)$

IF (NL.LT.2) GO TO 502

CALL DERVT $(A, B, C, D, A P, B P, C P, D P, A P P, B P P, C P P, D P P, N L)$

GO TO 503

$502 A P P=A P(1)$

$B P P=B P(1)$

$C P P=C P(1)$

$D P P=D P(1)$

503 IF (IS.NE.2) GO TO 501

IF (IM.EQ.0) GO TO 501

CALL SOLID (0.,R (1),KG,AG,IM,HF,HFP)

$Z R 1(1)=(-C P P+H F P * A X) / D X / D T$

$Z R 2(1)=-Z R 1(1)$

1400 FORMAT $(4 F 20.5)$

GO TO 1212

$501 \operatorname{RAP}(1)=0 P P$

$\operatorname{RAP}(2)=0$.

$\operatorname{RAP}(3)=A P P$

DO $2 I=1.3$

$C_{1}=R A P(I) / B X / D T$

$C 2=R B(I) * B P P / B X / B X / D T$

$Z R 2(I)=-C 1+C 2$

$2 Z R 1(I)=-Z R 2(I)+R B(I) / B X$

1212 CONT INUE

100 FORMAT $(3 F 20.6)$

C ROOTS OF $B(P)=0$.

212 NMAX $=40$

IF (IS.EQ.2.AND.IM.NE.0) NMAX $=100$

$P X=0.001$

$D P O=0.1 / D T$

IF (IS.EQ.2. AND.IM.NE. 0) DPO=3.1416*3.1416*AG/R( 1$) / R(1) * 0.25$

DLX $=0.0001$

IF (IS.EQ.2.AND.IM.NE.0) DLX $=D P O / 1000$ 
$N=0$

$11 D L=D P O$

$C A L L \quad A B C D 2(P X, K, L, R, G, A X, B X, C X, D X, I M, N L)$

IF (IS.EQ.2.AND.IM,NE.0) CALL SOLDX $(P X, R(1), K G, A G, I M, B X, D X, T E S T 1)$

$15 P X P=P X+D L$

$C A L L A B C D 2(P X P, K, L, R, G, A X P, B X P, C X P, D X P, I M, N L)$

IF (IS.NE.2) GO TO 213

IF (IM.EQ.0) GO TO 213

CALL SOLDX (PXP,R(1),KG,AG,IM, BXP,DXP,TEST2)

IF(TEST1*TEST2) $112,113.114$

114 PX $=P X P$

TEST $1=$ TEST2

GO TO 15

$112 \operatorname{IF}(D L-D L X) \quad 130 \cdot 130 \cdot 117$

$117 \mathrm{DL}=\mathrm{DL} / 2$.

GO. TO 15

113 IF (TEST1) $118,119,118$

119 RXX $=P X$

GO TO 31

118 RXX $=P X P$

GO TO 31

$130 \quad A B=A B S(T E S T 1 / T E S T 2)$

$R X X=(P X+A B * P X P) /(1+A B)$

GO TO 31

213 IF $(B X * B X P) \quad 12,13 \cdot 14$

$14 P X=P X P$

$B X=B X P$

TEST $X=P X * D T$

IF (TESTX -100.1$) 15.43 .43$

12 IF $(D L-D L X) 30 \cdot 30 \cdot 17$

$17 \mathrm{DL}=\mathrm{DL} / 2$.

GO TO 15

$13 \operatorname{IF}(B X) 18 \cdot 19 \cdot 18$

$19 \mathrm{RXX}=\mathrm{PX}$

GO TO 31

$18 R X X=P X P$

GO TO 31

$30 \quad A B=A B S(B X / B X P)$

$R X X=(P X+A B * P X P) /(1 \bullet+A B)$

$31 N=N+1$

$\operatorname{ROOT}(N)=R \times X$

$\operatorname{IF}(N, G T \cdot 1) \quad D P O=R O O T(N)-R O O T(N-1)$

$N R T=N$

41 FORMAT $(110.1720 .6)$

$P X=R X X+O L X$

TESTMX $=40$

TEST $X=R X X * D T$

IF (TESTX-TESTMX) 42.42 .43

42 IF (N.LT.NMAX) GO TO 11

43 CONT INUE

DO 600 JJ $=1$.NRT

$P X=R O O T(J J)$

DO $51 \mathrm{~J}=1$. NL

CALL $A B C D 2(P X, K(J), L(J), R(J), G(J), A(J), R(J), C(J), D(J),[M, 1)$

$51 C A L L A B C D P 2(P X, K(J), L(J), R(J), G(J), A P(J), B P(J), C P(J), D P(J), I M)$

$C A L L \quad A B C D 2(P X, K, L, R, G, A X, B X, C X, D X, I M, N L)$

IF (NL.LT.2) GO TO 504

$C A L L D E R V T(A, B, C, D, A P, B P, C P, D P, A P P, B P P, C P P, D P P, N L)$ 
GO TO 505

$504 \quad A P P=A P(1)$

$B P P=B P(1)$

$C P P=C P(1)$

$D P P=D P(1)$

505 IF(IS.NE.2) GO TO 214

IF $(I M \cdot E Q, 0)$ GO TO 214

CALL SOLID $(P X, R(1), K G, A G, I M, H F, H F P)$

IF (HF) 401.400 .401

401 PYS $=(H F * A X-C X) / P X / P X /(D P P-H F P * B X-H F * B P P) / D T$

GO TO 402

400 PYS $=0$.

402 RA $(1 \cdot J J)=P Y S$

GO TO 601

$214 P Y=B P P * P X * P X * D T$

$R A(1, J J)=D X / P Y$

$R A(2 \cdot J J)=1 \cdot / P Y$

$R A(3, J J)=A X / P Y$

$601 P Z=P X * D T$

IF (PZ.LT.40.) GO TO 52

$R \times(J J)=0.0$

$R Y(J J)=1 \cdot 0 E 30$

GO TO 600

$52 \operatorname{RX}(J J)=\operatorname{EXP}(-P Z)$

$5 R Y(J J)=(1,-E X P(P Z)) * * 2$

600 CONT INUE

54 FORMAT $(4 F 20.6)$

DO $154 \mathrm{JJ}=1$, NRT

DO $154 M=1, M 3$

$Z R 1(M)=R A(M, J J) * R X(J J)+Z R 1(M)$

$154 \quad Z R 2(M)=R A(M \cdot J J) * R \times(J J) *(R \times(J J)-2 \cdot)+Z R 2(M)$

$I I=1$

I I I $=2$

80 FORMAT(5OHO RESPONSE FACTORS OF FINITE SLAB

81 FORMAT(12OHO $J$ X J J

1 Z(J)

701 FORMAT $120 \mathrm{H} 1$ RESPONSE FACTORS FOR SOLID CYLINDRICAL ORJECTS

1

702 FORMAT $(120 H 1$ RESPONSE FACTORS FOR SOLID SPHERICAL ORJECTS

1

$\operatorname{IF}(Z R 1(2) \cdot L T \cdot 0) \quad Z R 1(2)=0$.

DO $67 M=1, M 3$

$\operatorname{ZRK}(M, 1)=Z R 1(M)$

$67 \operatorname{ZRK}\left(M_{0} 2\right)=Z R 2(M)$

55 FORMAT (I 10.3F20.6)

NT $=100$

DO $58 \mathrm{~N}=3$. NT

$N R=N$

DO $61 M=1 \cdot M 3$

$61 \operatorname{ZRK}(M \cdot N)=0$.

DO $57 \quad M=1.43$

DO $57 \mathrm{JJ}=1, \mathrm{NRT}$

$P Z=(R \times(J J)) * * N$

$57 Z R K(M, N)=Z R K(M, N)+P Z * R Y(J J) * R A(M, J J)$

IF (N.LT.5) GO TO 58

TEST $1=Z R K(1 \cdot N) / Z R K(1 \cdot N-1)$

TEST2 $=Z R K(1, N-1) / Z R K(1, N-2)$

TEST3 =ABS ( TEST $1-$ TEST2) 


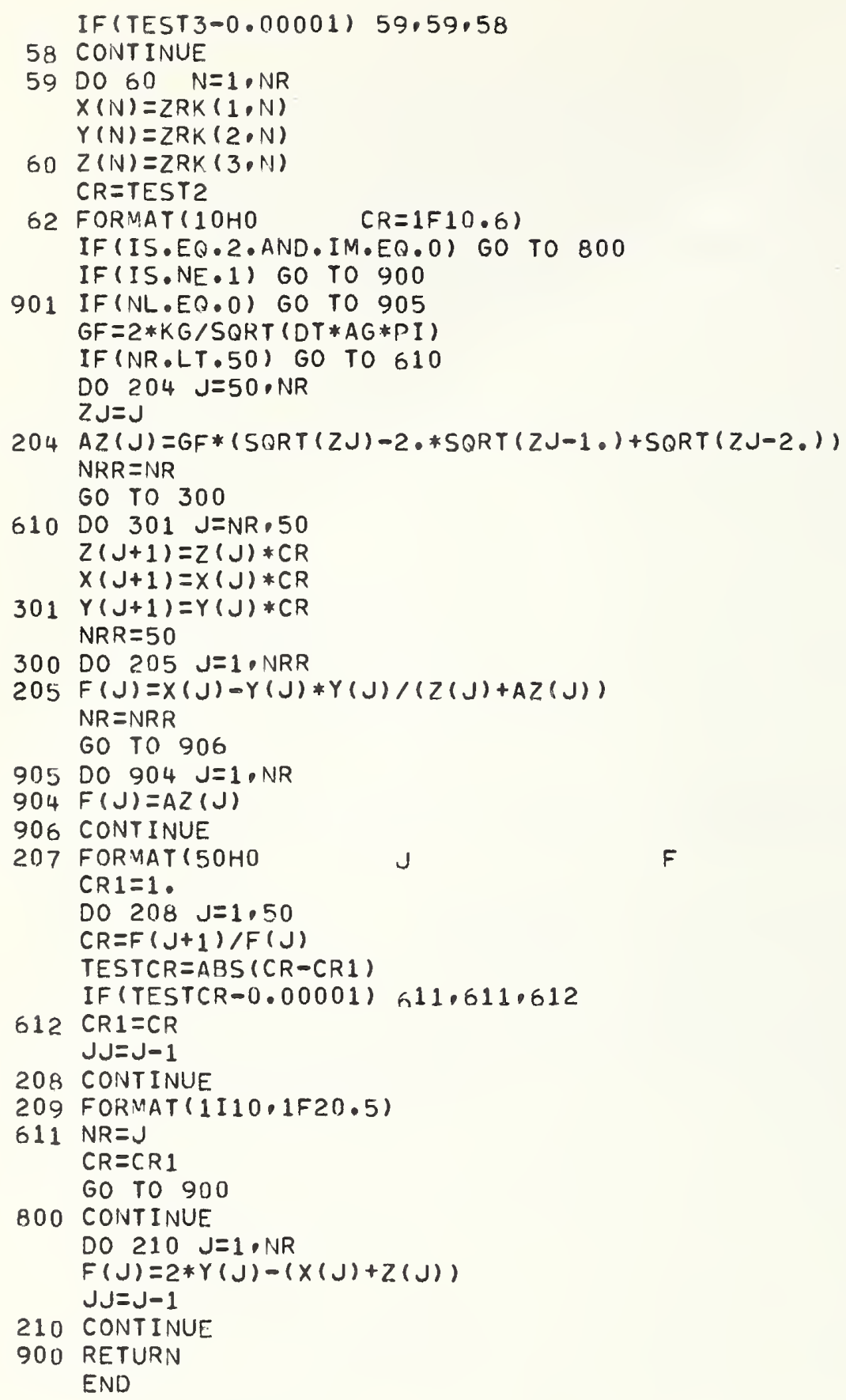


SUBROUTINE DERVT ( $, A, C, D, A P, B P, C P, D P, A P P, B P P, C P P, D P P, N)$ COMPUTES DERIVATIVE OF MATRIX ELEMENTS FOR PLANE LAYER

DIMENSION $A(N), B(N), C(N), D(N), A P(N), B P(N), C P(N), D P(N), A T(10), H T(10$ $1), C T(10), D T(10), A T T(10), B T T(10), C T T(10), D T T(10)$

DO $1 \quad I=1 \cdot N$

DO $2 J=1, N$

IF (I.EQ.J) GO TO 3

$A T(J)=A(J)$

$B T(J)=B(J)$

$\operatorname{CT}(J)=C(J)$

$\operatorname{DT}(J)=D(J)$

GO TO 2

$3 \operatorname{AT}(J)=A P(J)$

$B T(J)=B P(J)$

$C T(J)=C P(J)$

$\operatorname{DT}(J)=D P(J)$

2 CONTINUE

1 CALL MULT(AT,BT,CT,DT,ATT(I),BTT(I),CTT(I), OTT(I),N)

$A P P=A T T(1)$

$B P P=B T T(1)$

$C P P=C T T(1)$

DPP $=D T T(1)$

DO $4 \quad I=2, N$

$A P P=A P P+A T T(I)$

$B P P=B P P+B T T(I)$

$C P P=C P P+C T T(I)$

$4 D P P=D P P+D T T(I)$

RETURN

END

SUBROUTINE ABCD2 $(Z, K, L, R, G, A, B, C, D, I M, N L)$

C COMPUTES MATRIX ELEMENT FOR MULTI-LAYER PLANE AS SHOWN IN TABLE I

C OF KUSUDA'S PAPER

DIMENSION $A X(10), B X(10), C X(10), D X(10), R(10), G(10)$

DOUBLE PRECISION DBEJ,DBEY,ZQ1,ZQ2

REAL $K(10), L(10), J 01, J 02, J 11, J 12$

$P I=3.1415927$

$P P=P I * 0.5$

$I F(N L \cdot L T \cdot 2) \quad R(2)=R(1)+L(1)$

DO $4 \mathrm{I}=1 \cdot \mathrm{NL}$

IF (G(I)) $103 \cdot 103,102$

102 IF (Z) $1,1,101$

$101 Z Q=S Q R T(Z / G(I))$

$Z Q 1=Z Q * R(I)$

$Z Q 2=Z Q * R(I+1)$

$Z Q L=Z Q * L(I)$

IF (IM.NE.1) GO TO 3

$J 01=\operatorname{DBEJ}(Z Q 1,0)$

$J 11=\operatorname{DBE} J(Z Q 1,1)$

$J 02=D B E J(Z Q 2,0)$

$J 12=D B E J(Z Q 2,1)$ 


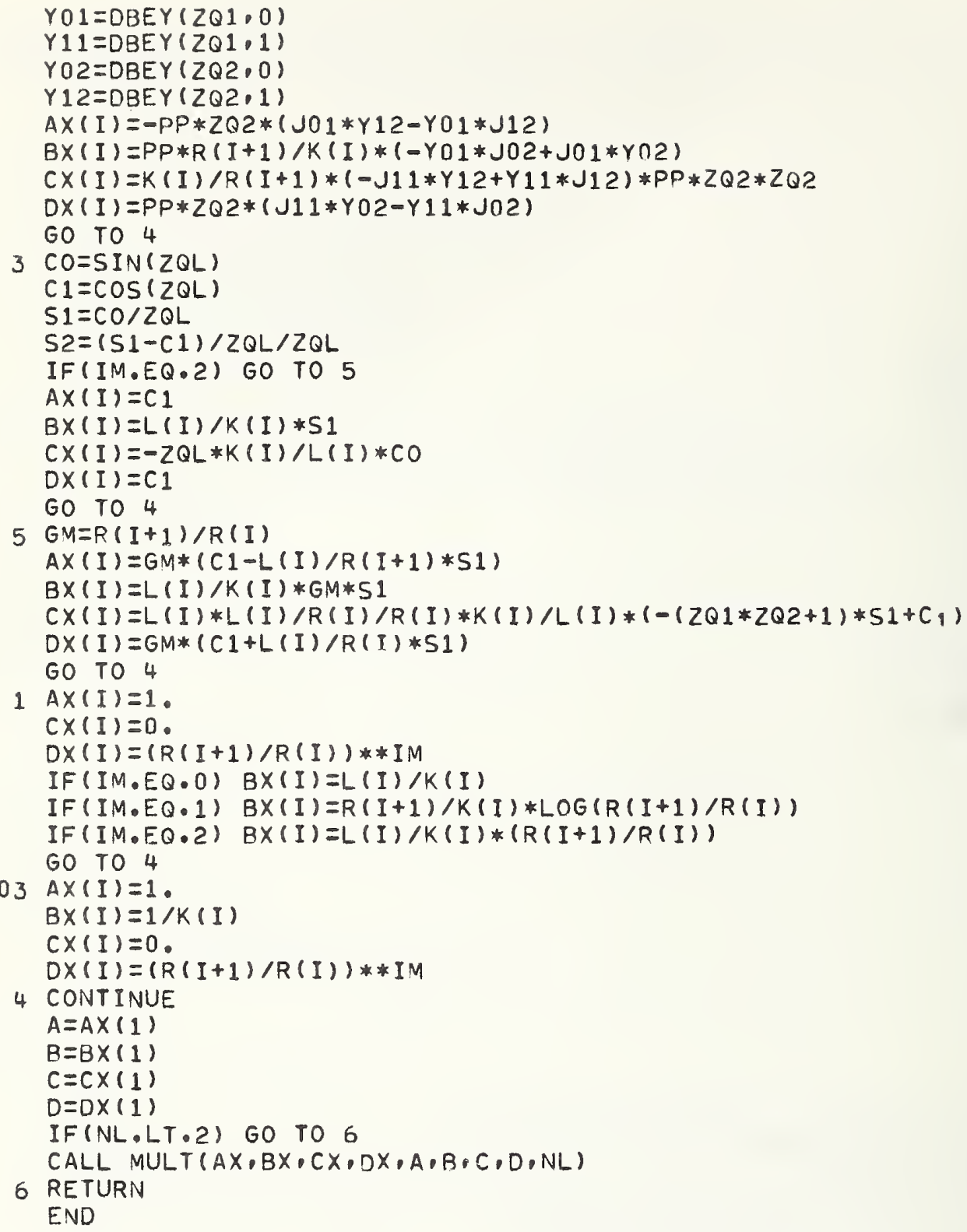


SUBROUTINE ABCDP2 $(Z, K, L, R, G, A P, B P, C P, D P, I M)$

C COMPUTES MATRIX ELEMENT FOR SINGLE-LAYER PLANE AS SHOWN IN TABLE I

C OF KUSUDA'S PAPER

DOUBLE PRECISION ZQ1,ZQ2,DBEJ,DBEY

REAL K,L,J01,J02,J11,J12

$P I=3.1415927$

IF (G) $103,103,104$

104 PP=PI/4./G

IF (Z) 101.101 .105

$105 Z Q=S Q R T(Z / G)$

$Z Q L=Z Q * L$

$Z Q 1=Z Q * R$

$Z Q 2=Z Q 1+Z Q L$

IF (IM.NE.1) GO TO 3

$X=R *(R+L)$

$Y=(R+L) * * 2$

$Z 1=(R+L) / K$

$J 01=D B E J(Z Q 1,0)$

$J 02=D B E J(Z Q 2,0)$

$J 11=D B E J(Z Q 1,1)$

$J 12=D B E J(Z Q 2,1)$

$Y 01=D B E Y(Z Q 1,0)$

$Y 02=D B E Y(Z Q 2,0)$

$Y 11=\operatorname{DBE} Y(Z Q 1,1)$

$Y 12=\operatorname{DBE} Y(Z Q 2,1)$

$A P=(-X *(J 11 * Y 12-Y 11 * J 12)+Y *(J 01 * Y 02-Y 01 * J 02)) * P P$

$B P=(X *(J 11 * Y 02-Y 11 * J 02) * Z 1 / Z Q 2+Y *(J 01 * Y 12-Y 01 * J 12) * Z 1 / 7 Q 2) * P P$

$C P=P P * Z Q 2 / Z 1 *(X *(J 01 * Y 12-Y 01 * J 12)+Y *(J 11 * Y 02-Y 11 * J 02))$

$D P=(X *(-J 01 * Y 02+Y 01 * J 02)-Y *(-J 11 * Y 12+Y 11 * J 12)) * P P$

GO TO 4

$3 X=L * L * 0,5 / G$

$R 1=R+L$

RES $=L / K$

CO $=S I N(Z Q L)$

$C 1=\cos (Z Q L)$

$\mathrm{S} 1=\mathrm{CO} / \mathrm{ZQL}$

$S 2=(S 1-C 1) / Z Q L / Z Q L$

IF (IM.EQ.0) GO TO 5

$A P=X *(R 1 * S 1 / R-L * S 2 / R)$

$B P=R E S * X * R 1 * S 2 / R$

$Z P 1=Z Q 1$

$Z P 2=Z Q 2$

$C P=X *(L / R) * * 2 / R E S *((2 * * R * R 1 / L / L+1) * S 1-(Z P 1 * 7 P 2+1) * S 2$.

$D P=X *(R 1 / R * S 1+(L / R) *(R 1 / R) * S 2)$

GO TO 4

$5 \quad A P=X * S 1$

$B P=X * R E S * S 2$

$C P=X *(S 1+C 1) / R E S$

$\mathrm{DP}=\mathrm{X} * \mathrm{S1}$

GO TO 4

103 AP $=0$.

$B P=0$.

$C P=0$.

$D P=0$.

GO TO 4

101 IF (IM.NE. 0) GO TO 6

$X=L * L * 0.5 / G$

$A P=X$

$B P=X * L / K / 3$

$C P=K / L * X * 2$.

$\mathrm{DP}=\mathrm{X}$

GO TO 4 
6 IF (IM.NE. 1) GO TO 7

$R 1=R+L$

$A P=(0.5 *(R * R-R 1 * R 1)+R 1 * R 1 * \operatorname{LOG}(R 1 / R)) * 0.5 / G$

$B P=R 1 / 4 / G / K *((R 1 * R 1+R * R) * L O G(R 1 / R)-(R 1 * R 1-R * R))$

$C P=K / R * 0 \cdot 5 / G *(R 1 * R 1-R * R)$

$D P=0.5 / G *(0.5 *(R 1 * R 1-R * R) * R 1 / R-R * R 1 * \operatorname{LOG}(R 1 / R))$

GO TO 4

$7 X=L * L * 0.5 / G$

$R 1=R+L$

$A P=X / 3 * *(2 * R 1 / R+1 \cdot)$

$B P=L / K * R 1 / R * X / 3$.

$C P=K / L * X * L / R * L / R *(2 . * R * R 1 / L / L+0.666667)$

$D P=X / 3 \cdot * R 1 / R *(R 1 / R+2)$

4 RETURN

END

SUBROUTINE MULT $(A, B, C, D, A T, B T, C T, D T, N)$

ROUTINE TO PERFORM MATRIX MULTIPLICATION

DIMENSION $A(N), B(N), C(N), D(N)$

$A T T=A(1)$

$B T T=B(1)$

$C T T=C(1)$

DTT $=D(1)$

IF $(N \cdot L T \cdot 2)$ GO TO 3

DO $1 J=2 \cdot N$

$A T=A T T * A(J)+B T T * C(J)$

$B T=A T T * B(J)+B T T * D(J)$

$C T=C T T * A(J)+D T T * C(J)$

$D T=C T T * B(J)+D T T * D(J)$

ATT $=A T$

$B T T=B T$

$C T T=C T$

1 DTT $=D T$

GO TO 4

$3 A T=A T T$

$B T=B T T$

$C T=C T T$

$D T=D T T$

4 RETURN

END 
COMPUTES RESPONSE FACTORS FOR SOLID MATERIAL

REAL KG.JO1.J11

DOUBLE PRECISION DBEJ.ZQD

$Z Q=S Q R T(Z / A G)$

$Z Q 1=Z Q * R 1$

$Z Q D=Z Q 1$

$Z A=R 1 * R 1 / A G$

CON $=K G / R 1$

IF (Z) $2,1,2$

2 IF (IM.NE.1) GO TO 100

J01 $=0 B E J(Z Q D, 0)$

$T X=A B S(J 01)$

IF $(T X-0.00001) 4 \cdot 4 \cdot 5$

$5 J 11=D B E J(Z Q D \cdot 1)$

$H F=C O N * Z Q 1 * J 11 / J 01$

HF $1=J 11 / J 01 / Z Q 1$

HF2 $=(J 01 * J 01+J 11 * J 11-J 01 * J 11 / Z Q 1) / J 01 / J 01$

HFP $=-C O N * 0 \cdot 5 * Z A *(H F 1+H F 2)$

GO TO 300

$100 \quad C=\cos (Z Q 1)$

$S=5 I N(Z Q 1) / Z Q 1$

$T X=A B S(S I N(Z Q 1))$

IF $(T X-0.00001) 4.4 \cdot 3$

$3 \mathrm{HF}=-\mathrm{CON} *(\mathrm{C} / \mathrm{S}-1)$

$H F P=-C O N * 0.5 * Z A *(1+C *(C-S) / S / S / Z Q 1 / Z Q 1)$

GO TO 300

$1 H F=0$.

IF $(I M, E Q \cdot 2) \quad H F P=-C O N * Z A / 3$.

IF (I $M, E Q \cdot 1) \quad H F P=-0.5 * C O N * Z A$

GO TO 300

$4 \mathrm{HF}=0$.

$H F P=0$.

300 RETURN

END 
DOUBLE PRECISION DBEJ.DBEY,ZQ

$P I=3.1415927$

SQTPI $=S Q R T(P I)$

$P I 2=2 . / P I$

$E B=0.001$

$\mathrm{DB}=0.1$

$Z(1)=2 * Z L * S Q R T(U) / S Q T P I$

$z z=z(1)$

$Z(2)=Z(1) *(S Q R T(2 \cdot)-2 \cdot)$

DO $2 K=3.50$

$Z K=K$

$2 Z(K)=Z(1) *(S Q R T(Z K)-2 \cdot * S Q R T(Z K-1)+S Q R T(Z K-2)$.

IF (IM.EQ.0) GO TO 70

IF (IM.EQ.1) GO TO 1

$Z(1)=Z(1)+Z L$

GO TO 70

$1 X=P I 2 * \operatorname{LOG}(0.5 * E B)+0.36746691$

SUN=PI*0.5*(ATAN $(X)+0.5 * P I)$

$I X=0$

$B=E B-D B$

DO $17 \mathrm{~L}=1,5000$

$B=B+D B$

$82 Q=B$

IF (IX.EQ.10) GO TO 30

$Z J O=D B E J(Z Q \cdot 0)$

$Z Y O=D B E Y(Z Q \cdot 0)$

TESTX $=Z J O * Z J O+Z Y O * Z Y O$

TESTY $=P I 2 / B$

TESTZ =ABS (TESTX - TESTY)

IF (TESTZ $=0.00001) \quad 30.30 .31$

$31 Z Z=B * B * B * T E S T X$

GO TO 32

$30 \quad Z Z=B * B * P I 2$

$I X=10$

$32 Z T(L)=1.1 Z Z$

$L T=L$

TEST $=A B S(2 T(L)) * 10$

IF (TEST -0.0001$) 11.11 .17$

17 CONTINUE

$11 L T Y=L T / 2$

$L T X=L T Y * 2-1$

$B M A X=E B+(L T X-1) * D B$

$B B=1$. / $B M A X$

$Z J=1 . / U$

SUT $=S U N * Z J$

$B=E B-D B$

$D O 28 L=1, L T$

$B=B+D B$

$2 B=B * B * Z J$

$62 P=E \times P(-Z B)$

$29 Z S(L)=(1 .-2 P) * Z T(L)$

CALL SIMS (2S,DB , SUM,LTX)

$G K=(S U M+S U T) * P I 2+B R$

$G G=G K * P I 2$

$Z(1)=G G * Z L * U$

70 CONTINUE

RETURN

END 
SUBROUTINE SOLDX $(Z, R 1, K G, A G, I M, B, D, T E S T)$

C DUMMY SUBROUTINE

END

SUBROUTINE DBEJ $(X, I)$

C DUMMY SUBROUTINE

END

SUBROUTINE DBEY $(X, I)$

C DUMUY SUBROUTINE

END

SUBROUTINE SIMS $(X, Y, Z, L)$

C DUMMY SUBROUTINE

END 


\section{Appendix E}

\section{Input and Output for the Response Factor Program}

The Response Factor Program (Appendix D) analyzes the thermal performance of the inside space of the experimental building under a prescribed outdoor air temperature cycle. When the inside air temperature is thermostated, this program calculates the rate of heat loss from the building at prescribed time intervals. If the inside building air temperature is not controlled and floats in response to the outdoor air temperature cycle, the program then calculates time dependent variations of the inside building air temperature. Table E-1 contains a sample set of data input.

A description of the data input is given below:

\section{Card Sequence}

1 Time increment of the temperature data in hours

2 Number of roof layers (includes the thermal resistances of the inside and outside surfaces)

3 Thermal resistance at inside surface of roof

4. Thickness, thermal conductivity, density, and specific heat of roof

5 Thermal resistance at outside surface of roof

6 Description of the inside surface of the roof

7 Description of roof

8 Description of the outside surface of roof

9 Number of wall layers

10 Thermal resistance at inside surface of wall

11 Thickness, thermal conductivity, density, and specific heat of wall

12 Thermal resistance of the outside surface of wall

13 Description of the inside surface of wall

14 Description of wall

15 Description of the outside surface of wall

16 Number of layers of the floor and the semiinfinite layer index (if basement floor)

17 Thermal resistance at inside surface of floor

18 Thickness, thermal conductivity, density, and specific heat of the first solid layer of the floor counted from the inside surface

19 Thickness, thermal conductivity, density, and specific heat of the second solid layer

20 Thermal conductivity, density, and specific heat of the earth

21 Description of the inside surface of floor

22 Description of the first solid layer

23 Description of the second solid layer

24 Description of the semi-infinite earth layer

25 Number of layers for inner mass

26 Thermal resistance at the outside surface of the interior mass

27 Thickness, density, specific heat, and thermal conductivity of the internal mass

28 Thermal resistance at the other outside surface of internal mass

29 Description of the outside surface of interior mass

30 Description of the interior mass
31 Description of the other outside surface of interior mass

32 Blank card (necessary to show end of above data)

33 Run No. card

34-37 Outside air temperatures

38-41 Inside air temperatures

42 Roof area, wall area, floor area, inner mass surface area, air flow (ventilation by air leakage), conductance of door, door area, conductance of window, window area, ground temperature, average inside air temperature.

Components possessing significant heat capacity (such as walls, roof, etc.) are described in cards 2 through 31 , while components having negligible heat capacity are described on card 42. Some various options available in the Response Factor program are discussed below.

Additional layers can be readily handled. For example, if the roof contains a second layer, then the number of layers given in card 2 would be in. creased to four. Also, a card giving the thermal and physical properties of this additional layer and a card giving a description of this layer would be inserted in proper sequence (from inside to outside). Additional layers in any component would be handled in a similar manner. If the additional layer is an air insulating layer, then only an average value of the thermal resistance of the air layer would be specified on the card giving layer properties. Another option is a floor which has no semi-infinite layer (such as the floor of a room of a multistory building). This case may be handled by omitting the semi-infinite layer index on card 16 and removing the card giving the properties of the earth and the card giving the layer description of the earth. Another option is the case of a building without a component (such as a building without windows). This case is handled by setting the area of that component (given on card 42) equal to zero. And finally, the option for determination of the inside building air temperature (floating test) is handled by inserting four blank cards for the inside air temperature (cards 38 through 41 ).

The computer printout for tests 6,7 , and 10 are found in tables E-2, E-3, and E-4, respectively. The first page of each table gives the test number, outside air temperature cycle, the inside air temperature cycle (if thermostated), and the data input given on card 42. The second page gives the description and composition of each building component having significant heat capacity. The third page of the printout gives the inside and outside air temperatures, the heat losses from the building at the inside surfaces of the building components, the air infiltration loss, and the net heat loss from the room at prescribed time intervals, in $\mathrm{Btu} \mathrm{h}^{-1}$. 
$\dashv$ ง

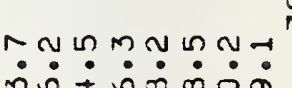

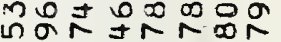
onm

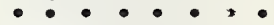
$\exists \operatorname{mos} 0 \dot{0} 0$ $n \rightarrow 0 \rightarrow 0$ roo $\because \div \div \div: 0.0$

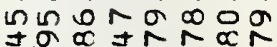
$0-0$ =0MN $\therefore \cdot \cdot \cdot \dot{0} \cdot \dot{0}$

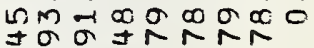

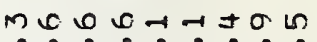
$\because \cdot 0 \cdot \div \cdot 0$

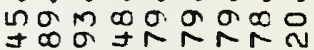
Nก ถ 100 $\bullet \cdot \bullet \cdot \bullet \cdot \ln$

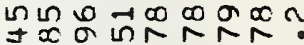
$N \rightarrow=m 00 \mathrm{mr}$ $\dot{0} \dot{0} \dot{0} \dot{0} \dot{0} \dot{0}$

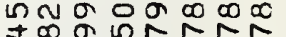
man $\operatorname{conan}$ กำ

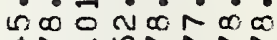
+rann ก) $\dot{0} \dot{0} \dot{0} \dot{0} \dot{0} \dot{0}$

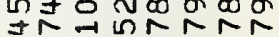
na?rahz7n $\dot{0} \dot{0} \dot{0} \cdot \dot{M}$

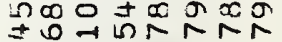

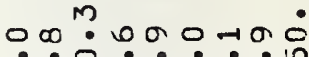

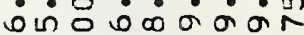

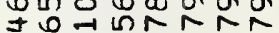

MN 0 OLMMN ○ $\dot{0} \dot{0} \dot{0} \dot{0} \dot{0} \dot{0}$

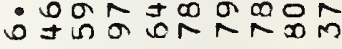




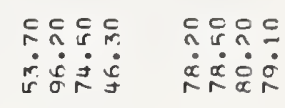

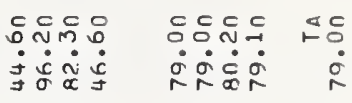

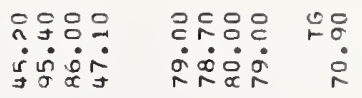
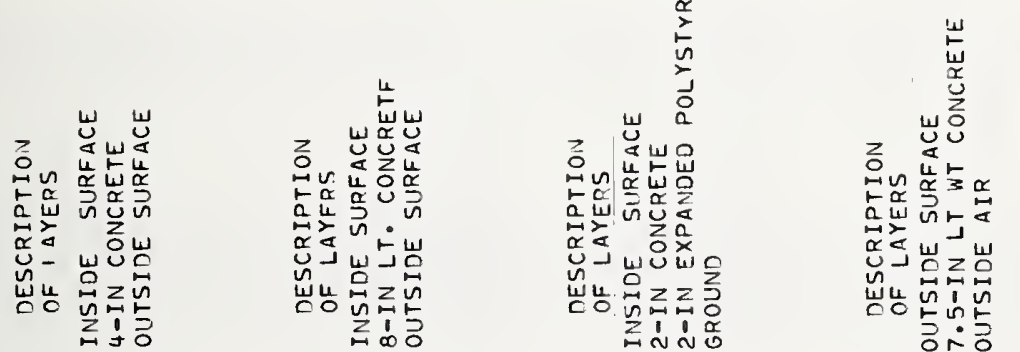

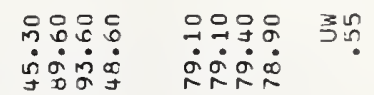

岁

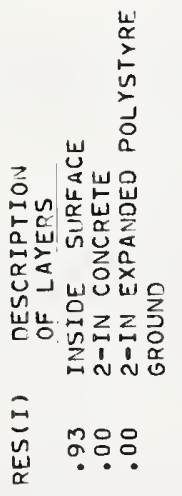

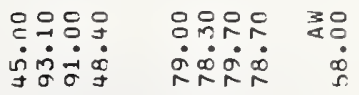

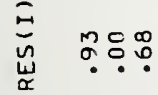

స్

च

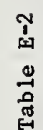

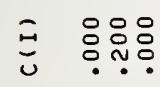

戸 을용

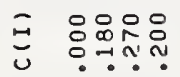

こ 응응

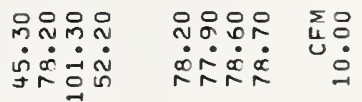

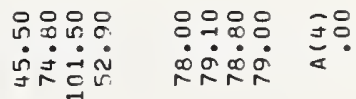

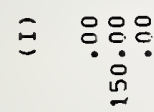

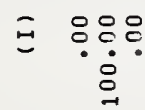

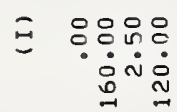

$\Xi \because$

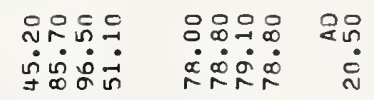

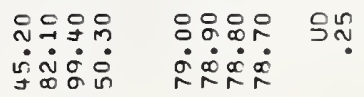

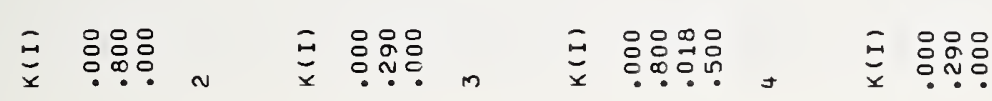

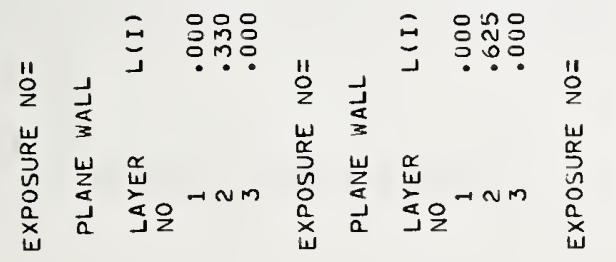

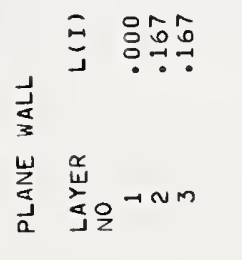

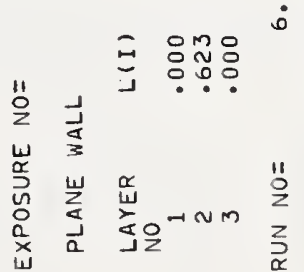

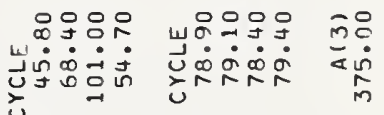

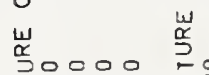

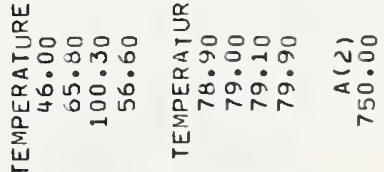

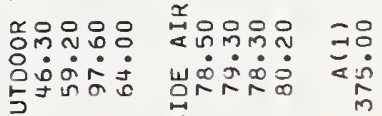
5 


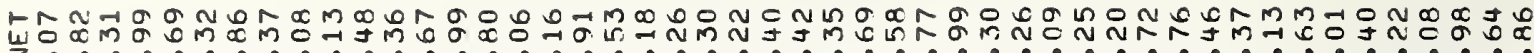

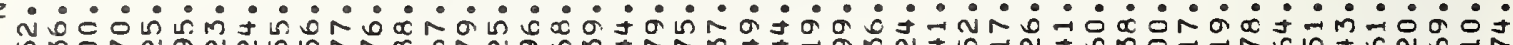
r.móñNN

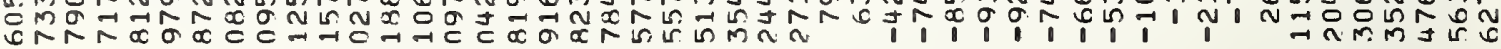

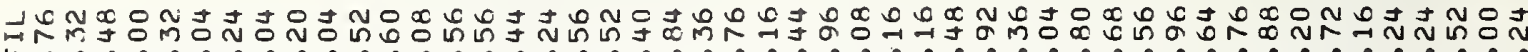

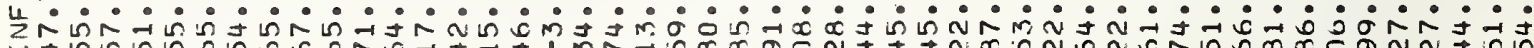

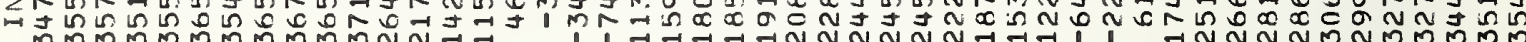

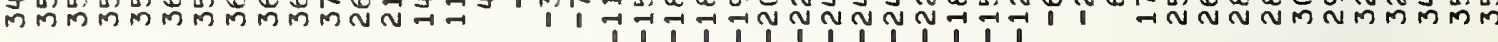

足

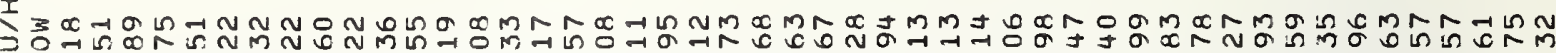
I

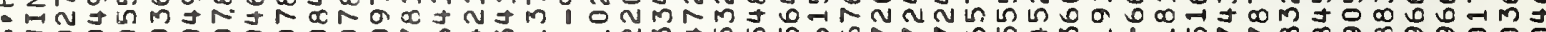

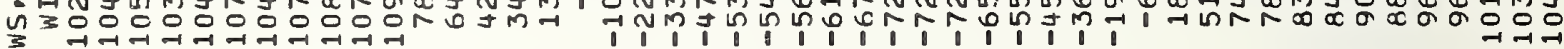
$\stackrel{3}{0}$

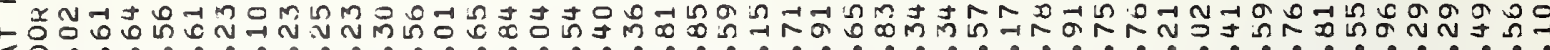

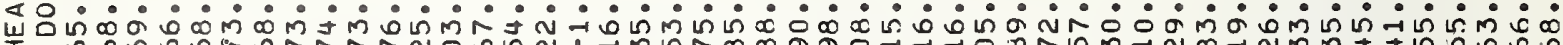
岂

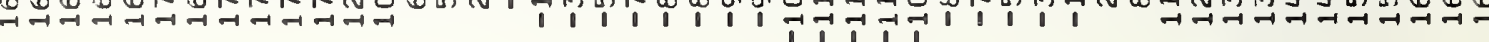

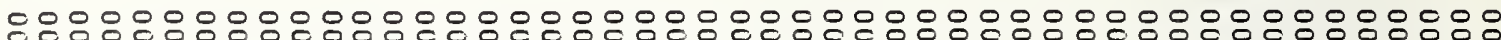
in

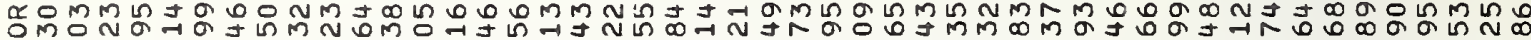

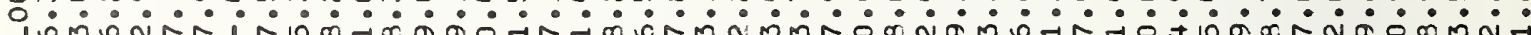

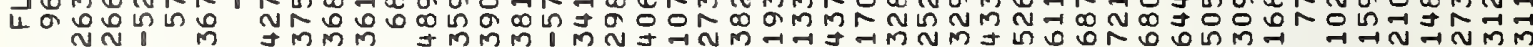

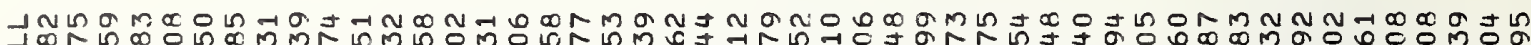
J

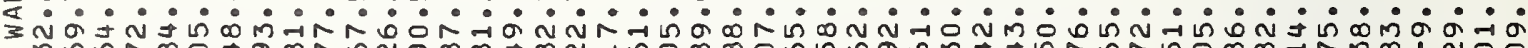

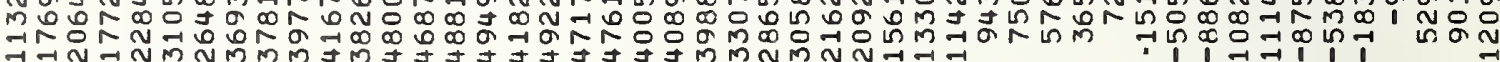

แ Oم.

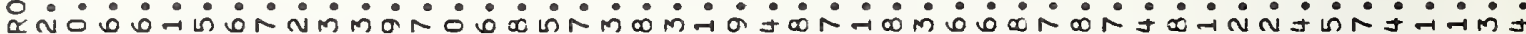

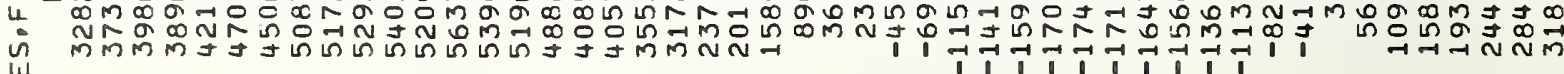
$\stackrel{w}{\underline{\sim}}$

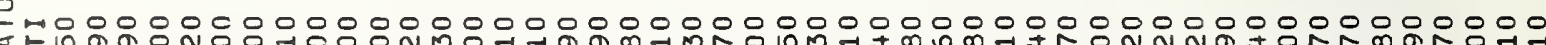

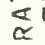

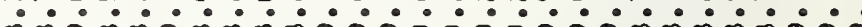
mpinis

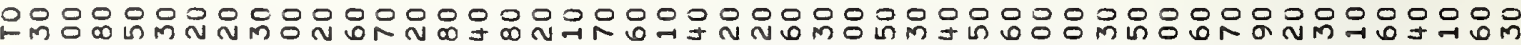

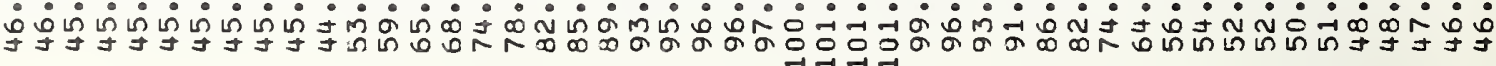

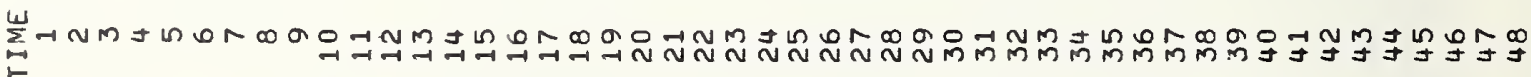




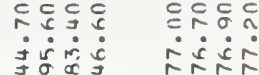

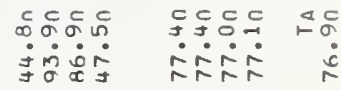

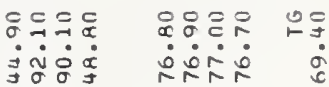

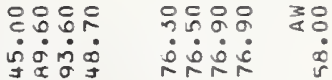

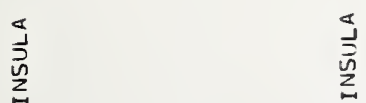

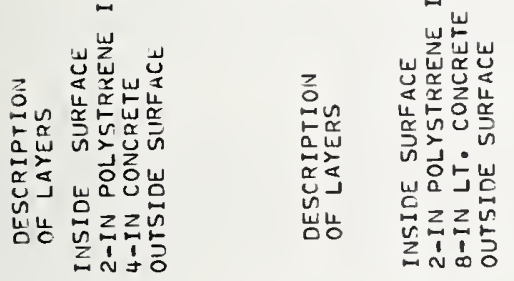

产

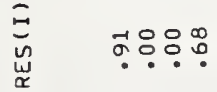

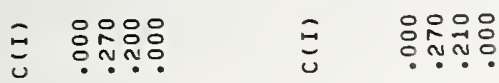

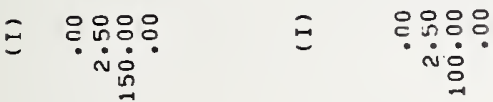

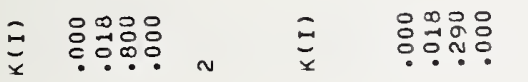

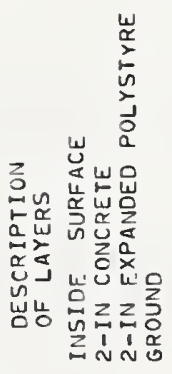

产

ำำจำำ

E

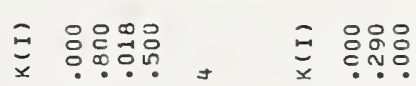

三om

章

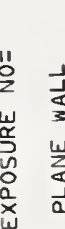

도.

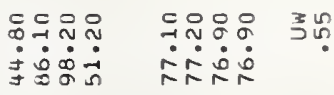

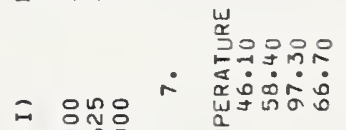

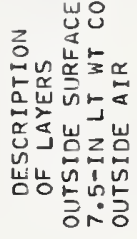

च

$=80 \%$

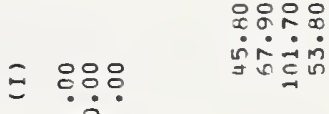

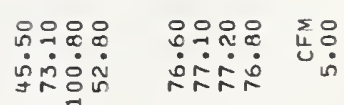

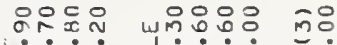

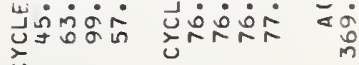

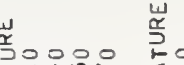
U

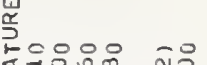

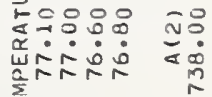
离

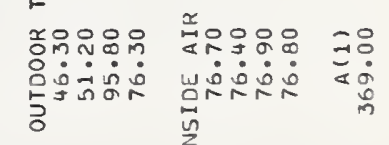




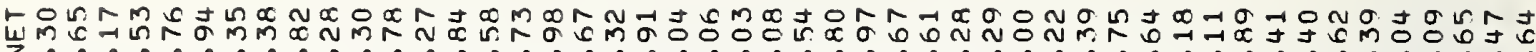

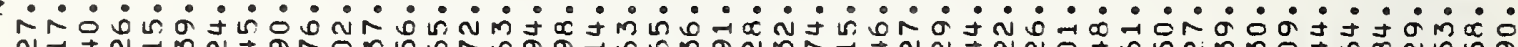

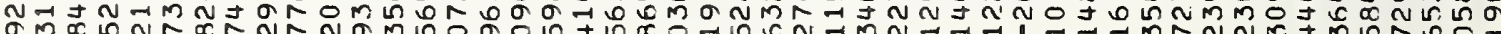

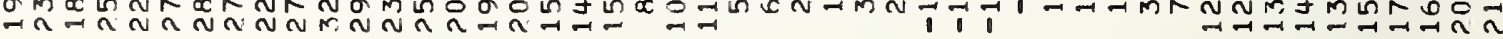

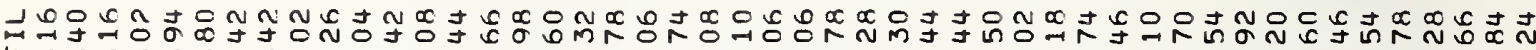

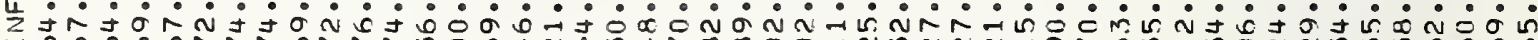

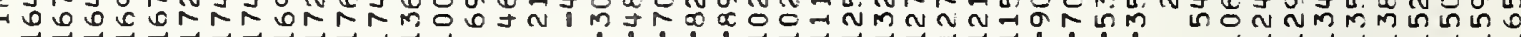
舟

囸

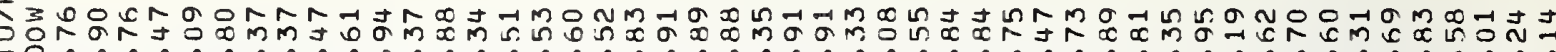
L -

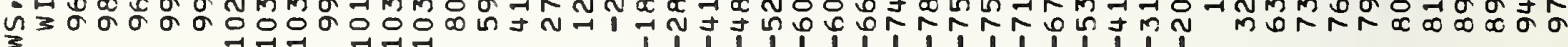
3

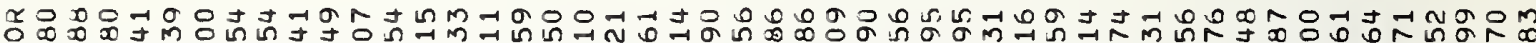

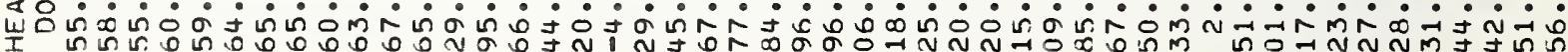
는

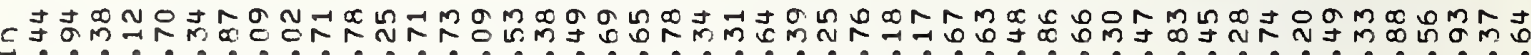

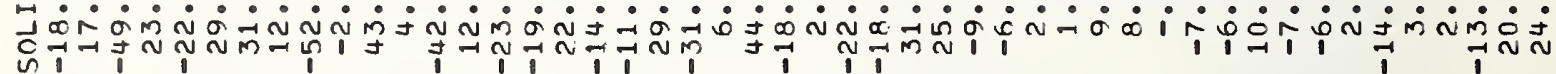

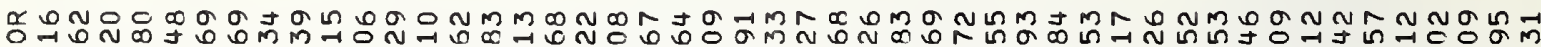

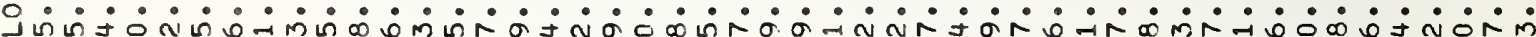

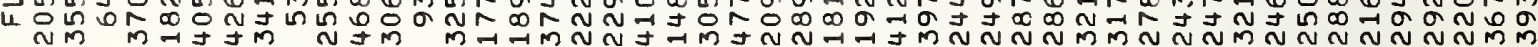

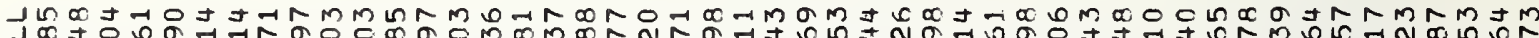

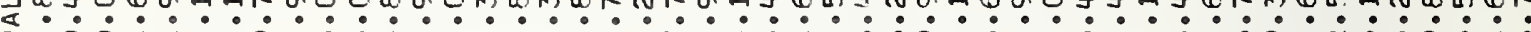

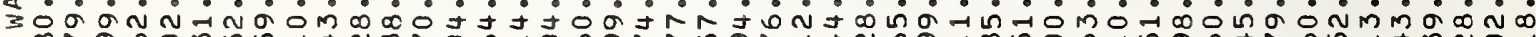

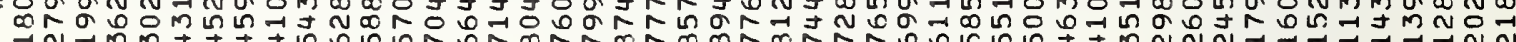

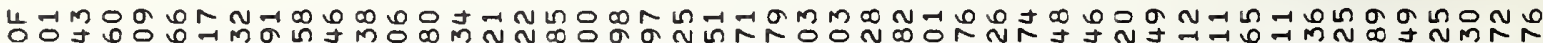

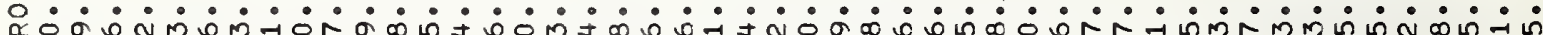

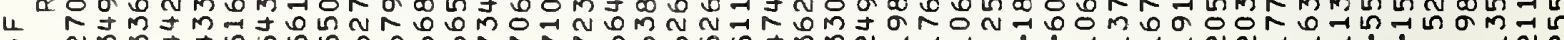

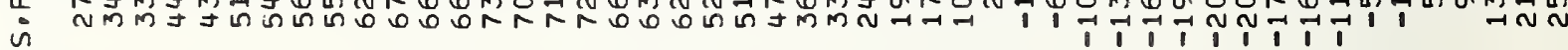
崖

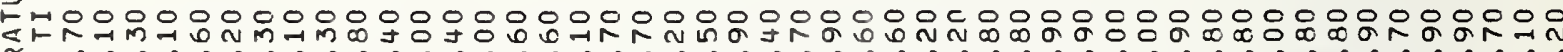
u

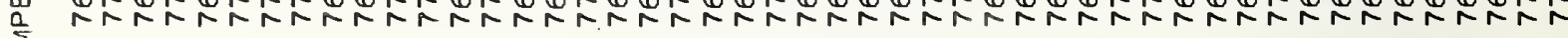
$\stackrel{\omega}{\llcorner}$

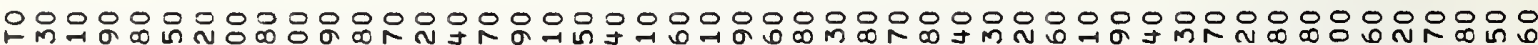

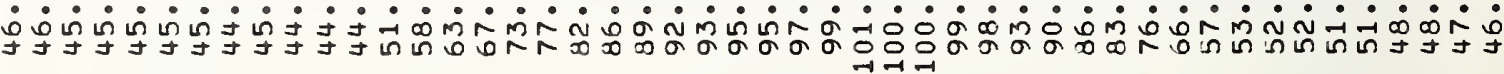

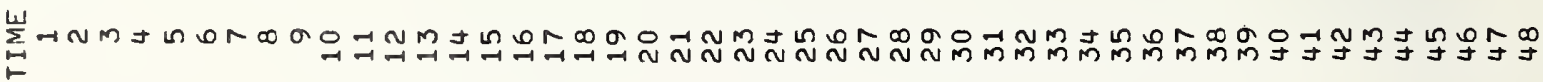




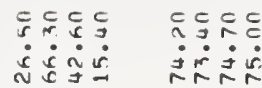

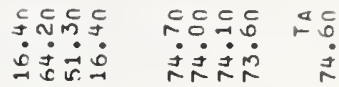

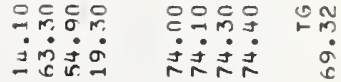

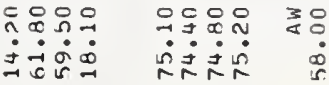

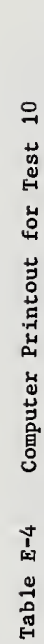

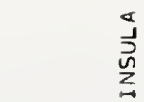

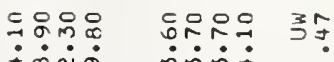

毛

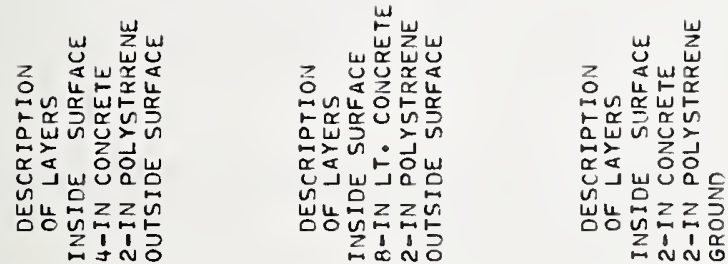

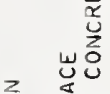

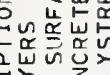

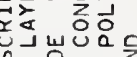

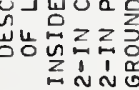

छ

点

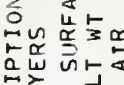

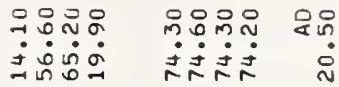

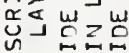

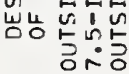

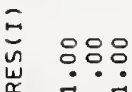

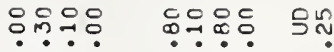

च

10

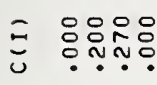

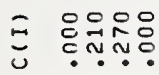

픈

픈 웅음

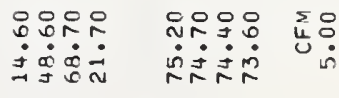

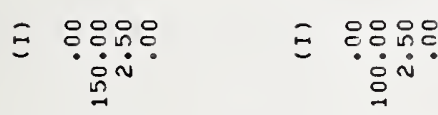

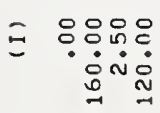

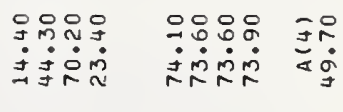

$\Xi \because \because \because$

웅ㅇㅇㅇㅜ

w요요

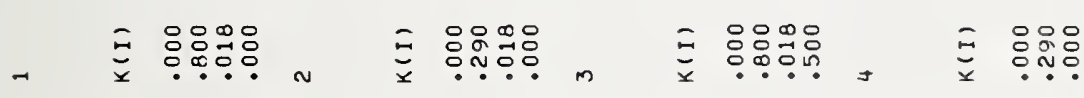

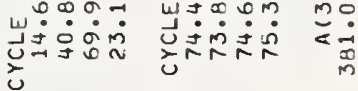

宸,

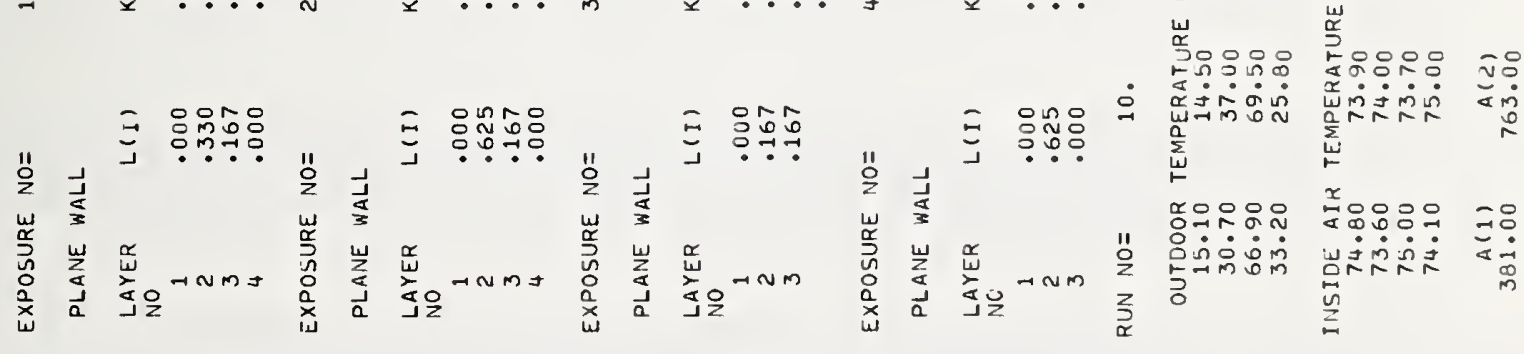




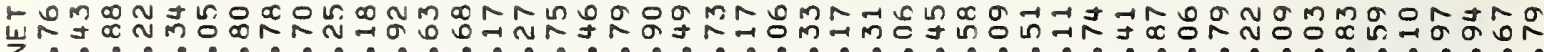

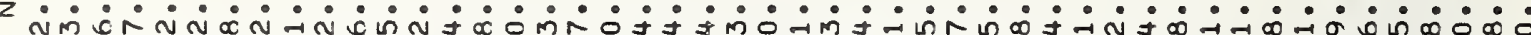

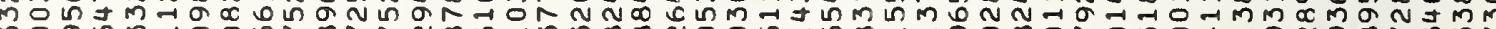

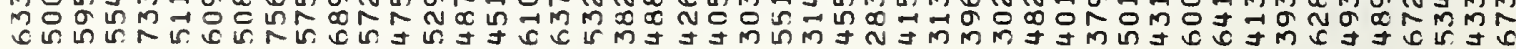

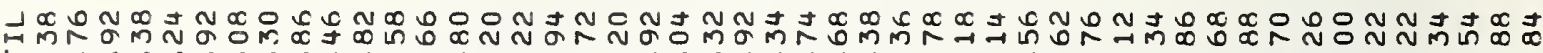

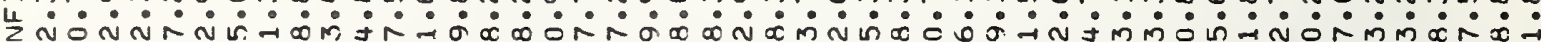

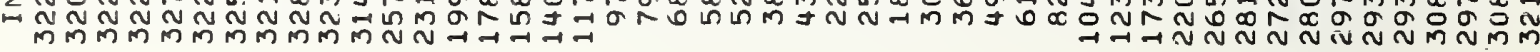

$\underline{\underline{I}}$

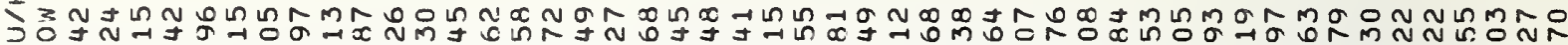

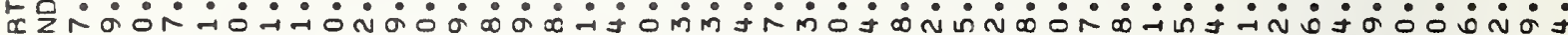

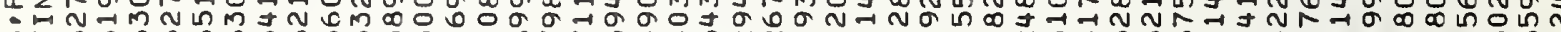
ง O

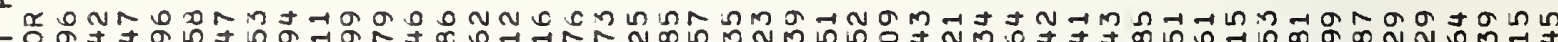

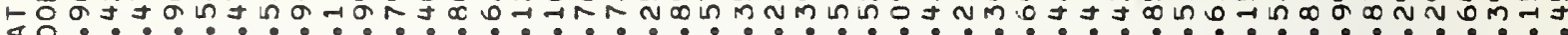

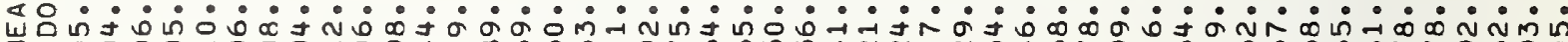

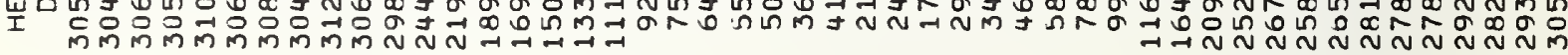

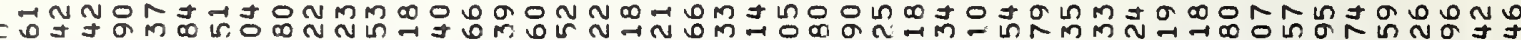

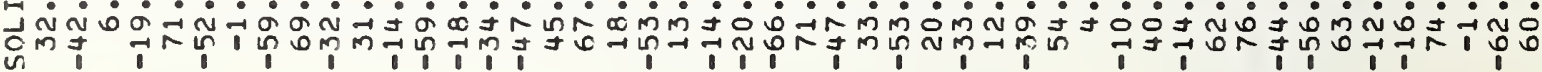

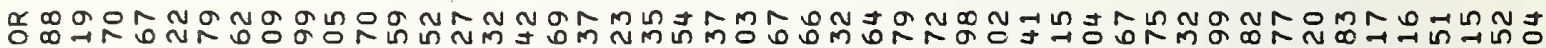
on แ

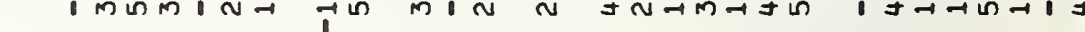

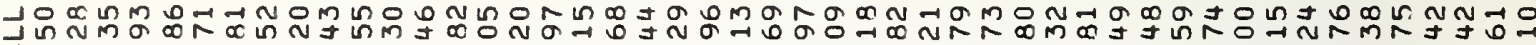

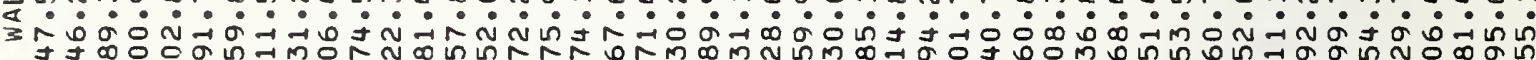

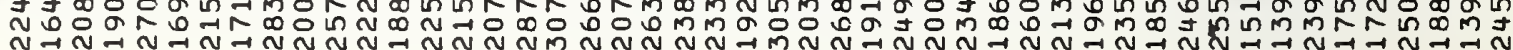

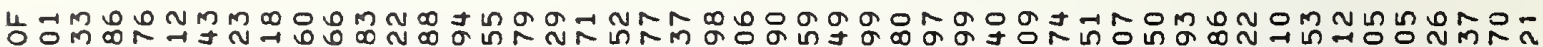

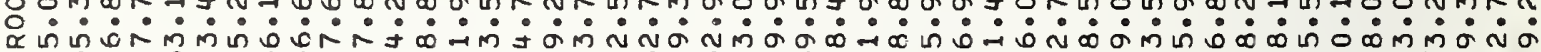
4 Jn in

$\stackrel{w}{\underline{\underline{x}}}$

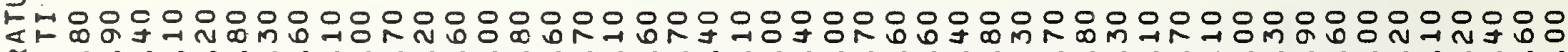
嶰 峁

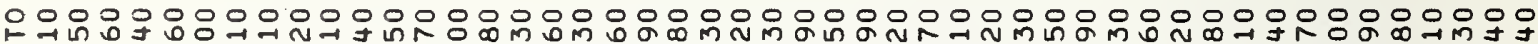

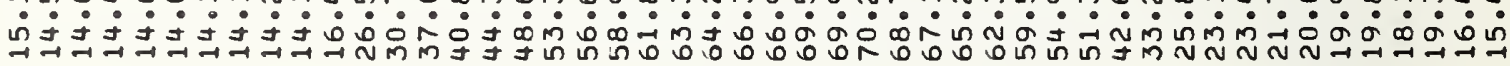

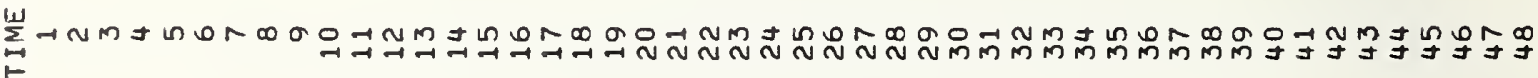


FORM NBS-114A (1.71)

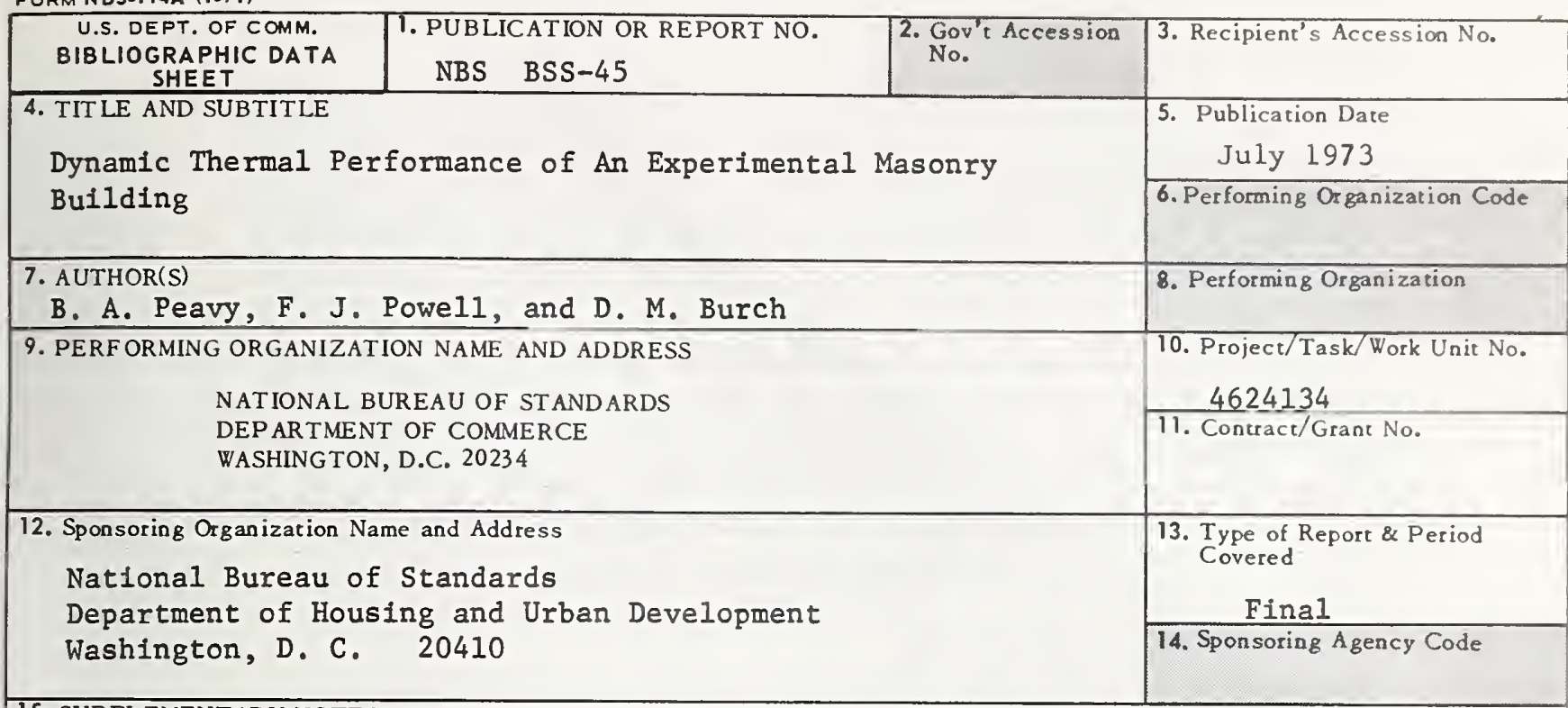

15. SUPPLEMENTARY NOTES

16. ABSTRACT (A 200-word or less factual summaty of most significant information. If document includes a significant bibliography or literature survey, mention it here.)

Measurements of the dynamic heat transfer in an experimental masonry building were made in a large environmental chamber to explore the validity of a computer program developed at NBS, labeled NBSLD, for computing heating and cooling loads, and indoor air temperatures. This study was jointly supported by the National Bureau of Standards and the Department of Housing and Urban Development, and is a part of a broader research program being supported by both agencies to improve performance test procedures and criteria for housing.

The experimental structure was a one-room house $20^{\prime}$ long, $20^{\prime}$ wide, and $10^{\prime}$ high with walls of solid concrete blocks and a flat roof made of reinforced precast concrete slabs During the tests changes were made in fenestration, the amount and location of insulation, and the indoor mass; and the building was exposed to a diurnal temperature cycle.

It was found that the combination of mass in the masonry walls and roof, and insulation placed on the outside of the masonry was very effective in reducing and controlling the variation of indoor air temperature. The NBSLD computer program realistically predicted the heat storage effects, and maximum heating loads during these tests. For five heating tests, the greatest difference between computed maximum heating load and measured values was 8 percent and the average difference was 4.3 percent. It was shown that steady-state methods of heating load calculation could result in oversizing heating equipwent by 30 percent or more for this particular building and imposed exterior conditions if the lowest outdoor temperature was selected as the design temperature.

17. KEY WORDS (Alphabetical order, separated by semicolons) Building heat transfer; computer programs; dynamic thermal performance; heat flow analysis; heating and cooling loads; temperature predictions; thermal analysis; thermal behavior; transient heat flows.

\begin{tabular}{|c|c|c|}
\hline $\begin{array}{l}\text { 18. AVAILABILITY STATEMENT } \\
\qquad \mathbf{x} \text { UNLIMITED. }\end{array}$ & $\begin{array}{l}\text { 19. SECURITY CLASS } \\
\text { (THIS REPORT) } \\
\text { UNCL ASSIFIED }\end{array}$ & $\begin{array}{c}\text { 21. NO. OF PAGES } \\
103\end{array}$ \\
\hline $\begin{array}{l}\square \text { FOR OFFICIAL DISTRIBUTION. DO NOT RELEASE } \\
\text { TO NTIS. }\end{array}$ & $\begin{array}{l}\text { 20. SECUR ITY CLASS } \\
\text { (THIS PAGE) } \\
\text { UNCL ASSIFIED }\end{array}$ & 22. Price $\$ 1.25$ \\
\hline
\end{tabular}




\section{Announcement of New Publications in Building Science Series}

Superintendent of Documents, U.S. Government Printing Office, Washington, D.C. 20402

\section{Dear Sir:}

Please add my name to the announcement list of new publications to be issued in the series: National Bureau of Standards Building Science Series.

Name

Company

Address

City State Zip Code

(Notification key $\mathrm{N}-339$ ) 


\section{NATIONAL BUREAU OF STANDARDS}

The National Bureau of Standards ${ }^{1}$ was established by an act of Congress March 3, 1901. The Bureau's overall goal is to strengthen and advance the Nation's science and technology and facilitate their effective application for public benefit. To this end, the Bureau conducts research and provides: (1) a basis for the Nation's physical measurement system, (2) scientific and technological services for industry and government, (3) a technical basis for equity in trade, and (4) technical services to promote public safety. The Bureau consists of the Institute for Basic Standards, the Institute for Materials Research, the Institute for Applied Technology, the Institute for Computer Sciences and Technology, and the Office for Information Programs.

THE INSTITUTE FOR BASIC STANDARDS provides the central basis within the United States of a complete and consistent system of physical measurement; coordinates that system with measurement systems of other nations; and furnishes essential services leading to accurate and uniform physical measurements throughout the Nation's scientific community, industry, and commerce. The Institute consists of a Center for Radiation Research, an Office of Measurement Services and the following divisions:

Applied Mathematics - Electricity - Mechanics - Heat - Optical Physics — Nuclear Sciences $^{2}$ - Applied Radiation ${ }^{2}$ - Quantum Electronics ${ }^{3}$ - Electromagnetics ${ }^{3}$ - Time and Frequency ${ }^{3}$ - Laboratory Astrophysics ${ }^{3}$ - Cryogenics ${ }^{3}$.

THE INSTITUTE FOR MATERIALS RESEARCH conducts materials research leading to improved methods of measurement, standards, and data on the properties of well-characterized materials needed by industry, commerce, educational institutions, and Government; provides advisory and research services to other Government agencies; and develops, produces, and distributes standard reference materials. The Institute consists of the Office of Standard Reference Materials and the following divisions:

Analytical Chemistry - Polymers - Metallurgy - Inorganic Materials - Reactor Radiation - Physical Chemistry.

THE INSTITUTE FOR APPLIED TECHNOLOGY provides technical services to promote the use of available technology and to facilitate technological innovation in industry and Government; cooperates with public and private organizations leading to the development of technological standards (including mandatory safety standards), codes and methods of test; and provides technical advice and services to Government agencies upon request. The Institute consists of a Center for Building Technology and the following divisions and offices:

Engineering and Product Standards - Weights and Measures - Invention and Innovation - Product Evaluation Technology - Electronic Technology - Technical Analysis - Measurement Engineering - Structures, Materials, and Life Safety * Building Environment " - Technical Evaluation and Application" — Fire Technology.

THE INSTITUTE FOR COMPUTER SCIENCES AND TECHNOLOGY conducts research and provides technical services designed to aid Government agencies in improving cost effectiveness in the conduct of their programs through the selection, acquisition, and effective utilization of automatic data processing equipment; and serves as the principal focus within the executive branch for the development of Federal standards for automatic data processing equipment, techniques, and computer languages. The Center consists of the following offices and divisions:

Information Processing Standards - Computer Information - Computer Services Systems Development - Information Processing Technology.

THE OFFICE FOR INFORMATION PROGRAMS promotes optimum dissemination and accessibility of scientific information generated within NBS and other agencies of the Federal Government; promotes the development of the National Standard Reference Data System and a system of information analysis centers dealing with the broader aspects of the National Measurement System; provides appropriate services to ensure that the NBS staff has optimum accessibility to the scientific information of the world. The Office consists of the following organizational units:

Office of Standard Reference Data — Office of Technical Information and Publications Library - Office of International Relations.

1 Headquarters and Laboratories at Gaithersburg, Maryland, unless otherwise noted; mailing address Washington, D.C. 20234.

a Part of the Center for Radiation Research.

3 Located at Boulder, Colorado 80302 .

- Part of the Center for Building Technology. 
U.S. DEPARTMENT OF COMMERCE

National Bureau of Standards

Washington. 0.C. 20234

OFFICIAL BUSINESS

Penalty for Private Use, $\$ 300$
POSTAGE AND FEES PAID U.S. DEPARTMENT OF COMMERCE $C O M-295$

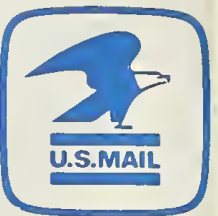

